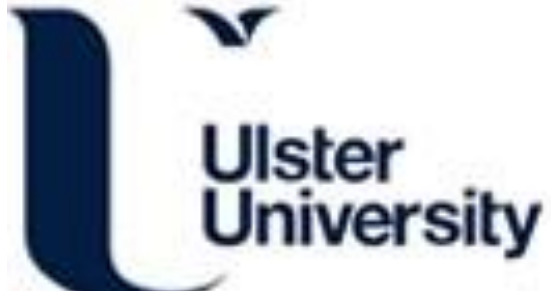

\section{Anti-bacterial activity of inorganic nanomaterials and their antimicrobial peptide conjugates against resistant and non-resistant pathogens}

Pardhi, D. M., Șen Karaman, D., Timonen, J., Wu, W., Zhang, Q., Satija, S., Mehta, M., Charbe, N., Mccarron, P., Tambuwala, M., Bakshi, H. A., Negi, P., Aljabali, A. A., Dua, K., Chaellappan, D. K., Behera, A., Pathak, K., Watharkar, R. B., Rautio, J., \& Rosenholm, J. M. (2020). Anti-bacterial activity of inorganic nanomaterials and their antimicrobial peptide conjugates against resistant and non-resistant pathogens. International Journal of Pharmaceutics, 586, [119531]. https://doi.org/10.1016/j.ijpharm.2020.119531

Link to publication record in Ulster University Research Portal

\section{Published in:}

International Journal of Pharmaceutics

Publication Status:

Published (in print/issue): 30/08/2020

DOI:

10.1016/j.ijpharm.2020.119531

\section{Document Version}

Author Accepted version

\section{General rights}

Copyright for the publications made accessible via Ulster University's Research Portal is retained by the author(s) and / or other copyright owners and it is a condition of accessing these publications that users recognise and abide by the legal requirements associated with these rights.

\section{Take down policy}

The Research Portal is Ulster University's institutional repository that provides access to Ulster's research outputs. Every effort has been made to ensure that content in the Research Portal does not infringe any person's rights, or applicable UK laws. If you discover content in the Research Portal that you believe breaches copyright or violates any law, please contact pure-support@ulster.ac.uk. 
Elsevier Editorial System(tm) for

International Journal of Pharmaceutics

Manuscript Draft

Manuscript Number: IJP-D-19-02907R2

Title: Anti-bacterial activity of inorganic nanomaterials and their antimicrobial peptide conjugates against resistant and non-resistant pathogens

Article Type: VSI: Europe

Section/Category: Pharmaceutical Nanotechnology

Keywords: Nanomaterials; antibacterial; conjugates; antimicrobial peptides; antibiotics

Corresponding Author: Professor Jessica M. Rosenholm, D.Sc.(Tech.)

Corresponding Author's Institution: Åbo Akademi University

First Author: Dinesh Pardhi

Order of Authors: Dinesh Pardhi; Didem Sen Karamn; Juri Timonen; Wei Wu; Qi Zhang; Saurabh Satija; Meenu Mehta; Nitin Charbe; Paul McCarron; Murtaza Tambuwala; Hamid A Bakshih; Poonam Negi; Alaa A Aljabali; Kamal Dua; Dinesh K Chaellappan; Ajit Behera; Kamla Pathak; Ritesh B Watharkar; Jarkko Rautio; Jessica M. Rosenholm, D.Sc.(Tech.)

Abstract: This review details the antimicrobial applications of inorganic nanomaterials of mostly metallic form, and the augmentation of activity by surface conjugation of peptide ligands. The review is subdivided into three main sections; of which the first describes the antimicrobial activity of inorganic nanomaterials against gram-positive, gram-negative and multidrug-resistant bacterial strains. The second section highlights the range of antimicrobial peptides and the drug resistance strategies employed by bacterial species to counter lethality. The final part discusses the role of antimicrobial peptide-decorated inorganic nanomaterials in the fight against bacterial strains that show resistance. General strategies for the preparation of antimicrobial peptides and their conjugation to nanomaterials are discussed, emphasizing the use of elemental and metallic oxide nanomaterials. Importantly, the permeation of antimicrobial peptides through the bacterial membrane is shown to aid the delivery of nanomaterials into bacterial cells. By judicious use of targeting ligands, the nanomaterial becomes able to differentiate between bacterial and mammalian cells and thus, reduce side effects. Moreover, peptide conjugation to the surface of a nanomaterial will alter surface chemistry in ways that lead to reduction in toxicity and improvements in biocompatibility. 


\section{A \\ Åbo Akademi \\ University}

Dr. Jessica Rosenholm Professor in Pharmaceutical Development Pharmaceutical Sciences Laboratory Åbo Akademi University BioCity ( $3^{\text {rd }}$ floor) Tykistökatu 6A 20520 Turku, Finland Email: jerosenh@abo.fi Tel. +35822153255

In Turku, Finland, 23.12.2019

Dear Editor and Referees of International Journal of Pharmaceutics,

We are hereby submitting our review manuscript titled "Anti-bacterial effects of inorganic nanomaterials and their antimicrobial peptide conjugates against resistant and non-resistant pathogens" by Dinesh M. Pardhi, Didem Şen Karaman, Juri Timonen, Wei Wu, Qi Zhang, Saurabh Satija, Meenu Mehta, Nitin Charbe, Paul McCarron, Hamid A. Bakshi, Murtaza Tambuwala, Jarkko Rautio and Jessica M. Rosenholm, to be considered for publication in the Special Issue "Pharmaceutical Technology in Europe" in International Journal of Pharmaceutics.

Our report represents a comprehensive review on the antibacterial activity of inorganic nanomaterials and antimicrobial peptides, and how concomitant use of the two can effectively tackle a range of bacterial infections which is a rapidly escalating issues in public health care worldwide. We believe this is of particular current interest with regard to "antimicrobial resistance" being declared one of the top-10 global health threats in 2019 by the WHO. In this group of authors, we have teamed up within the NordForsk-funded university hub Nordic POP (Patient Oriented Products), which we wish to showcase with this contribution. We are currenlty carrying out joint research supported by this network within the topic of the review, so we view this a valuable contribution also within the dissemination of Nordic POP activities.

We appreciate your consideration and look forward to hearing from you.

Sincerely,

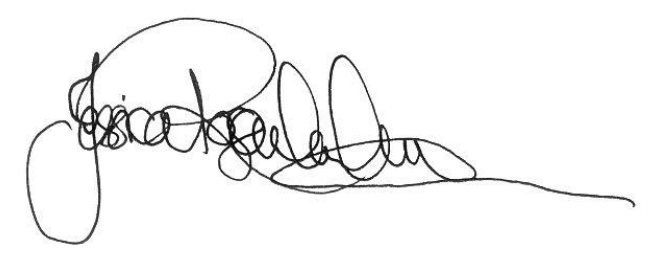


Ms. Ref. No.: IJP-D-19-02907R1

Title: Anti-bacterial effects of inorganic nanomaterials and their antimicrobial peptide conjugates against resistant and non-resistant pathogens

International Journal of Pharmaceutics

\section{Reviewers' comments:}

Reviewer \#2:

The paper must be very carefully checked for various inconsistencies, wordings, inconsistent numbering and so on.

It has not been prepared with sufficient care.

Comments from the editor:

As reviewer \#2 points out, you must very carefully double check the entire paper.

I had a quick look and found the following examples:

a) The title now reads: "Anti-bacterial activity of inorganic nanoparticles/nanoparticles and their antimicrobial peptide conjugates against resistant and non-resistant pathogens".

b) Abstract: "The review is subdivided into four sections, the first of which describes antimicrobial activity of inorganic nanoparticles against gram-positive, gram-negative and multidrug-resistant bacterial strains. The second section highlights the range of antimicrobial peptides and the drug resistance strategies employed by bacterial species to counter lethality. The final part discusses the role of antimicrobial peptides in the fight against bacterial strains that show resistance."

FOUR sections: First section, second section, final part. Where is section 3 ?

C) Section numbering:

"3. Antimicrobial peptides (AMP)

3.1 Antimicrobial action of AMP

Membrane disruption

Intracellular targets

3.1.3 Modulation of immune responses"

"3.1.1" and "3.1.2" are missing.

d) Wordings like "The European Commission's definition of a nanomaterial is definable as materials with,..." .

I expect that there are many more issues like these.

Please note that I cannot accept your manuscript, if it has not very carefully been prepared.

Please highlight all changes you make in yellow.

\section{Response to the Reviewer's and Editor's comments:}

We thank the Reviewer and Editor for constructive comments and profusely apologize for these omissions in our original revision. We have re-read the manuscript and re-checked the numbering to correct any such mistakes in the new revision. We deeply hope we managed to catch them all this time around. 


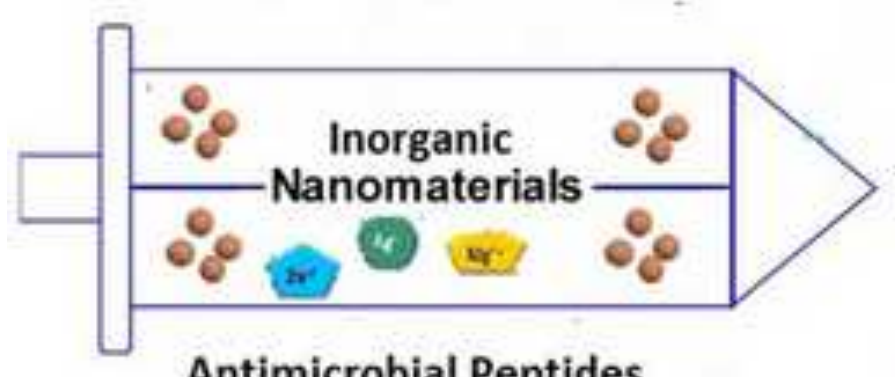

Antimicrobial Peptides

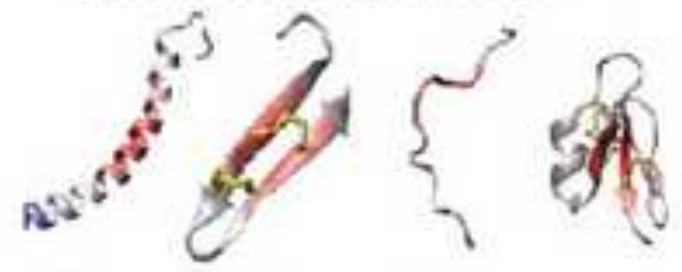

Free radical generation $\mathrm{OH}^{\circ}$
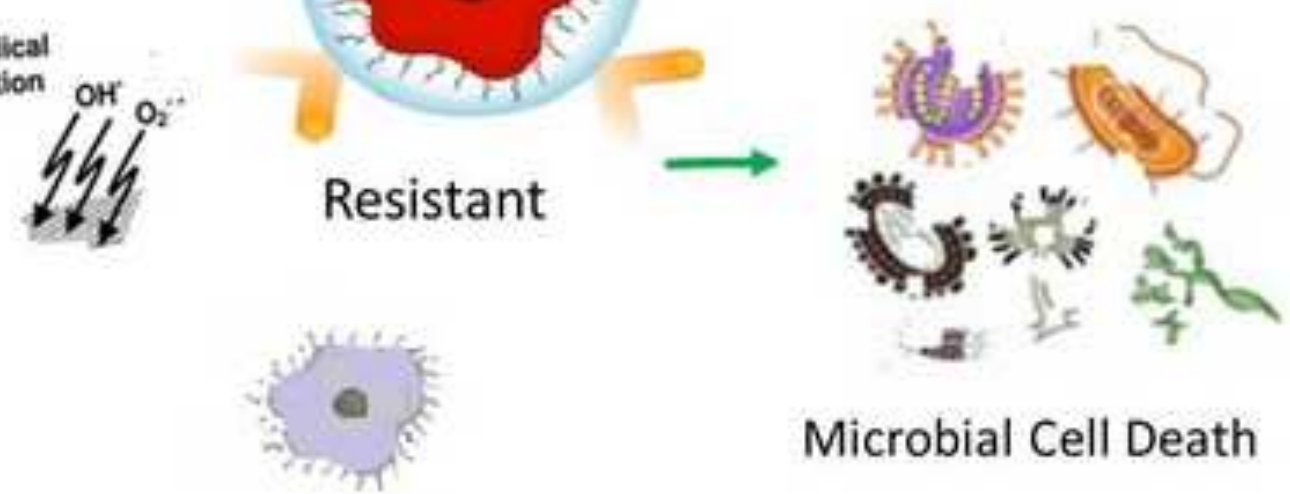

Microbial Cell Death

Non-resistant 


\section{Anti-bacterial activity of inorganic nanomaterials and their antimicrobial peptide conjugates against resistant and non-resistant pathogens}

Dinesh M. Pardhi ${ }^{a^{*}}$, Didem Şen Karaman ${ }^{\text {b,c }}$, Juri Timonen ${ }^{\mathrm{a}}$, Wei Wu ${ }^{\mathrm{d}}$, Qi Zhang ${ }^{\mathrm{e}}$, Saurabh Satija $^{\mathrm{f}}$, Meenu Mehta ${ }^{\mathrm{f}}$, Nitin Charbe ${ }^{\mathrm{g}}$, Paul McCarron ${ }^{\mathrm{h}}$, Murtaza Tambuwala ${ }^{\mathrm{h}}$, Hamid A. Bakshi $^{\mathrm{h}}$, Poonam Negi ${ }^{\mathrm{i}}$, Alaa A Aljabali ${ }^{\mathrm{j}}$, Kamal Dua ${ }^{\mathrm{k}}$, Dinesh K Chaellappan ${ }^{\mathrm{l}}$, Ajit Behera ${ }^{\mathrm{m}}$, Kamla Pathak $^{\mathrm{n}}$, Ritesh B. Watharkar ${ }^{\mathrm{o}}$, Jarkko Rautio ${ }^{\mathrm{a}}$, Jessica M. Rosenholm ${ }^{\mathrm{b} *}$

${ }^{\mathrm{a}}$ School of Pharmacy, Faculty of Health Sciences, University of Eastern Finland, P.O. Box 1627, FI-70211 Kuopio, Finland

${ }^{\mathrm{b}}$ Pharmaceutical Sciences Laboratory, Faculty of Science \& Engineering, Åbo Akademi University, 20500 Turku, Finland.

${ }^{\mathrm{c}}$ Biomedical Engineering Department, Faculty of Engineering and Architecture, İzmir Katip Çelebi University, İzmir, Turkey

${ }^{\mathrm{d}}$ Department of Pharmaceutics, School of Pharmacy, Fudan University, Shanghai, China

${ }^{\mathrm{e}}$ Department of Chemistry, Fudan University, Shanghai, China

${ }^{\mathrm{f}}$ School of Pharmaceutical Sciences, Lovely Professional University, Phagwara (Punjab), India.

${ }^{\mathrm{g}}$ Departamento de Química Orgánica, Facultad de Química, Pontificia Universidad Católica de Chile, Av. Vicuña McKenna 4860, Macul, Santiago 7820436, Chile

${ }^{\mathrm{h}}$ School of Pharmacy and Pharmaceutical Sciences, Ulster University, Coleraine, County Londonderry, BT52 1SA, Northern Ireland. United Kingdom.

${ }^{\mathrm{i}}$ School of Pharmaceutical Sciences, Shoolini University of Biotechnology and Management Sciences, Solan, India 
${ }^{\mathrm{j}}$ Department of Pharmaceutical Sciences, Yarmouk University, Faculty of Pharmacy, irbid 566, Jordan

${ }^{k}$ Priority Research Centre for Healthy Lungs, Haunter Medical Research Institute (HMRI) and school of Biomedical Sciences and Pharmacy, University of Newcastle, Callaghan, New South Wales NSW 230, Australia.

${ }^{1}$ Department of Life Sciences, School of Pharmacy, International Medical University, Bukit Jalil, Malaysia.

${ }^{\mathrm{m}}$ Department of Metallurgical \& Materials Engineering National Institute of Technology -, Rourkela Odisha-769008, India

${ }^{\mathrm{n} U t t a r}$ Pradesh University of Medical Sciences SAIFAI, Etawah 206130, India.

${ }^{\circ}$ Sharamshakti College of Food Technology, Sangamner 422605, Maharashtra, India

Corresponding authors* Email: dpardhi9@gmail.com; jerosenh@abo.fi 


\begin{abstract}
This review details the antimicrobial applications of inorganic nanomaterials of mostly metallic form, and the augmentation of activity by surface conjugation of peptide ligands. The review is subdivided into three main sections; of which the first describes the antimicrobial activity of inorganic nanomaterials against gram-positive, gram-negative and multidrug-resistant bacterial strains. The second section highlights the range of antimicrobial peptides and the drug resistance strategies employed by bacterial species to counter lethality. The final part discusses the role of antimicrobial peptide-decorated inorganic nanomaterials in the fight against bacterial strains that show resistance. General strategies for the preparation of antimicrobial peptides and their conjugation to nanomaterials are discussed, emphasizing the use of elemental and metallic oxide nanomaterials. Importantly, the permeation of antimicrobial peptides through the bacterial membrane is shown to aid the delivery of nanomaterials into bacterial cells. By judicious use of targeting ligands, the nanomaterial becomes able to differentiate between bacterial and mammalian cells and thus, reduce side effects. Moreover, peptide conjugation to the surface of a nanomaterial will alter surface chemistry in ways that lead to reduction in toxicity and improvements in biocompatibility.
\end{abstract}

Keywords: Nanomaterial, antimicrobial, conjugates, antimicrobial peptides, antibiotics 


\section{Contents}

1. Introduction

2. NM as antimicrobial agents

\subsection{Mechanisms of action of NM}

Impaired cell membrane function

Reactive oxygen species (ROS) production

Protein dysfunction and loss of enzyme activity

The release of toxic ions

Photocatalysis

2.2. NM against gram-positive and gram-negative bacteria

Silver nanomaterials (Ag NM)

Gold nanomaterials ( $\mathrm{Au} \mathrm{NM}$ )

Titanium dioxide nanomaterials $\left(\mathrm{TiO}_{2} \mathrm{NM}\right)$

Copper and copper oxide nanomaterials ( $\mathrm{Cu}$ and $\mathrm{CuO} \mathrm{NM})$

Zinc oxide nanomaterials ( $\mathrm{ZnO} \mathrm{NM}$ )

Mesoporous silica nanoparticles (MSNs)

2.3. NMagainst multidrug-resistant (MDR) bacterial strains

\subsubsection{Antibiotic conjugated NM against MDR}

\subsection{NM against biofilms}


3. Antimicrobial peptides and their antimicrobial potential

\subsection{Antimicrobial action of peptides}

Membrane disruption

Intracellular targets

Modulation of immune responses

\subsection{Resistance to AMP}

4. Inorganic NM as carriers for AMP

4.1. Inorganic NM for the delivery of loaded AMP

4.2. Inorganic NM for the delivery of the surface conjugated AMP

4.3. Antimicrobial applications of AMP-conjugated inorganic NM

AMP functionalized $\mathrm{Au} \mathrm{NM}$

AMP functionalized Ag NM

5. Conclusion and perspectives 


\section{Introduction}

Unnecessary and frequent use of antibiotics has caused a worrying and wide-ranging rise in bacterial resistance, which has led to serious and life-threatening restrictions in their clinical use (Shimanovich and Gedanken, 2016)(Rizzo et al., 2013). Microbes are adept at developing antibiotic resistance, and they do this by employing one or more evasive mechanisms. These are diverse and include (i) drug target alteration, (ii) enzymatic degradation of antibiotic compounds, (iii) efflux-pump of antibiotic molecules from the cell and (iv) biofilm formation (Ahmed, Raman and Veerappan, 2016)(Alekshun and Levy, 2007)(Salouti and Ahangari, 2014)(Huang et al., 2015; Fidler and Fidler, 2016). Resistance has become serious and is now a global concern. It will most likely be responsible for at least 10 million deaths by 2050 (O'Neill, 2014). According to the WHO, methicillin-resistant Staphylococcus Aureus (MRSA) infection is fatal and multidrug-resistant. Therefore, the development of innovative strategies for combating bacterial infection is of pressing need (Wang et al., 2010). The options under investigation for addressing this issue are numerous. Among other strategies, antimicrobial peptides (AMP) have attracted much interest due to favorable biocompatibility and a low probability of inducing bacterial resistance (Baltzer and Brown, 2011)(L. Peng et al., 2016).

AMP works in efficient ways that are not overly specific. For example, the formation of pores may be a general outcome following use with no specificity to bacterial type. They exhibit a range of toxicities to bacteria, fungi, parasites, and viruses. They are capable of bypassing and disintegrating into bacterial cell surfaces of multidrug-resistant bacteria (Wang et al., 2016)(Yount et al., 2006). Some AMP, such as Bactericin and Cap-18, are stable in the presence of proteases, elevated temperatures, and $\mathrm{pH}$; properties found to be responsible for a long-term 
bacterial resistance (Ebbensgaard et al., 2015) (Hassan et al., 2014). Nevertheless, several pathogens have developed resistance against antibiotics by modifying the cellular surface, expression of efflux pumps, and proteolytic degradation by microbial enzymes (Joo Fu and Otto, 2016)(Andersson, Hughes and Kubicek-Sutherland, 2016). Therefore, AMP are used as commercially available antimicrobials with potential as alternatives to traditional cell wall inhibitors, nucleic acid inhibitors, plasma membrane inhibitors, and protein synthesis inhibitors (Peters, Shirtliff and Jabra-Rizk, 2010; Tillotson and Theriault, 2013).

Different kinds of inorganic, mostly metal, nanomaterials (NM) have to date been used as antimicrobial agents. A significant benefit of metal and metal oxide NM is their various modes of action and lack of traditional therapeutic targets, which is why it is challenging for microbes to develop resistance against them (Karaman et al., 2017). According to The European Commission, NM are materials with at least one external dimension in the size range 1-100 nm. In this review, we are going to discuss inorganic nanomaterials with focus on metals and metal oxides, and their inherent antimicrobial activity. For instance, to date many different shapes of $\mathrm{Au}$ and $\mathrm{TiO}_{2} \mathrm{NM}$ have been studied as antimicrobial agents (Bhattacharya and Mukherjee, 2008)(Khan et al., 2011). Furthermore, other metal oxides, such as Copper (II) oxide (CuO), Magnesium oxide $(\mathrm{MgO})$, and $\mathrm{Zinc}$ oxide $(\mathrm{ZnO})$, exhibit affinity towards the bacterial surface and interfere with bacterial integrity. (Bhattacharya and Mukherjee, 2008)(Richards et al., 2000). The selective nature of NM in bacterial cells over mammalian cells is due to their differentiated perception for these two cells, e.g., from cell wall composition, ribosomes, and Ergosterol composition (Lemire, Harrison and Turner, 2013). 
Although NM show promise for treatments against microbial infections, several essential requirements must be met before they can be used for clinical therapies (Casals et al., 2019). The first is to address the specific physicochemical properties of NM, such as composition, size, crystallinity, and morphology (Kumar et al., 2012) since they are strongly related to the activity of NM. Secondly, stable and non-agglomerating NM is engineered to monitor the toxicity. NM has a known physical and chemical impact on their toxicity, which can also be severely altered depending on their surroundings, for instance, because NM in biological fluids tend to agglomerate (Hajipour et al., 2012) (Sutariya et al., 2014). The last one is the biocompatibility of NM (Yen, Hsu and Tsai, 2009). The combination of these strategies with AMP allows the creation of unique designs that unleashes the promising potential to use the AMP's natural functionalities for microbial infections with increased effecacy.

Namely, AMP-conjugated NM can address the disadvantages of free AMP, such as proteolytic degradation and low permeability across biological barriers (Rajchakit and Sarojini, 2017b). Synergistic behavior can be rendered by amplifying the AMP's anti-microbial strength with that of the NM carrier, not only through the conjugation with NM but also, the therapeutic efficacy of AMP can be increased. For instance, since AMP can further show selectivity for species, researchers have started using NM combined with AMP to carefully release NM from the body into the coat of arms where pathogens can be hyperthermally killed (Zharov et al., 2006).

This review illustrates the chemistry, biology, interfacial science, and utilization of AMPconjugated NM, not only to hinder the growth but also to kill the bacteria based on their inherent action. We will provide the reader with an overview of the antimicrobial mechanisms of action 
of inorganic NM, AMP, and their conjugates for antibacterial treatments. This review aims to summarise the latest promising findings and propose future approaches for building peptide conjugated NM for bacterial infection therapy.

\section{NM as antimicrobial agents}

\subsection{Mechanisms of action of NM}

NM can exert a beneficial antimicrobial effect due to sub-micrometer scales of size and high surface-to-volume ratios. These properties enhance the contact area able to interact with pathogens. For this reason, NM exhibit increased biological and chemical activity and can be used to target different bacterial structures (Holban and Andronescu, 2016). Figure 1 illustrates the general mechanisms of antimicrobial activity exerted by different NM.

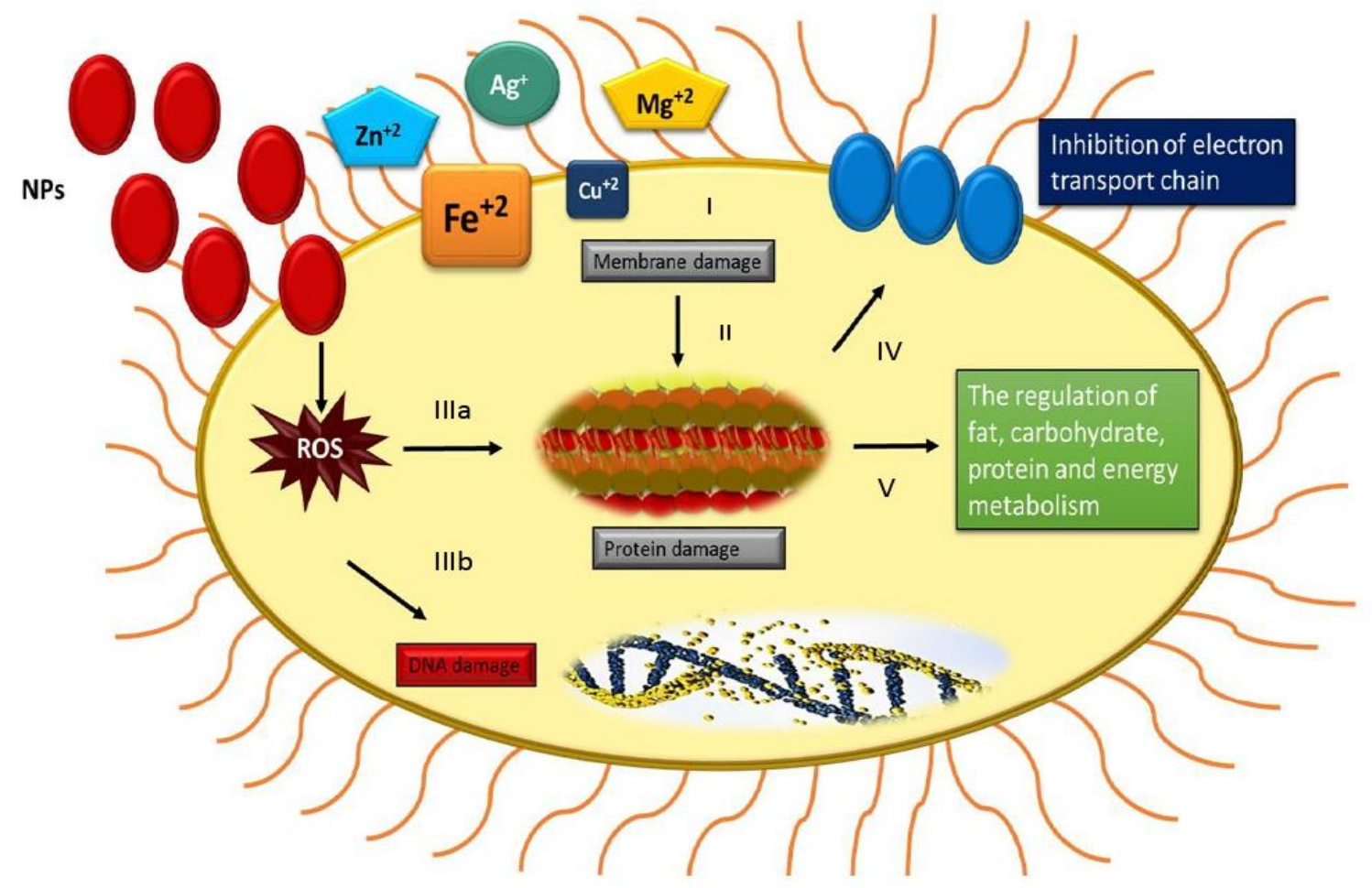


Fig.1 Different mechanisms of antibacterial action by NM. I) Metal ions released from their respective NM electrostatically bind and disturb the phospholipid bilayer of the bacterial membrane, causing membrane damage. II) Oxidative stress generated by the membrane disruption responsible for the bacteria protein damage. III) ROS is generated by NM, which is accountable for the IIIa) damage of the cell's protein, and IIIb) DNA damage. Protein damage leads to loss of metabolic activity through IV) the disruption of the transmembrane electron transport chain. V) Protein damage interferes with fat, carbohydrate, protein, and energy metabolism. Adapted with the permission from (Wang, Hu and Shao, 2017) Copyright (C) 2017 Dovepress.

\section{Impaired cell membrane function}

Bacterial membranes are negatively charged with a high binding affinity for positively charged metal ions (Lemire, Harrison and Turner, 2013)(Palza, 2015). Several researchers have investigated the bacterial toxicity of Ag NM (Yamanaka, Hara and Kudo, 2005)(Sondi and Salopek-Sondi, 2004) and Au NM (Yaganza et al., 2004) against E. coli and S. aureus, and found that both induce damage to the plasma membrane. Another research by Marius et al. (Marius et al., 2011) revealed that Ag NM deposited on the bacterial cell wall surface form clusters, leading to bacterial death through cell lysis. Furthermore, Sondi and Salopek-Sondi (Sondi and Salopek-Sondi, 2004), as well as Prabhu and Poulose (Prabhu and Poulose, 2012) explained that the formation of pores in bacterial cell membranes was due to the NM deposition on the bacterial cell surface. Other evidence suggests that the antimicrobial activity of ion release from NM surfaces is connected with interruption of the electron transport chain of the membrane (Rainnie and Bragg, 1974)(Gordon et al., 2010). For example, micromolar concentrations of $\mathrm{Ag}^{+}$ interact with NADH: ubiquinone oxidoreductase (NQR) enzyme, a component of the respiratory chain of bacteria, and inhibit energy-dependent $\mathrm{Na}^{+}$transport resulting in energy depletion and 
pathogen death (Travan et al., 2007). Lipid peroxidation is another mechanism of $\mathrm{Cu}^{2+}$ and $\mathrm{Cd}^{2+}$ toxicity in bacteria (Hong et al., 2012)

\section{Reactive oxygen species (ROS) production}

NM induce reactive oxygen species (ROS) directly when they interact with aerobically grown bacteria, which ultimately leads to necrotic and apoptotic bacterial death (Acker and Coenye, 2016)(Held and Instruments, 2015). The redox transition of the ROS is carried out using reaction mechanisms of Fenton in biologically based systems, including $\mathrm{Si}, \mathrm{Fe}, \mathrm{Cu}, \mathrm{Cr}, \mathrm{V}$ and Ni. (Huang, Wu and Aronstam, 2010)(Kirisits, 2015)(Ubini, 2003)(Tee et al., 2016). Hydrogen peroxide $\left(\mathrm{H}_{2} \mathrm{O}_{2}\right)$, which is toxic to biological molecules during the Fenton reactions, oxidizes transition metal ions such as $\mathrm{Fe}^{2+}$ to produce $\left(\mathrm{HO}^{-}\right)$and highly relational hydroxyl radicles $(\mathrm{OH})$. (Thannickal and Fanburg, 2000).

When exposed to the acidic environment in lysosomes, metal NM produce ions $\mathrm{Ag}^{+}, \mathrm{Cd}^{2+}$, $\mathrm{Fe}^{2+/ 3+}, \mathrm{Au}^{1+/ 3+)}$ that can induce different chemical reactions from ROS species ( $\mathrm{Li}$ et al., 2010)(Pokhrel et al., 2009). Furthermore, NM can communicate directly with redox active proteins such as NADPH oxidase, and stimulate large scale production of ROS in immune cells, including macrophages and neutrophils (Manke, Wang and Rojanasakul, 2013). Many recent studies clarify the antimicrobial activity of metal NM through the production of ROS. Ag NM are well known for their ROS production through surface oxidation or release $\mathrm{of}^{\mathrm{Ag}}$ in biological medium (Ivask et al., 2010). Moreover, chitosan-coated iron oxide $\left(\mathrm{Fe}_{2} \mathrm{O}_{3}\right) \mathrm{NM}$ (IONM) also induced significant production of ROS and thus, exhibited bactericidal activity against E. coli and B. subtilis (Arakha et al., 2015). Significant intracellular ROS production by $\mathrm{CuO} \mathrm{NM}$ in E. coli was attributed to the release of Cu cations (Ivask et al., 2010)(Meghana et 
al., 2015). Vijayaraghavan et al. (Padmavathy and Vijayaraghavan, 2008) studied the formation of ROS in terms of superoxides $\left(\mathrm{O}_{2}^{-}\right), \mathrm{OH}^{-}$and $\mathrm{H}_{2} \mathrm{O}_{2}$, when $\mathrm{ZnO} \mathrm{NM}$ was in contact with microbial cells. Because of their negative charge, $\mathrm{OH}^{-}$and $\mathrm{O}_{2}^{-}$cannot penetrate the bacterial membrane (Xie et al., 2011) and therefore stay in direct contact with the bacteria's exterior surface. In contrast, $\mathrm{H}_{2} \mathrm{O}_{2}$ penetrates the bacterial cell wall and causes lipid, DNA, and protein destruction (Dutta et al., 2012). Interestingly, halogen adsorption on MgO NM surface induced higher antibacterial activity (Blecher, Nasir and Friedman, 2017). The rough surface of NM, the oxidative action of adsorbed halogens and strong electrostatic interaction with the negatively charged bacterial membrane is a major reason for their excellent antimicrobial activity (He et al., 2016)(Chen et al., 2014).

\section{Protein dysfunction and loss of enzyme activity}

Several studies have shown that the FeS family of bacteria are susceptible to site-specific inactivation by toxic metals, including dihydroxy acid dehydratases (DHAD) and isopropylmalate isomerases (IPMIs) involved in branched-chain amino acid synthesizes (Xu and Imlay, 2012)(Booth, Weljie and Turner, 2015). Moreover, the reduced fumarase A and 6phosphogluconate dehydratase activity are one of the most significant toxic effects of $\mathrm{Cu}$, two enzymes that also depend upon Fe-S catalysts (Macomber and Imlay, 2009). It was reported that $\mathrm{Ag}, \mathrm{Hg}, \mathrm{Cd}$, and $\mathrm{Zn}$ (but not $\mathrm{Mn}, \mathrm{Co}, \mathrm{Ni}$ or $\mathrm{Pb}$ ) might harm $\mathrm{FeS}$ clusters in vitro and in vivo, which contains dehydrates independently of the ROS with bacteriostatic effect. Proteins that repair FeS clusters, such as cysteine desulphurase (IscS) or the SufA scaffold protein FeS cluster,

may restore inactive bacterial enzymes (Xu and Imlay, 2012). In addition to the destruction of FeS clusters, metals are also able to use a route called the ionic simulation to inhibit the site's 
enzyme. For example, $\mathrm{Pb}$ removes $\mathrm{Zn}$ from the $\delta$ aminolevulinic acid dehydratase (ALAD) active site, leading to enzymatic inhibition (Scinicariello et al., 2007) and antimicrobial toxicity (Ogunseitan, Yang and Ericson, 2000). Further, Ni can substitute $\mathrm{Zn}$ at the non-catalytic $\mathrm{Zn}$ site of fructose-1,6-bisphosphate aldolase (FbaA) in E. coli, resulting in loss of activity (Macomber, Elsey and Hausinger, 2011).

\section{Release of toxic ions}

The antimicrobial efficacy of NM is directly commensurate with the release of ions. Metal ions accumulate and pass through cell membranes and intercalate with proteins and nucleic acids inhibiting bacterial function (Slavin et al., 2017). For instance, Ag NM can be oxidised by $\mathrm{O}_{2}$ and other cellular molecules leading to the release of $\mathrm{Ag}^{+}$ions. $\mathrm{Ag} \mathrm{NM}$ can penetrate the bacterial membrane and release $\mathrm{Ag}^{+}$ions, which subsequently bind to amino acids (cysteine) affecting their functionality (Hu and Hong, 2017)(Sharma, Kwon and Chen, 2013)(Kanematsu and Barry, 2015). Yamanaka et al. (Yamanaka, Hara and Kudo, 2005) used two-dimensional electrophoresis to evaluate the influence of $\mathrm{Ag}^{+}$ions on specific proteins in E. coli. Reduced expression of $30 \mathrm{~S}$ ribosomal subunit, succinyl CoA synthetase (SCS), maltose transporter (MalK), and fructose bisphosphate aldolase were observed after E. coli incubation with $900 \mathrm{ppb}$ $\mathrm{Ag}^{+}$ions compared to the untreated group. The authors sulfurized $\mathrm{Ag} \mathrm{NM}$ to $\mathrm{Ag}_{2} \mathrm{~S} \mathrm{NM}$ and found out that sulfidation reduced the release of $\mathrm{Ag}^{+}$ions from $\mathrm{Ag} \mathrm{NM}$ and reduced their toxicity towards E. coli. Similarly, bacterial toxicity of $\mathrm{ZnO} \mathrm{NM}$ is associated with the dissolution of $\mathrm{Zn}^{2+}$ ions within the microbes (Chang et al., 2012)(Ivask et al., 2012). It has been reported that

the $\mathrm{Zn}^{2+}$ ions are toxic towards S. cerevisiae (Kasemets et al., 2009). Similarly, Cu NM exhibited bacterial toxicity in the same manner (Zhang, 2016). 


\section{Photocatalysis}

Photocatalysis is the excitation of $\mathrm{NM}$, such as $\mathrm{Fe}_{2} \mathrm{O}_{3}, \mathrm{WO}_{3}, \mathrm{ZnO}$, and $\mathrm{TiO}_{2}$, by $\mathrm{UV}$ irradiation to generate ROS that first damage the lipopolysaccharide layer of the bacterial cell wall, followed by the inner peptidoglycan layer. Also, ROS induce peroxidation of lipids and proteins in the cell membrane, eventually resulting in organelles leaching from the plasma membrane $(\mathrm{PM}) . \mathrm{TiO}_{2}$ has been shown to produce ROS under UV irradiation (Nowack, 2008). High photocatalyticmediated antimicrobial activity of $\mathrm{TiO}_{2} \mathrm{NM}$ compared to $\mathrm{ZnO} \mathrm{NM}$ under UV irradiation has been observed (Leung et al., 2016). Saito et al. (Saito et al., 1992) used TEM to study the effect of $\mathrm{TiO}_{2}$ NM and observed disruption of PM of bacteria due to photocatalytic induced ROS. Carre et al. used proteomics data to conclude that $\mathrm{TiO}_{2} \mathrm{NM}$ can not only down-regulate but also impair membrane proteins under UV irradiation (Carré et al., 2014). Wu et al. studied the photocatalytic activity of $\mathrm{PdO} / \mathrm{TiO}_{2}$ nanofibers against E. coli (Wu, Imlay and Shang, 2010). The authors reported changes in membrane permeability of $E$. coli, followed by DNA damage upon photocatalytic irradiation of $\mathrm{PdO} / \mathrm{TiO}_{2}$.

\subsection{NM against gram-positive and gram-negative bacteria}

Difference in composition of the cell wall of gram-positive and gram-negative bacteria affects the NM activity. It has been shown that gram-positive bacteria are more resistant to Ag NM than gram-negative bacteria. The thick peptidoglycan layer of gram-positive bacteria restricts the entry of most of the NM. However, a study conducted by Ruparelia et al. (Ruparelia et al., 2008) observed higher antimicrobial activity of $\mathrm{CuO}$ NM towards gram-positive B. subtilis, which may be due to strong affinity of $\mathrm{CuO} \mathrm{NM}$ for amine and carboxyl groups. Antimicrobial activity of NM may be altered by other characteristics of the NM, like form, size, 
coating/capping agent, microbial type, surface morphology, crystallinity, and $\mathrm{pH}$ (Agnihotri, Mukherji and Mukherji, 2014). In this section, will discuss the bacteriostatic and bactericidal role of various NM against gram-positive and gram-negative bacteria

\section{Silver nanomaterials (Ag NM)}

Ag has, for prolonged times, been used as an antimicrobial agent in medicine. It has several mechanisms of bactericidal/bacteriostatic effects. As a result, Ag NM are incorporated into various consumer goods such as surgical coatings, medical implants, food packaging, textiles, and cosmetics. A study, which investigated the size-dependent antimicrobial efficacy of Ag NM on gram-positive and gram-negative strains found a significant reduction in bacterial count when treated with $5 \mathrm{~nm} \mathrm{Ag} \mathrm{NM}$ on E. coli, B. subtilis, and S. aureus species for 90, 20 and 120 min, respectively. Similarly, the reduction of E. coli, B. subtilis, and S. aureus in 180 min was observed when treated with 7 and $10 \mathrm{~nm} \mathrm{Ag} \mathrm{NM.} \mathrm{The} \mathrm{fastest} \mathrm{bactericidal} \mathrm{effect} \mathrm{was} \mathrm{observed} \mathrm{for} \mathrm{the} \mathrm{smaller}$ $5 \mathrm{~nm}$ sized NM compared to 7 and $10 \mathrm{~nm}$ sized NM, which may be attributed to the higher surfacearea-to-volume ratio of smaller sized NM. The antimicrobial behavior was due to the same mechanisms as found by other researchers, such as membrane disruption and interferences. The negative charge of citrate-capped Ag NM tended to enable the electrostatic attraction reported in Figure 2 (Agnihotri, Mukherji and Mukherji, 2014). 

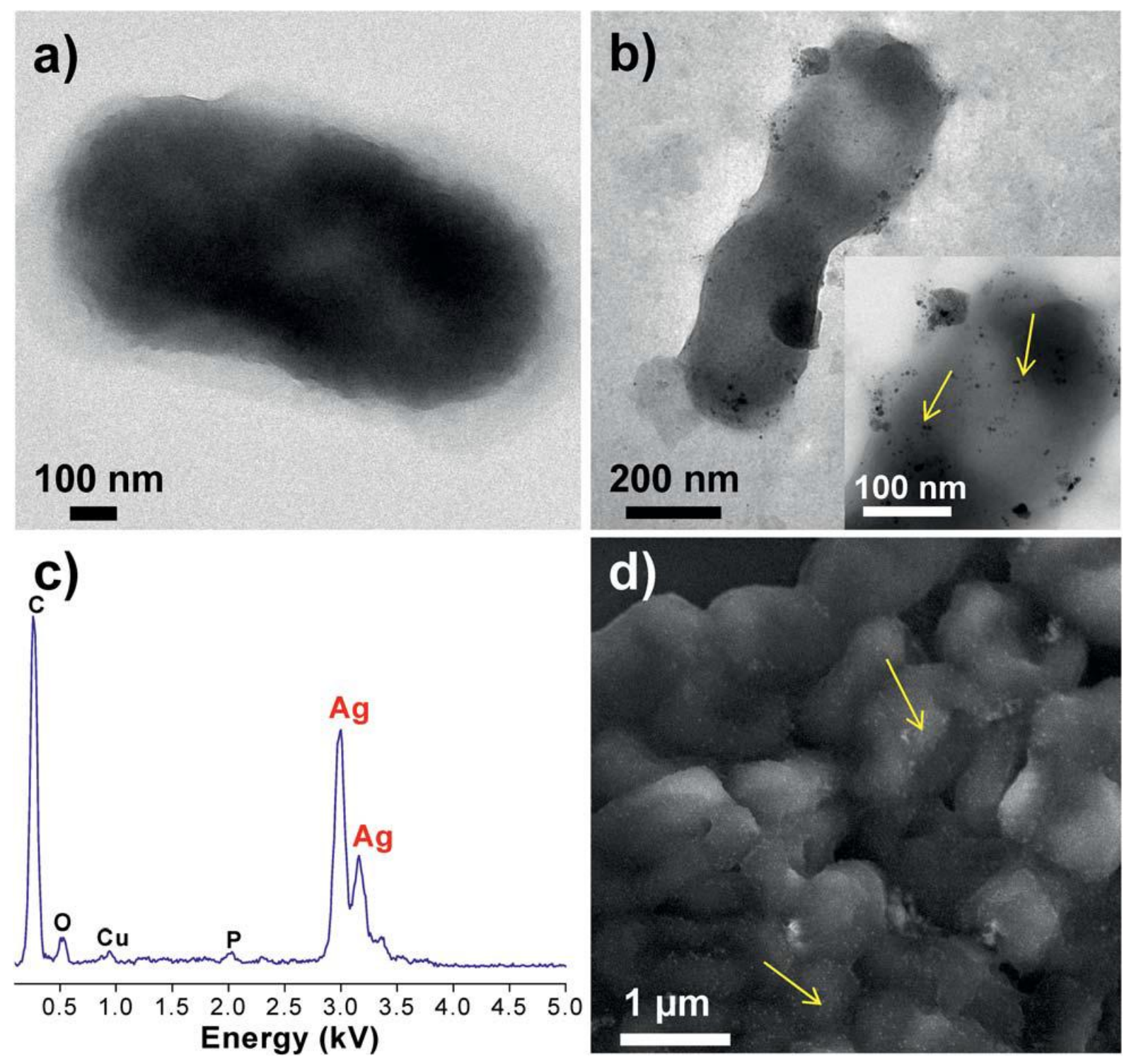

Fig.2 FEG-TEM images of E. coli (a) untreated and (b) treated with Ag NM. The inset, as indicated by arrows, shows the presence of Ag NM. EDX spectrum (c) demonstrates the presence of.Ag The FEGSEM picture (d) confirms the Ag existence throughout the bacterial surface. Reproduced with the permission from (Agnihotri, Mukherji and Mukherji, 2014) Copyright (C) 2014 The Royal Society of Chemistry. 
Another study comparing the antimicrobial efficacy of different shapes of Ag NM (triangular, spherical, and rod) incubated with E.coli of Ag concentrations 1, 12.5, 50, and $100 \mu \mathrm{g}$, concluded that triangular and nanosphere forms killed E.coli more efficiently than rods and ionic $\mathrm{Ag}$ (Pal, Tak and Song, 2015). Triangular Ag NM with an average width of $1 \mu \mathrm{m}$ was found to produce a bacteriostatic effect, and inhibited E. coli $10^{6}$ colony forming units (CFUs). Considering the effect of Ag spheres, almost $12.5 \mu \mathrm{g} \mathrm{Ag}$ was required to reduce E. coli CFUs. In contrast, rodshaped and $\mathrm{Ag}^{3+}$ were unable to reduce $E$. coli viability even at $100 \mu \mathrm{g} \mathrm{Ag}$ concentration. This experiment further confirms the size and dose-dependent antimicrobial activity of Ag NM. Another similar in vitro study investigated Ag-spheres (Ag NM-sp) and Ag-rods (AgNR) on gram-positive and gram-negative bacteria using an optical density method. The study reported lower MIC values of Ag NM-sp $(190,195,188,184,190 \mu \mathrm{g} / \mathrm{ml})$ than AgNR $(358,350,348,320,340$ $\mu \mathrm{g} / \mathrm{ml}$ ) for S. aureus, B. subtilis, P. aeruginosa, K. pneumonia, and E. coli, respectively. When studied against K. pneumonia, different concentrations of Ag NM-sp (184,197,207 $\mu \mathrm{g} / \mathrm{ml})$ and Ag NR $(320,560,720 \mu \mathrm{g} / \mathrm{ml})$, that were selected based on their MIC values, were incubated with $10^{8}-10^{9} \mathrm{CFU} / \mathrm{ml}$. Cellular viability was reduced to $71.0 \%$ and $42.63 \%$, respectively, in the presence of $197 \mu \mathrm{g} / \mathrm{ml}$ of Ag NM-sp and $720 \mu \mathrm{g} / \mathrm{ml}$ of AgNR. The higher antimicrobial effect of Ag NM-sp over AgNR was attributed to its granular shape with the larger surface area and better distribution.

Green synthesis of Ag NM, which are produced from biologically derived moieties, have shown to be more toxic than traditionally synthesized Ag NM (Siddiqi, Husen and Rao, 2018). One approach of Ag NM synthesis from Ricinus communisvar plant extract has been reported by Bora et al. (Ojha, Sett and Bora, 2017). Leave extracts acted as reducing and capping agents to generate 
spherical Ag NM with a particle size of 30-40 nm. Antimicrobial activity against B. subtilis, $S$. aureus, S. zooepidemicus, E. coli, and E. aerogenes was reported as Ag NM having maximum inhibitory activity (MIC $10 \mu \mathrm{g} / \mathrm{ml}$ ) against B. subtilis and S. aureus. Ag NM also showed antimicrobial activity against $E$. coli and $S$. zooepidemicus at $20 \mu \mathrm{g} / \mathrm{ml}$ concentration, while showing no cytotoxicity towards mouse fibroblast cells. Another approach observed high antibacterial effect of Ag NM synthesized from flower extract of Millettiapinnata against Proteus vulgaris, Staphylococcus aureus, Klebsiella pneumonia, E. coli, and Pseudomonas aeruginosa. The mode of action for the antimicrobial activity of Ag NM is distinct. First, positively charged Ag NM electrostatically adsorbed to the negative bacteria. Subsequently, Ag NM interacts with cysteines in protein, which eventually deactivates the protein and releases ROS (Rajakumar $e t$ al., 2017).

\section{Gold nanomaterials (Au NM)}

The bactericidal activity of Au NM is related to their increased penetration into the bacterial cell wall, inducing vacuole formation as an indication of the elevated oxidative stress within the cytoplasm. For instance, Au NM with an average size of $25 \pm 5 \mathrm{~nm}$ and surface charge of -39 $\mathrm{mV}$ were shown to reduce the viability of $C$. pseudotuberculosis at a concentration of $200 \mu \mathrm{g} / \mathrm{ml}$ (Mohamed et al., 2017). Mixed charged (+/-) Au NM were non-toxic to mammalian cells while exhibiting selectivity towards different bacterial strains. For example, a positively charged NM surface strongly interacts with gram-negative bacteria, whereas negative surface charge has a preference for gram-positive bacteria. Wang et al. studied the selective photothermal ablation of Salmonella over E. coli using oval-shaped Au NM conjugated with an anti-Salmonella antibody. 
The authors observed almost $97 \%$ reduction of the bacterial viability under irradiation of $\lambda_{670} \mathrm{~nm}$ for 15 min, whereas E. coli bacteria survived under the same conditions (Wang et al., 2010).

\section{Titanium dioxide nanomaterials $\left(\mathrm{TiO}_{2} \mathrm{NM}\right)$}

The evaluation of ROS from the $\mathrm{TiO}_{2} \mathrm{NM}$ surface under UV irradiation have shown to exhibit a linear correlation between the viability of $E$. coli and ROS concentration induced after UV irradiation (Li et al., 2012). Interactions between superoxide radicals with the unsaturated phosphate lipids in $E$. coli membrane, followed by its lipid peroxidation, was believed to interrupt the cell membrane integrity; ultimately reducing bacterial viability (Cai, Strømme and Welch, 2013)(Figure 3).

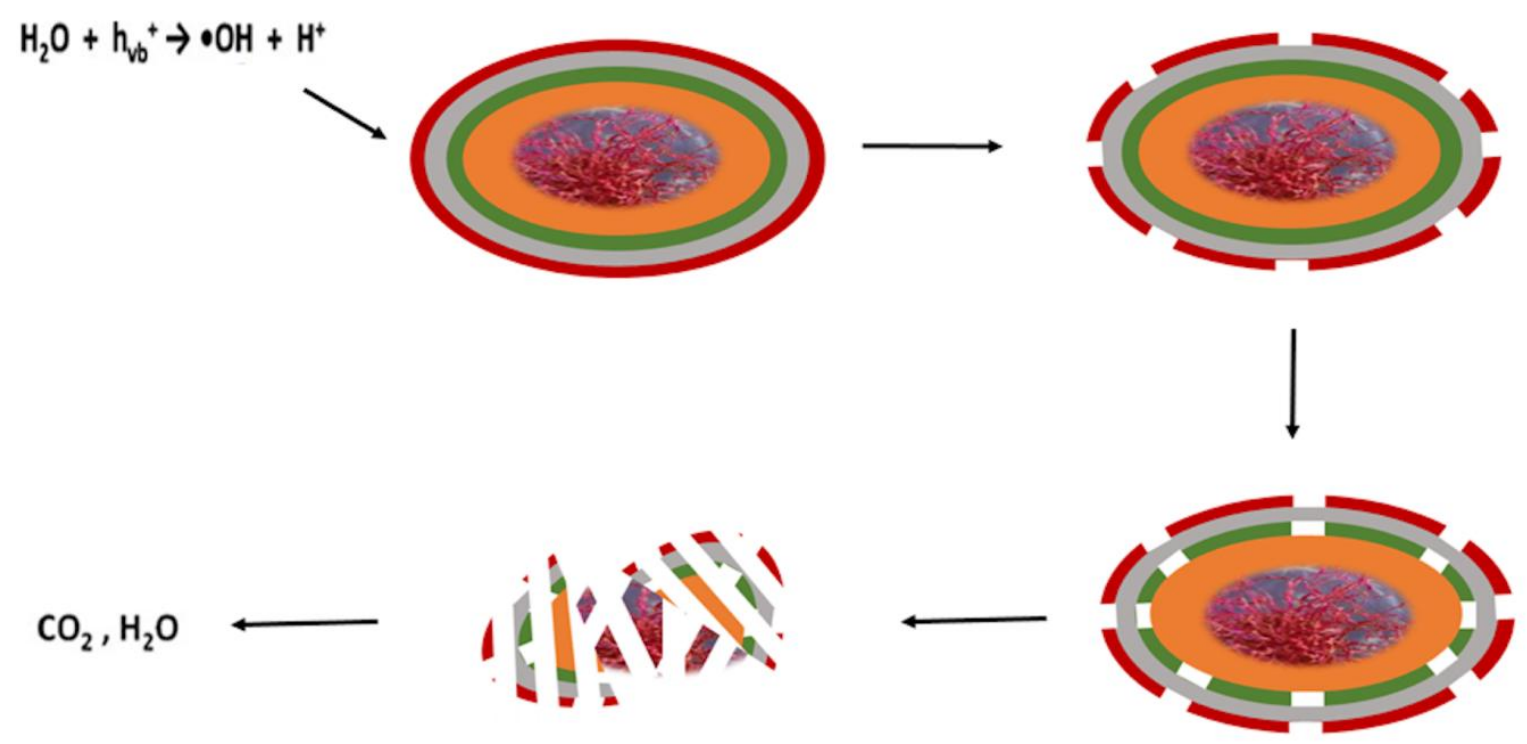

Fig.3 Photocatalytic bactericidal activity of $\mathrm{TiO}_{2}$ based photocatalyst.

However, $\mathrm{TiO}_{2} \mathrm{NM}$ induce adverse effects on human cells and tissue; hence, their use as antibacterial agents remains under limitation (Shah et al., 2017). Doping with Au, Ag, Pt, or Ag, 
can narrow the bandgap of $\mathrm{TiO}_{2} \mathrm{NM}$ and enhance its photocatalytic effect (Ahamed et al., 2017). Various reports have described the visible-light-induced antimicrobial activity of $\mathrm{Fe}, \mathrm{Cu}, \mathrm{Ni}$, and Ag-doped $\mathrm{TiO}_{2} \mathrm{NM}$ against $S$. aureus and E.coli bacteria (Yadav et al., 2016)(Moongraksathum and Chen, 2018).

\section{Copper and copper oxide nanomaterials (Cu and $\mathrm{CuO} N M)$}

In different composite forms of $\mathrm{Cu}$ and $\mathrm{CuO} \mathrm{NM}$, such as $\mathrm{SiO}_{2}-\mathrm{Cu}, \mathrm{Cu} \mathrm{NM}$ were proven to be efficient antimicrobial agents against different strains of bacteria (Muthukrishnan, 2015). Bacterial membrane destruction was found to be the primary source of bacterial death if subjected to such composites. In addition, $\mathrm{CuO} \mathrm{NM}$ have recently been found to exert a $\mathrm{pH}$-dependent antibacterial effect against $S$. aureus. $\mathrm{CuO} \mathrm{NM}$ interact with $S$. aureus at acidic $\mathrm{pH}(\mathrm{pH}=5)$ whereby significant bactericidal activity was observed due to their lower agglomeration, which facilitates

solubility dependent release of $\mathrm{Cu}^{2+}$ ions compared to $\mathrm{pH} 6$ and 7. The released $\mathrm{Cu}^{2+}$ ions induced the production of ROS (Hsueh, Tsai and Lin, 2017)(Hajipour et al., 2012).

$\mathrm{Cu}$ substituted with hydroxyapatite and fluorapatite (a bone mimetic material) was studied against gram-positive and gram-negative bacteria, as well as fungi to overcome possible infection of artificial bone implant material after surgery (Shanmugam and Gopal, 2014). In this study, $\mathrm{Cu}-$ substituted hydroxyapatite displayed antimicrobial activity against gram-positive bacteria. In contrast, $\mathrm{Cu}$-substituted fluorapatite showed antimicrobial activity not only against gram-positive and gram-negative bacteria but also fungi. A higher release of $\mathrm{Cu}$ from $\mathrm{Cu}$-substitutedfluorapatite is the main reason for this intense antimicrobial action. Compared with $\mathrm{Ag} \mathrm{NM}, \mathrm{Cu}$ NM are much more potent, and a promising therapeutic with higher colloidal stability and 
resistance for surface oxidation; being critical factors for $\mathrm{Cu} \mathrm{NM}$ as antimicrobial agent (Khurana and Chudasama, 2018).

\section{Zinc oxide nanomaterials ( $\mathrm{ZnO} \mathrm{NM}$ )}

$\mathrm{ZnO}$ displays vigorous antimicrobial activity due to its electrostatic interaction and internalization, the release of $\mathrm{Zn}^{2+}$ ions, and ROS formation. $\mathrm{ZnO} \mathrm{NM}$ was proven effective against $S$. typhimurium, C. jejuni, Vibrio fischer, P. aeruginosa, P. alcaligenes, P. vulgaris, $S$. entericaserovar enteritidis, and E. coli (Xie et al., 2011)(Heinlaan et al., 2008)(Jones et al., 2008) (Nair et al., 2011)(Nair et al., 2011). The cytotoxic action of ZnO NM against prokaryotic and eukaryotic cells via flow cytometry viability assays concluded that $\mathrm{ZnO} \mathrm{NM}$ more effectively reduced $S$. aureus and $E$. coli strains. In contrast, $\mathrm{ZnO} \mathrm{NM}$ were least effective on human $\mathrm{CD}^{+}{ }^{\mathrm{T}}$ cells. Significant reduction of $E$. coli and $S$. aureus colonies were observed when $>3.4$ and $1 \mathrm{mM}$ of $13 \mathrm{~nm} \mathrm{ZnO}$ was added to the agar plate. Dose and time-dependent inhibition of bactericidal activity was observed for $\mathrm{ZnO} \mathrm{NM}$, with entire colonies inhibition after $24 \mathrm{~h}$ of treatment. Alternatively, $\mathrm{ZnO}$ was tested against human T-lymphocytes, whereby no significant reduction of cell viability was observed. Overall, these findings display selective antimicrobial activity of $\mathrm{ZnO} / \mathrm{ZnO} \mathrm{NM}$ against prokaryotic cells without harming eukaryotic cells (Reddy et al., 2007).

In a study comparing inhibition produced by $\mathrm{ZnO}, \mathrm{CuO}$, and $\mathrm{Fe}_{2} \mathrm{O}_{3} \mathrm{NM}$ against gram-positive $(S$. aureus and B. subtilis) and gram-negative (P. aeruginosa and E. coli), ZnO NM was reported as more potent antibacterial agents in comparison to those of $\mathrm{Fe}_{2} \mathrm{O}_{3}$ and $\mathrm{CuO} \mathrm{NM}$ (Yemmireddy and Hung, 2017). The antimicrobial mechanism of $\mathrm{ZnO} \mathrm{NM}$ is believed to be related to particle size, which facilitates their bacterial penetration and generation of ROS, being more effective against 
gram-positive than gram-negative bacteria (Seil and Webster, 2012) (Premanathan et al., 2011).

For E. coli and S. aureus, the viability was reduced upon the incubation overnight with three nmsized $\mathrm{ZnO} \mathrm{NM}$ at a concentration of $3.1 \mathrm{mg} / \mathrm{ml}$ and $1.5 \mathrm{mg} / \mathrm{ml}$, respectively. Gram-positive bacteria were more impacted due to the structural differences of the cell wall composition. Smaller ZnO NM were able to interact and increase abrasiveness on the bacterial cell wall (Nair et al., 2009) (Yuan et al., 2018).

$\mathrm{ZnO} \mathrm{NM}$ photoconductivity was reported following UV illumination $\left(390 \mathrm{~nm}, 1.8 \mathrm{~W} \mathrm{~cm}^{-2}\right) \mathrm{ZnO}-$ rods and $\mathrm{ZnO}$-plates reduced viability of $E$. coli by $18 \%$ ( $\mathrm{ZnO}-$ rod) and $13 \%$ (ZnO-plate), whereas the viability of S. aureus was reduced by $22 \%$ when exposed to ZnO-rod and by $21 \%$ with ZnO-plate compared to control. $\mathrm{ZnO} \mathrm{NM}$ illumination lead to the desorption of loosely bound oxygen molecules, thereby increasing its concentration on the $\mathrm{ZnO}$ surface, which ultimately generated oxygen species such as $\mathrm{H}_{2} \mathrm{O}_{2}, \mathrm{O}_{2}{ }^{-}$and $\mathrm{OH}^{-}$. These ROS inactivate proteins, enzymes, and DNA (Ann et al., 2014). In a similar study by Zhou et al. (Zhou et al., 2008) a strong antibacterial rate of $\mathrm{ZnO}$ complex was obtained in S. aureus $(99.45 \%)$ due to higher permeability of $\mathrm{OH}^{-}$ions generated under UV light through the membrane of S. aureus compared to E. coli (95.65\%), whose outer lipopolysaccharide (LPS) membrane restricts $\mathrm{OH}^{-}$ions inside E. coli. For microbes, OHions interact with nuclear acids or respiratory classes of sulfhydryl and stop breathing for bacteria. The $\mathrm{Zn}-\mathrm{CuO}$-coated fabrics benefit from injection into $\mathrm{Cu}$, giving different benefits in contrast to $\mathrm{ZnO}$ and $\mathrm{CuO} \mathrm{NM}$. For example, $\mathrm{Zn}-\mathrm{CuO} \mathrm{NM}$ display 10000 times more antibiotic activity within a short time. The potency of antimicrobial bandages, which were prepared by depositing $\mathrm{Zn}-\mathrm{CuO} \mathrm{NM}$ on cotton fabric using ultrasound irradiation to exert activity, was evaluated by using four microbial models (E. coli, S. aureus, MRSA, and MDR E. coli). Zn-CuO coated fabrics were incubated with $10^{8}$ CFUs for 30 min. 5 and $6 \log$ reduction of E. coli and S. aureus were observed 
after 10 min of treatment. In contrast, inhibition of only 1 and 2 orders of magnitude was detected for $S$. aureus after $\mathrm{ZnO}$ and $\mathrm{CuO}$ treatment and negligible effect was observed for $E$. coli. An elevated amount of $\mathrm{OH}^{-}, \mathrm{O}_{2}^{-}$, and singlet oxygen formation by $\mathrm{Zn}-\mathrm{CuO}$ composites resulted in higher bactericidal activity compared to ZnO and $\mathrm{CuO}$ NM (Malka et al., 2013).

\section{Mesoporous silica nanoparticles (MSNs)}

Silicon dioxide NM, especially so the type of mesoporous silica nanoparticles (MSNs), have attracted significant attention as an ideal antibacterial platform (Şen Karaman, Manner and Rosenholm, 2018) (Martínez-Carmona, Gun'ko and Vallet-Regí, 2018). Their size, matrix, and surface functionality can be adjusted to improve their interaction with bacteria and improve biofilm penetration (Camporotondia et al., 2013). Besides, MSNs may also interfere with bacterial cell-to-cell communication (quorum sensing) to avoid the development of biofilms. For just over a decade, the use of MSNs as effective drug delivery systems, particularly for anticancer therapies, has been thoroughly documented. The unique physical features of MSNs (e.g. high specific surface areas, large pore volumes and tunable pore sizes), two distinct (external and internal) surfaces that can be independently functionalized and further utilised for incorporating controlled drug release strategies, and the ability of MSNs to penetrate through biological barriers make them compelling candidates for the design of sophisticated antibacterial delivery systems (Gounani et al., 2019). Recent studies have reported the usefulness of MSNs for efficient antibiotic supply and the preparation of hybrid materials by incorporating MSNs with antibacterial enzymes (Li and Wang, 2013), peptides (Braun et al., 2016), metal ions/particles (Tian et al., 2014) and polymers (surface modifiers) (Şen Karaman et al., 2016). Moreover, MSNs have been developed for dual antibiotic delivery. For instance, recently, Gounani et al. (Gounani et 
al., 2019) performed the loading of two different antibiotics into MSNs to increase the therapeutic efficiency on both gram-positive and gram-negative bacteria. Thus, combinatory therapy with dual antibiotic-loaded MSNs could be provided with better treatment results for diseases requiring elevated levels of various drugs.

In another study, hollow structured, well-defined mesoporous shells for sustained release of entrapped antimicrobial agents were prepared. Such hollow, mesoporous shells not only confers stability to the entrapped biological moieties but also acts as a reservoir. For example, aminefunctionalized hollow MSN (HMSN) have shown to act as an efficient carrier for antimicrobial agents. When loaded with antituberculosis drug isoniazid, HMSN could release isoniazid in a sustained manner (released $60 \%$ after $72 \mathrm{~h}$ ). Isoniazid loaded HMSN exhibited potent antimicrobial activity against isoniazid resistant M. smegmatis stain $\mathrm{mc}^{2} 651$ (MIC 640 and 320 $\mathrm{ug} / \mathrm{mL})$ and lowered the half inhibitory concentration $\left(\mathrm{IC}_{50}\right)$ by 3.3- and 4.1-fold compared to free isoniazid (MIC $1280 \mathrm{ug} / \mathrm{mL}$ ) after 24 and $72 \mathrm{~h}$ treatment, respectively. The enhanced bactericidal activity of isoniazid loaded HMSN may be attributed to increased intra-bacterial accumulation of isoniazid in a sustained manner from the well-defined mesoporous shell, conjointly with a strong interaction of amine moieties on the HMSN surface with bacteria (Hao et al., 2015).

\subsection{NM against multidrug-resistant (MDR) bacterial strains}

Multidrug resistance (MDR) developed by certain microorganisms against multiple drugs is a leading cause of hospital-acquired infections. It is being assessed that MDR causes $40-60 \%$ of nosocomial infections in the United States and the United Kingdom (Haque et al., 2018). Metal 
oxides, metals, doped metals, and metal halides play a vital role in the selective and non-selective photothermal killing of MDR (Khlebtsov and Dykman, 2011)(Dizaj et al., 2014). Several metallic NM have superior antibacterial activity against MDR bacteria over traditional antibiotics (Blair et al., 2015). Bacteria can develop resistance towards metal NM through different mechanisms: 1) reduction of metal ions to non-toxic neutral oxidation, 2) increase in efflux of metal ions through chemiosmotic antiporters or P-type adenosine triphosphatases, and 3) production of flagellin, a bacterial adhesive protein from gram-negative strains, which aggregate metal NM on the bacterial surface and reduces antimicrobial efficacy (Nies, 2003)(Li, Nikaido and Williams, 1997)(Gupta et al., 1999)(Panáček et al., 2018). Recently, Graves et al. (Siddiqi, Husen and Rao, 2018) observed a genetic mutation in E.coli for 225 generations after regular exposure of Ag NM. To date, there have been no studies demonstrating the resistance of bacteria towards ROS species. However, most of the photosensitisers are water-insoluble and aggregate in water, which ultimately reduces their ROS generation capacity. To overcome this issue, a new hydrophobic photosensitiser based on amphiphilic block copolymer containing Chlorin e6 (Ce6) conjugated to Au NM surface, have shown effectiveness against Staphylococcus aureus (MRSA) (Wijesiri et al., 2017). Table 1 summarises other metal and metal oxide designs that have been investigated against MDR bacteria. 
Table 1 Antimicrobial activity of metallic NM and metal oxide NM against multi-drug resistant bacteria

\begin{tabular}{|c|c|c|c|c|}
\hline $\begin{array}{l}\text { Metal } \\
\text { NMs }\end{array}$ & Test MDR Bacteria & Mechanism of antimicrobial activity & Formulation Type & References \\
\hline \multirow[t]{3}{*}{$\mathrm{Ag}$} & $\begin{array}{l}\text { MRSA } \\
\text { VRE }\end{array}$ & Investigation under process & Ag containing dressing & $\begin{array}{l}\text { (Percival, Bowler and } \\
\text { Dolman, 2007) }\end{array}$ \\
\hline & MRSA & $\begin{array}{l}\text { Reduce glucose uptake and ATP synthesis, } \\
\text { production of ROS, alter membrane } \\
\text { permeability }\end{array}$ & Ag supported silicate platelets & (Su et al., 2011) \\
\hline & $\begin{array}{l}\text { Erythromycinresistant } \\
\text { S.pyogenes } \\
\text { Ampicillin resistant } \\
\text { E. coli } \\
\text { Multidrug-resistant } P \text {. } \\
\text { aeruginosa }\end{array}$ & $\begin{array}{l}\text { Inhibit respiratory enzymes, binds to DNA and } \\
\text { RNA and inhibit its replication, denature } 30 \mathrm{~S} \\
\text { ribosome subunit, alter membrane permeability }\end{array}$ & NM & (Lara et al., 2010) \\
\hline
\end{tabular}




\begin{tabular}{|c|c|c|c|c|}
\hline Metal NMs & Test MDR Bacteria & $\begin{array}{l}\text { Mechanism of antimicrobial } \\
\text { activity }\end{array}$ & Formulation Type & References \\
\hline \multirow{3}{*}{$\mathrm{Ag}$} & $\begin{array}{l}\text { Erythromycin resistant Bacillus cereus } \\
\text { Erythromycin resistant S. typhimurium } \\
\text { Erythromycinresistant Enterococcus } \\
\text { faecalis }\end{array}$ & Cell membrane disruption & $\begin{array}{l}\text { Ag-Alginate } \quad(\mathrm{Ag}-\mathrm{Alg}) \\
\text { biohydrogel }\end{array}$ & (Otari et al., 2013) \\
\hline & $\begin{array}{l}\text { Extended-spectrum beta-lactamases } \\
\text { (ESBL) positive } E \text {. coli } \\
\text { Teicoplanin resistant } S \text {. pneumoniae } \\
\text { MRSA }\end{array}$ & $\begin{array}{l}\text { Generation and uptake of } \\
\text { Ag+ inside the bacteria } \\
\text { membrane }\end{array}$ & $\begin{array}{l}\text { AgNMs coated surgical } \\
\text { suture }\end{array}$ & (Thapa et al., 2017) \\
\hline & MDR P. aeruginosa & $\begin{array}{l}\text { Thermal destruction of the } \\
\text { membrane, ROS generation, } \\
\text { Penetration of } \mathrm{Ag}^{+} \text {inside the } \\
\text { membrane }\end{array}$ & AgNMs with blue light & (El Din et al., 2016) \\
\hline
\end{tabular}




\begin{tabular}{|c|c|c|c|c|}
\hline Metal NMs & Test MDR Bacteria & $\begin{array}{l}\text { Mechanism of antimicrobial } \\
\text { activity }\end{array}$ & Formulation Type & References \\
\hline \multirow[t]{2}{*}{$\mathrm{Au}$} & MRSA & $\begin{array}{l}\text { Photothermal abilation and } \\
\text { ROS production }\end{array}$ & Au Nanorod (Au NR) & (Kuo et al., 2009) \\
\hline & $\begin{array}{l}\text { MDR E. Coli } \\
\text { MDR E. Cloacae } \\
\text { MDR K. pneunoniae }\end{array}$ & $\begin{array}{l}\text { Membrane disruption, singlet } \\
\text { oxygen generation, DNA } \\
\text { degradation }\end{array}$ & MB@GNM ${ }_{D E X}-C o n A$ & (Khan et al., 2017) \\
\hline $\mathrm{Cu}$ & MRSA & $\begin{array}{l}\mathrm{Cu}+\text { release that damage } \\
\text { bacterial DNA } \\
\text { Size-dependent antimicrobial } \\
\text { activity of } \mathrm{CuONMs}\end{array}$ & NM & (Kruk et al., 2015) \\
\hline $\mathrm{ZnO}$ & MRSA & $\begin{array}{l}\text { Inhibition of } \beta \text {-galactosidase } \\
\text { (GAL) }\end{array}$ & $\mathrm{ZnO}$ nanopyramids & (Cha et al., 2015) \\
\hline
\end{tabular}




\begin{tabular}{|c|c|c|c|c|}
\hline Metal NMs & Test MDR Bacteria & Mechanism of antimicrobial activity & $\begin{array}{l}\text { Formulation } \\
\text { Type }\end{array}$ & References \\
\hline $\mathrm{ZnO}$ & $\begin{array}{l}\text { Meticillin resistant S. agalactiae } \\
\text { and S. aureus }\end{array}$ & $\begin{array}{l}\text { penetration and disorganization of cell } \\
\text { membranes }\end{array}$ & NM & (Huang et al., 2008) \\
\hline $\mathrm{CuO}$ & MRSA & $\begin{array}{l}\mathrm{Cu}^{2+} \text { ions released from the NMs } \\
\text { permeate through the bacterial } \\
\text { membrane and disturb enzyme function }\end{array}$ & NM & (Ren et al., 2009) \\
\hline $\begin{array}{l}\mathrm{Fe} 3 \mathrm{O} 4 \\
\text { (Iron Oxide) }\end{array}$ & $\begin{array}{l}\text { MDR E. Coli } \\
\text { MDR S. aureus }\end{array}$ & $\begin{array}{l}\text { Magnetic core under radiofrequency } \\
(\mathrm{RF}) \text { current alter bacterial membrane } \\
\text { potential }\end{array}$ & NM & (Chaurasia et al., 2016) \\
\hline $\mathrm{Al}_{2} \mathrm{O}_{3}$ & $\begin{array}{l}\text { MRSA, MSSA } \\
\text { MSCoNS (methicillin-sensitive } \\
\text { Coagulasenegative } \\
\text { Staphylococcus) }\end{array}$ & $\begin{array}{l}\text { Damage of membrane, leakage of } \\
\text { cellular content, and interacts with } \\
\text { macromolecules }\end{array}$ & NM & (Ansari et al., 2013) \\
\hline
\end{tabular}




\begin{tabular}{|c|c|c|c|c|}
\hline Metal NMs & Test MDR Bacteria & Mechanism of antimicrobial activity & $\begin{array}{l}\text { Formulation } \\
\text { Type }\end{array}$ & References \\
\hline $\mathrm{Al}_{2} \mathrm{O}_{3}$ & ESBL positive $E$. coli & $\begin{array}{l}\text { uptake of NMs inside the membrane and } \\
\text { damage the biomolecules }\end{array}$ & NM & (Ansari et al., 2014) \\
\hline \multirow[t]{2}{*}{$\mathrm{TiO}_{2}$} & MRSA & $\begin{array}{l}\text { Interact and inactivate the bacterial } \\
\text { surface proteins }\end{array}$ & NM & (S. Roy et al., 2010) \\
\hline & & $\begin{array}{l}\text { UV light-induced ROS generation and } \\
\text { physical damage of the membrane }\end{array}$ & $\begin{array}{l}\text { Biphasic } \\
\text { brookite-anatase } \\
\mathrm{TiO}_{2} \mathrm{NMs}\end{array}$ & (Shah et al., 2008) \\
\hline $\begin{array}{l}\text { NO (Nitric } \\
\text { Oxide) }\end{array}$ & MRSA & Induce immune response & NM & (Han et al., 2009) \\
\hline
\end{tabular}




\subsubsection{Antibiotic conjugated NM against MDR}

Metallic NM conjugated with antibiotics can exhibit synergistic antimicrobial activity. As stated above in section 2.3, metallic NM may effectively inhibit the viability of MDR bacteria. As a result, the potency of antibiotics increases, thereby reducing the side effects towards mammalian cells as well as antibacterial resistance (Allahverdiyev et al., 2011). Moreover, metallic NM are suitable carriers for the delivery of antibiotics. For example, tetracycline conjugated Ag NM increased antibacterial action of tetracycline, due to enhanced accumulation of the $\mathrm{Ag}^{+}$around the bacterial cell membranes (Kumar, Curtis and Hoskins, 2018). Similarly, when Au NM was conjugated to a fluoroquinolone antibiotic, the antibacterial effects of fluoroquinolone was boosted lowering the MIC against MDR bacteria by $8-16$ folds compared to free fluoroquinolone; which was due to their capacity of conjugates to behave as Tolc-AcrAB efflux pumps (Gupta et al., 2017). Recently, Katya et al. (Katva et al., 2018) pointed out the synergistic antimicrobial activity of Ag NM with gentamicin and chloramphenicol against MDR E. faecalis compared to antibiotics alone. Several studies involving the antibacterial activity of NM are listed in Table 2. 


\begin{tabular}{|c|c|c|c|}
\hline $\begin{array}{l}\text { Antibiotic conjugated } \\
\text { Nanometals }\end{array}$ & Test MDR strain & Mechanism of antimicrobial action & References \\
\hline Ampicillin-Ag NMs & $\begin{array}{l}\text { Ampicillin resistance } E . \text { coli } \\
\text { Ampicillin } \quad \text { resistance } \quad P \text {. } \\
\text { aeruginosa }\end{array}$ & Blockage of the efflux pump & (Brown et al., 2012) \\
\hline Clindamycin- Ag NMs & MRSA & $\begin{array}{l}\text { Synergistic antimicrobial activity, inhibition } \\
\text { of protein synthesis, an altercation in the } \\
\text { respiratory chain }\end{array}$ & (Rahim and Mohamed, 2015) \\
\hline \multirow[t]{2}{*}{ Vancomycin- Ag NMs } & MRSA & Synergistic antimicrobial activity & (Saeb et al., 2014) \\
\hline & $\begin{array}{l}\text { MDR E. faecalis } \\
\text { MDR S. epidermidis }\end{array}$ & An altercation of bacterial permeability & $\begin{array}{l}\text { (Esmaeillou et al., } \\
\text { 2017)(Panácek et al., 2016) }\end{array}$ \\
\hline Ofloxacin- Ag NMs & MDR P. aeruginosa & Inhibition of multidrug efflux pump activity & (Ding et al., 2018) \\
\hline Tetracycline- Ag NMs & $\begin{array}{l}\text { Tetracycline resistance } E . \text { coli } \\
\text { Tetracycline resistance } S . \text { aureus }\end{array}$ & Cytotoxic effect of $\mathrm{Ag}^{+}$ & (Djafari et al., 2016) \\
\hline
\end{tabular}




\begin{tabular}{|c|c|c|c|}
\hline $\begin{array}{l}\text { Antibiotic conjugated } \\
\text { Nanometals }\end{array}$ & Test MDR strain & Mechanism of antimicrobial action & References \\
\hline $\begin{array}{l}\text { Tetracycline- Ag } \\
\text { NMs } \\
\text { Neomycin- Ag NMs }\end{array}$ & MDR S. typhimurium & $\begin{array}{l}\text { Antibiotics facilitate binding of } \mathrm{Ag} \mathrm{NM} \text { to } \\
\text { the bacteria membrane, increase in the } \\
\text { concentration of } \mathrm{Ag}^{+} \text {on bacteria membrane }\end{array}$ & (McShan et al., 2015) \\
\hline $\begin{array}{l}\text { Anti-S. aureus- } \mathrm{Au} \\
\mathrm{NMs}\end{array}$ & MRSA & $\begin{array}{l}\text { Antibiotics facilitate binding of Au NM to } \\
\text { the bacteria membrane, photothermal } \\
\text { destruction of bacteria cells }\end{array}$ & (Millenbaugh et al., 2015) \\
\hline $\begin{array}{l}\text { Levofloxacin, } \\
\text { ceftriaxone, } \\
\text { cefotaxime, and } \\
\text { ciprofloxacin- } \quad \mathrm{Au} \\
\mathrm{NMs}\end{array}$ & $\begin{array}{l}\text { MDR E. coli } \\
\text { MDR K. Pneumoniae } \\
\text { MDR S. Aureus }\end{array}$ & $\begin{array}{l}\text { Disorganization and disruption of the } \\
\text { bacterial membrane, } \\
\text { loss of intracellular cytoplasmic content }\end{array}$ & (Pradeepa et al., 2016) \\
\hline Cefotaxime-Au NMs & $\begin{array}{l}\text { Cefotaxime resistance E. coli, } K \text {. } \\
\text { Pneumoniae }\end{array}$ & $\begin{array}{l}\text { Altercation in the bacterial cell wall, DNA } \\
\text { damage }\end{array}$ & (Shaikh et al., 2017) \\
\hline Meropenem-Au NMs & $\begin{array}{llll}\text { Carbapenem } & \text { resistance } & K . \\
\text { Pneumoniae, } & P . & \text { Mirabilis, } & A . \\
\text { Baumanii } & & & \end{array}$ & $\begin{array}{l}\text { Alter osmatic balance and membrane } \\
\text { integrity, damage of membrane, inhibition } \\
\text { of protein synthesis }\end{array}$ & (Shaker and Shaaban, 2017) \\
\hline
\end{tabular}




\begin{tabular}{|c|c|c|c|}
\hline $\begin{array}{l}\text { Antibiotic conjugated } \\
\text { Nanometals }\end{array}$ & Test MDR strain & Mechanism of antimicrobial action & References \\
\hline Kanamycin-Au NMs & $\begin{array}{l}\text { Kanamycin resistance } S . \text { Bovis, } S \text {. } \\
\text { Epidermidis, E. Aerogenes } \\
\text { P.Aeruginosa PAO1 } \\
\text { MDR P. Aeruginosa }\end{array}$ & $\begin{array}{l}\text { Alter cell membrane integrity, lysis of cell } \\
\text { wall, leakage of cellular content, inhibition } \\
\text { of protein synthesis }\end{array}$ & (Payne et al., 2016) \\
\hline Vancozycin-Au NMs & $\begin{array}{l}\text { vancomycin-resistant E. faecium } \\
\text { (VRE4), E.faecalis (VRE1) } \\
\text { MRSA } \\
\text { Pandrug-resistant A. baumannii } \\
\text { (PDRAB) }\end{array}$ & Bacteriostatic effect & (Lai et al., 2015) \\
\hline Antibiotics- $\mathrm{TiO}_{2}$ & MRSA & Synergistic antimicrobial activity & (S. Roy et al., 2010) \\
\hline
\end{tabular}




\begin{tabular}{|l|l|l|l|}
\hline Antibiotic conjugated & Test MDR strain & Mechanism of antimicrobial action & References \\
Nanometals & & MRSA sensitive near-infrared (Zhao et al., 2017) \\
Vancomycin-Silica & MRSA & fluorescence (NIRF) nanoprobe for & imaging and photothermal antibacterial \\
& & therapy & \\
& & & \\
\end{tabular}




\subsection{NM against biofilms}

Biofilm is a bacterial cell community that adheres to metals, plastics, and human or animal tissues with the aid of highly hydrated extracellular polymeric substance (EPS) matrix (Wingender, Neu and Flemming, 1999)(Donlan, 2002). Secreted EPS is responsible for the maintenance of the threedimensional biofilm structure (Flemming and Wingender, 2010)(Markowska, Grudniak and Wolska, 2013). In a biofilm environment, bacteria can propagate quickly with efficient protection and consequently create 100-1000 times more resistance of the cells towards the phagocytic process (Aaron et al., 2002)(Khan and Khan, 2016). Several studies have shown that biofilmgrown microorganisms acquire resistance by a variety of mechanisms as listed below:

A) EPS in biofilm acts as a physicochemical barrier and restricts the penetration of antimicrobial drugs (Billings et al., 2013)(Tseng et al., 2013). Additionally, an enzymatic substance in biofilm matrix hydrolyzes antimicrobial agents and reduces their activity. For example, $\beta$-lactamase present in P. aeruginosa degrades $\beta$-lactam antibiotics (Mah and O'Toole, 2001)(Ciofu et al., 2000)(Schooling and Beveridge, 2006).

B) High-density bacterial growth within a biofilm promotes stress response, which induces the production of antimicrobial degrading enzymes (Schembri, Kjaergaard and Klemm, 2003).

C) Increased DNA exchange between bacteria, which facilitates resistance-gene transmission (Qayyum et al., 2016).

D) By quorum sensing, bacteria are capable of controlling gene transcription (Husain et al., 2016).

E) The slow growth of bacteria in biofilms is another mechanism of resistance (Mah and O'Toole, 2001).

NM are increasingly regarded as an alternative to standard antibiotics to eliminate biofilms or limit their development on biomedical devices (Iannitelli et al., 2011)(Lellouche et al., 2012). 
Metal NM have a benefit over other frequently used antimicrobials because they do not differentiate between pathogenic and drug-resistant microbes with no specific target (Campoccia, Montanaro and Arciola, 2013)(Rai, Yadav and Gade, 2009). A diagrammatic representation of the antibiofilm mode of action of NM is shown in Figures 4 and 5.

(a)

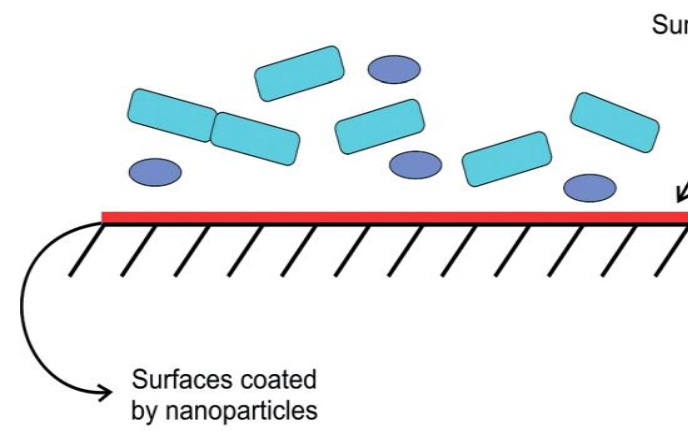

Surfaces under microbial

(b)

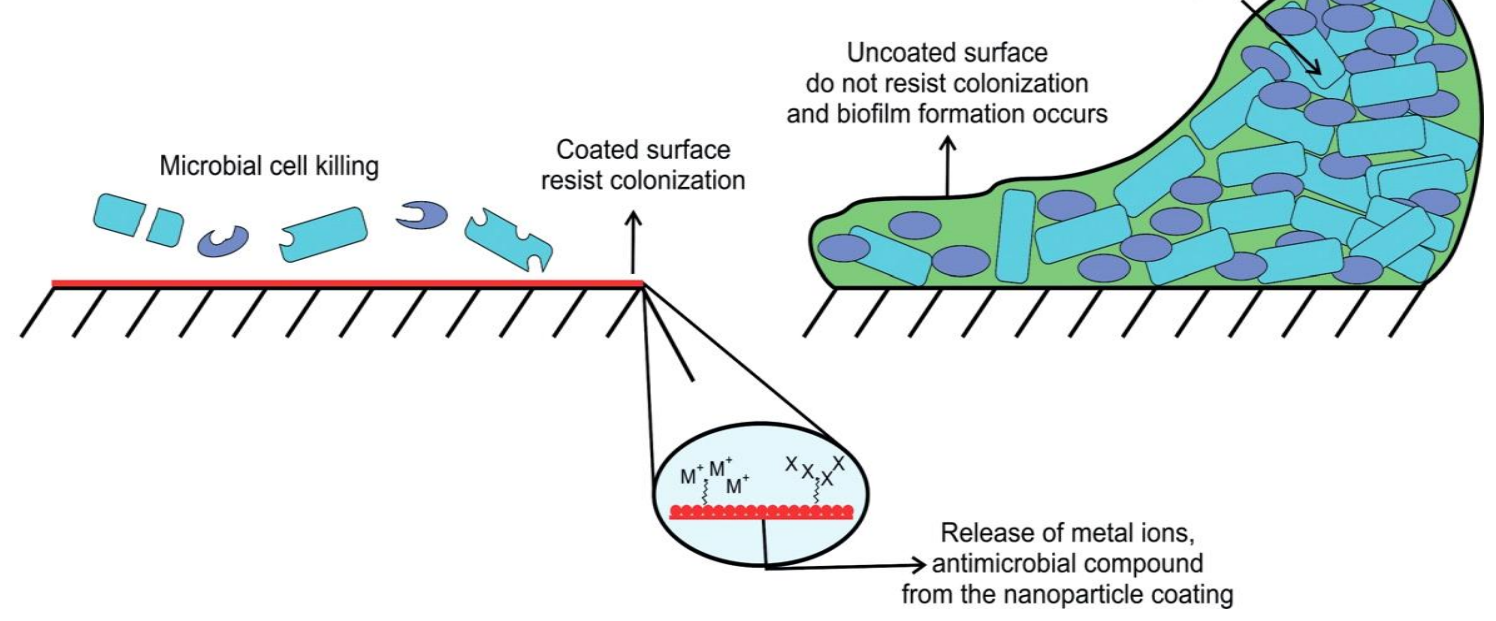

Fig. 4. Illustration of the inhibition of biofilm formation on surfaces coated by metal NM. Reproduced with permission (Qayyum et al., 2016) Copyright @ 2016 RSC Publishing 

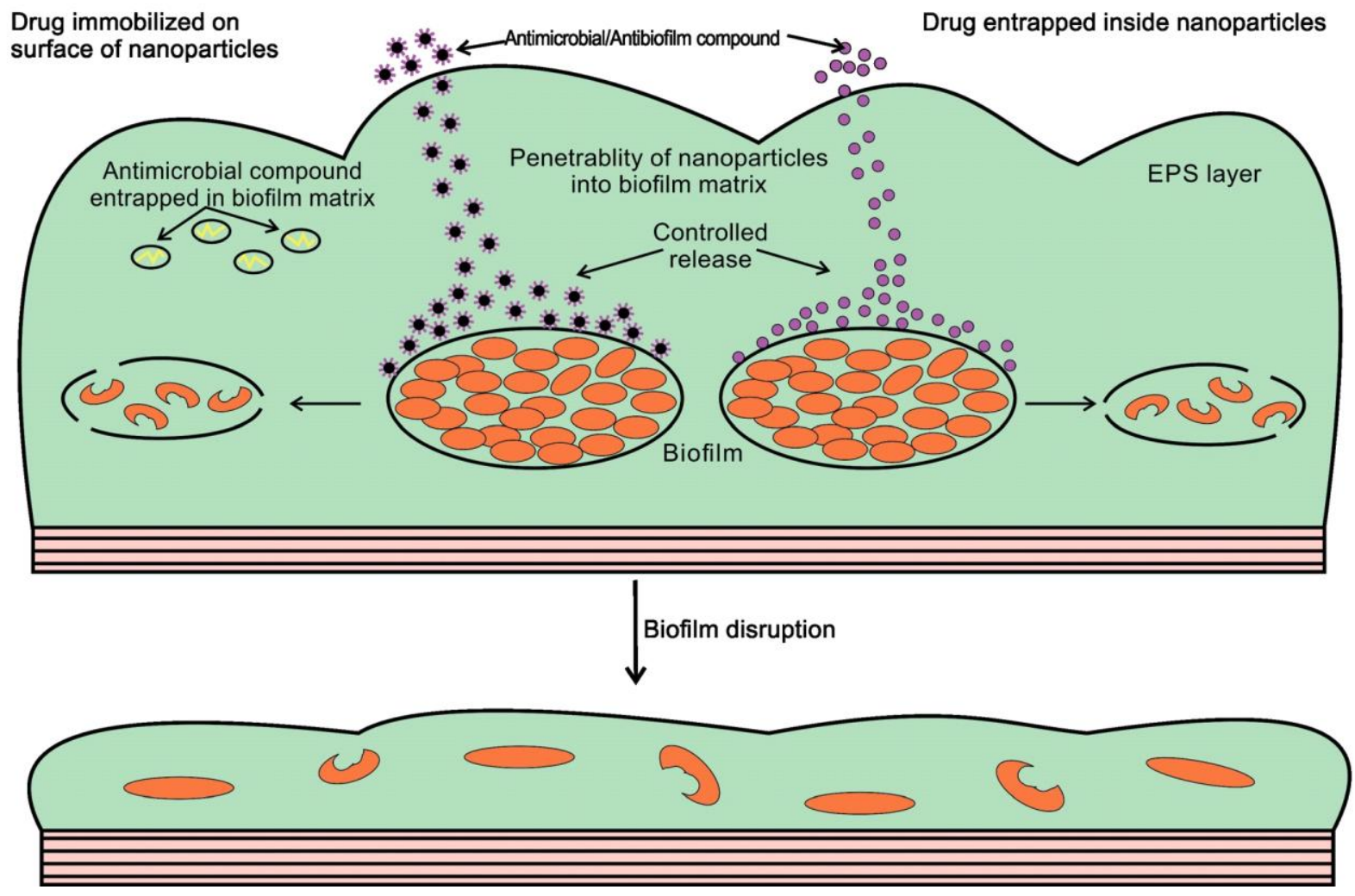

Fig. 5 Biofilm disrupting the action of metal NM on the pre-formed biofilms. Reproduced with permission (Qayyum et al., 2016) Copyright @ 2016 RSC Publishing

Several approaches have been developed to eradicate biofilms, bactericidal, and bacteriostatic antibiofilm formation (Chen, Yu and Sun, 2013)(Dos Santos Ramos et al., 2018). For example, Ag NM have been widely used to prevent biofilm formation for various applications such as catheters, dental materials, medical devices, implants, and wound dressings (Wang, Shen and Haapasalo, 2014)(Thiwawong, Onlaor and Tunhoo, 2013). Secinti et al. (Secinti et al., 2011) studied the antibiofilm properties of $\mathrm{Ag}^{+}$ion coated titanium implants against $S$. aureus biofilm in $20 \mathrm{New}$ Zealand rabbits; the result showed that no bacteria or biofilm layer formed on the coated implants, whereas biofilm was detected on uncoated implants. Additionally, no $\mathrm{Ag}^{+}$accumulation was observed in host tissues (cornea, kidney, liver, and brain) after 28 days post-implantation. However, coating 
medical devices with $\mathrm{Ag}^{+}$ions or $\mathrm{Ag} \mathrm{NM}$ sometimes have disappointing results, probably due to dose-dependent cytotoxicity (Huang et al., 2016). At optimal concentration, Ag NM is non-toxic with low bactericidal effects in mammalian cells (Ewald et al., 2006) (Burd et al., 2007). Han et al. (Han et al., 2014) studied the potential toxicity of $20 \mathrm{~nm} \mathrm{Ag} \mathrm{NM} \mathrm{in} \mathrm{male} \mathrm{and} \mathrm{female} \mathrm{mice} \mathrm{in} \mathrm{vivo,}$ and found a negative impact of Ag NM on the reproduction of mice. Catheters coated with the Ag NM reported inducing thrombin formation and platelet activation, resulting in thrombosis (Stevens et al., 2009). Recently, Lee et al. (Ramasamy, Lee and Lee, 2017) studied the antibiofilm activity of Au NM linked cinnamaldehyde (CNMA-Au NM) and reported significant biofilm inhibition of MSSA, MRSA (gram-positive) as well as E.coli (gram-negative) compared to non-conjugated Au NM. The smaller size of Au NM and lipophilic nature of cinnamaldehyde facilitated attraction between CNMA-Au NM and bacterial membrane within biofilms, which can lead CNMA-Au NM to penetrate the biofilm architecture and inhibit biofilm formation by reducing metabolic activity and bacterial motility. In a subsequent study, the results demonstrated that cinnamaldehyde conjugated with silica $\left(\mathrm{SiO}_{2}\right)$ coated $\mathrm{Au}$ NM (CNMA-Si-Au NM) led to disintegration and disorganization of the bacterial membrane, while preserving its integrity when treated with $\mathrm{SiO}_{2}-$ $\mathrm{Au} \mathrm{NM}$ (silica coated-Au NM). The authors also reported that $\mathrm{CNMA}_{-} \mathrm{SiO}_{2}-\mathrm{Au} \mathrm{NM}$ hydrolyzed in the acidic $\mathrm{pH}$ environment of the biofilm (Mohankandhasamy et al., 2017).

\section{Antimicrobial peptides and their antimicrobial potential}

Antimicrobial peptides (AMP) are components of the immune system of many organisms, such as bacteria, plants, fish, amphibians, insects, mammals, and even viruses; which not only protect them against infections but also display remarkable ability to tune the innate immune responses for microbial clearance (Papo and Shai, 2003)(Hancock and Sahl, 2006)(Malmsten, 
2014)(Etayash et al., 2013). AMP are amphipathic arrangements of $12-50$ amino acids, categorised into $\alpha$-helical, $\beta$-sheet, extended, and mixed $(\alpha \& \beta)$ with different secondary structure configurations (Figure 6) (Wang and Wang, 2004)(Wang, Li and Wang, 2009).

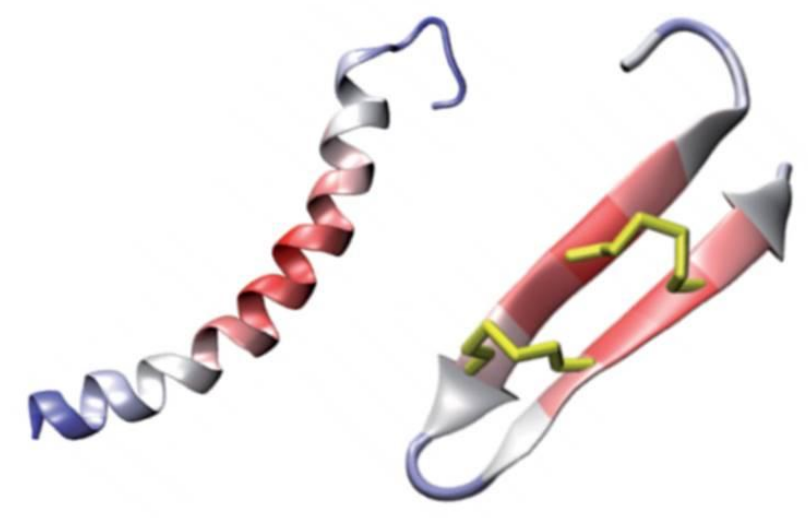

(A) $\alpha$-helical

(B) $\beta$-sheet

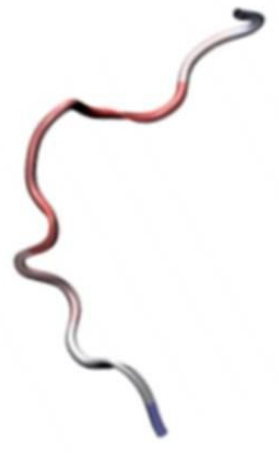

(C) Extended

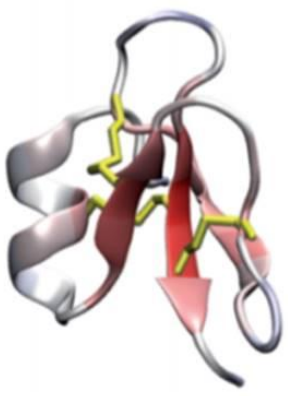

(D) Mixed

Figure 6. Structural classification of AMP. (A) $\alpha$-helical, (B) $\beta$-sheet, (C) extended, and (D) mixed ( $\alpha \& \beta$ ) peptides. Reproduced with the permission from (Rajchakit and Sarojini, 2017a) Copyright (C 2017 ACS Publication.

AMP can be aromatic, non-cationic, and anionic peptides; the largest group belonging to cationic AMP (Marshall and Arenas, 2003). The $\alpha$-helical class of cationic AMP has two separate characteristics: first, they have a polycationic sequence with a net positive charge (arginine and/or lysine) (Wang, Li and Wang, 2009)(Dennison et al., 2005). Positively charged residues are the primary driving force for AMP to target anionic membranes of gram-positive and gramnegative bacteria. Negatively charged moieties (phospholipids, phosphatidylglycerol, cardiolipin, phosphatidylserine, and phosphatidylethanolamine) present on the membrane of gram-positive and gram-negative bacteria confer electronegativity to the bacterial surface, whereas eukaryotic 
cells have a neutral net charge on their surface. Cationic AMP are, therefore, ideal for prokaryotic cell targeting.

Additionally, cholesterol in mammalian cell membranes reduces the activity of AMP. AMP retain their antibacterial activity in prokaryotic cells, as cells have lower cholesterol levels. In essence, negative surface charge and lack of cholesterol content of prokaryotic membrane attribute for the particular bactericidal activity of AMP (Ebenhan et al., 2014)(Zasloff, 2002). Second, the common characteristic of all AMP is hydrophobicity (alanine, leucine, isoleucine, valine, methionine, phenylalanine, tyrosine, and tryptophan), which is an essential requirement for membrane internalization and selective antimicrobial activity. It has been observed that excessive hydrophobicity is not only cytotoxic to mammalian cells, but also induces non-selective antimicrobial activity. For instance, the increased hydrophobicity of $\alpha$ helical AMP (V13KL) resulted in RBC hemolysis, which may have been due to the penetration of AMP deep inside the hydrophobic membrane of RBCs. Additionally, excessive hydrophobicity increased the dimerization of $\alpha$-helical AMP (V13KL) and restricted AMP access to through the pathogen membrane, which decreased its antimicrobial activity (Chen et al., 2007). In addition to being polycationic and hydrophobic, AMP are amphiphilic, with segregated hydrophobic and hydrophilic residues, which allows them to be inserted into a pathogen plasma membrane (Cornup et al., 1994).

\subsection{Antimicrobial action of peptides}

AMP can affect bacteria by various mechanisms, which are divided into three major classes: membrane disruption, intracellular targeting, and activation of immune responses. 


\section{Membrane disruption}

Bacterial cell wall $(\mathrm{CW})$ provides cellular integrity and stress-bearing ability, and as a result, maintains higher osmotic pressure and prevents cell lysis. Due to the bacterial CW composition compared to eukaryotic cells, these are a viable drug targeting choice. Among the potential targeting ligands are AMP, which display combinatory activity of cell membrane disorganization and inhibition of $\mathrm{CW}$ formation. AMP self-assembles on the prokaryotic membrane by hydrophobic/electrostatic interactions followed by cell membrane disintegration and disorganization. Three different significant models explain the action of AMP: Barrel-Stave Model, toroidal pore, and carpet model.

In the Barrel-Stave Model, parallel orientation of $\alpha$-AMP on the PM is achieved through electrostatic interactions (Huang, 2009), leading to formation of transmembrane pores, which leads to cell death through the leakage of ribosome and mitochondrial organelles (Brogden, 2005)(Yang et al., 2001)(Vedovato and Rispoli, 2007). For example, intestinal C-type lectin binds to the peptidoglycan carbohydrate of bacteria and kills it by forming membranepenetrating pores (Mukherjee et al., 2014)(Miki, Holsts and Hardt, 2012).

According to the toroidal pore model, AMP accumulates at specific concentrations on the PM surface and bends it by increasing the distance between phospholipid moieties, which eventually results in a toroidal pore. Subsequently, phospholipids disturb with PM forming pores. In this model, unlike Barrel-Stave Model, the lipophilic and hydrophilic arrangement of PM bilayer is disorganised. AMP such as magainin-2 (Lee and Aguilar, 2016), lacticin Q (Lee and Aguilar, 2016), aurein 2.2 (Cheng et al., 2009), and melittin (Lee and Aguilar, 2016) can self-assemble around bacteria in toroidal pore fashion. 
In the carpet model, AMP are oriented on the PM to disturb the bilayer in a detergent-like manner resulting in micelle formation, causing cell death. Human peptides such as cathelicidin LL-37 (Shai, 2002), cecropin (Sitaram and Nagaraj, 1999), indolicidin (Rozek, Friedrich and Hancock, 2000), and aurein 1.2 (Fernandez et al., 2012) can kill different bacteria by carpet mechanism (Gable et al., 2009).

AMP often binds to various precursors, which are engaged in CW synthesis. uppP (bacA) genes of UppP enzyme, a membrane protein engaged in CW synthesis, is one example of such precursors. AMP such as Lactococcin-G and Enterocin-1071 interact with uppP (bacA) genes and inhibit CW synthesis (Kjos et al., 2014)(Belguesmia et al., 2017). Likewise, AMP (class I\&II) bacteriocins bind to the lipid-II, essential for the synthesis of peptidoglycan in gram-positive and gram-negative bacteria, and inhibit the formation of CW through pores formation (Islam et al., 2012)(Yount and Yeaman, 2013). Some AMP can induce CW production of a lytic enzyme called Nacetylmuramoyl-L-alanine amidase, responsible for $\mathrm{CW}$ wall disintegration and disorganization (Wilmes et al., 2014)(Bierbaum and Sahl, 1987). Pep5, nisin, Ө-defensin are examples of AMP that induce the activity of $\mathrm{N}$-acetylmuramoyl-L-alanine amidase.

\section{Intracellular targets}

Recently, it has been reported that some AMP produce a bactericidal effect by cellular accumulation inside the PM targeting intracellular organelles. AMP induce activities such as inactivation of bacterial ribosomes, inhibition of protein synthesis, and interference in enzyme activity. For example, $\mathrm{Bac} 7_{1-35}$, oncocin, and apidaecins rich in proline residues that bind to the $70 \mathrm{~S}$ ribosome and block its exit tunnel, eventually inhibits protein synthesis (Gagnon et al., 2016). 
Buforin-II, a cationic peptide, accumulates and interacts with nucleic acids without interfering with the E. coli PM (Park, Kim and Kim, 1998). Interestingly, buforin-II displays anti-endotoxin activity, reducing endotoxin generated in gram-negative bacteria (Giacometti et al., 2002). Because of the inhibitory effect on endotoxin level, buforin-II prevents multiple organ failure and septic shock associated with the endotoxin-induced cytokines production. Microcins, antimicrobial peptides from gram-negative enterobacteria, can target intracellular and extracellular pathogens. For example, Microcin $\mathrm{C}(\mathrm{McC})$ translocates into sensitive cells to reach the target site via external membrane porins and internal $\mathrm{ABC}$ membrane transporters. In the cytoplasm, $\mathrm{McC}$ releases non-hydrolyzable aminoacyl adenylate, which obstructs a crucial aminoacyl-tRNA synthetase, enzyme for biosynthesis of protein (Fang and Guo, 2015)(Nocek et al., 2012)(Rebuffat, 2012). Microcidin B17 is a peptide that enables the J25 (MccJ25) micron to cross the envelope of the cells, which inhibits DNA replication by inhibiting bacterial RNA polymerase (Mukhopadhyay et al., 2004) (Hassan et al., 2014). Haney et al. studied the antimicrobial effect of puroindoline derived Pur-B peptide against gram-positive and gramnegative bacteria (Haney et al., 2013). They found that the positive charge of peptides leads to electrostatic attachment to negatively charged membranes. Pur-B peptide further penetrates PM and binds to nucleic acids, which ultimately inhibits the transcription and translation process. Gosh et al. found that Indolicidin, an antimicrobial peptide from cathelicidin family, binds and wraps around duplex DNA, which leads to transcription inhibition (Ghosh et al., 2014). PR39 is another family of cathelicidin peptides with potent antimicrobial activity. This AMP obstructs bacterial nucleic acid replication (Bals and Wilson, 2003). This peptide has also been discovered to play a crucial role in innate immunity (Veldhuizen et al., 2014). Some studies have observed that PR-39 inhibits the 20S proteasome in a non-competitive and reversible manner and blocks degradation 
of NF-kB inhibitor. As a result, NF-kB dependent pro-inflammatory gene expression is suppressed in mouse myocardial infarction model and cell culture, thereby reducing inflammatory responses (Gao et al., 2000)(Anbanandam et al., 2008). Two bovine bactenecins, Bac5 and Bac7, exhibited potent bactericidal activity by obstructing the production of nucleic acid and proteins in E. coli and K. pneumonia (Skerlavaj, Romeo and Gennaro, 1990). Interestingly, some antimicrobial peptides produced from bacteria, such as bacteriocins, kill the pathogens through areceptor-mediated mechanism.

\section{Modulation of Immune Responses}

Apart from direct bactericidal activity, AMP generate different innate immune responses. They induce the modulation and expression of multiple cytokines and chemokines, as well as reduce inflammation by neutralizing cytokines released from macrophages and monocytes, promoting wound repair, modulating the responses of T-cells, and dendritic cells inducing angiogenesis (Diamond et al.,2009). Such responses further modulate the innate immunity protecting the host against microbial infection. For example, human defensins bind to the CCR6, a protein-coupled receptor, and raise the amount of dendritic and T cells at the site of microbial infection. A very low MIC (> 2 $\mu \mathrm{g} / \mathrm{ml})$ of LL37 in vivo compared to in vitro $(32 \mu \mathrm{g} / \mathrm{ml})$ against $E$. coli, confirmed the indirect antimicrobial activity of AMP in vivo through modulating immune responses (Jenssen, Hamill and Hancock, 2006). AMP also recruit phagocytes cells at bacteria-infected sites and modulate immune responses against microbial infections. As-CATH2-6, out of six novel cathelicidins (AsCATH1-6) from Chinese alligator (A. sinensis), showed antimicrobial and immunomodulatory activity in a bacteria-infected murine mouse model. As-CATH2-6 generate chemokines and recruit neutrophils, monocytes, and macrophages at the microbial infected sites; these intracellular granules invade and kill bacteria through phagocytosis (Chen et al., 2017). Likewise, 
the immunomodulatory role of mammalian host defense peptides (HDP) in combating Leishmania infection has also been studied by Rafati et al. (Abdossamadi, Seyed and Rafati, 2016). Upon stimulation by pathogens at microbial infected sites, LL-37 promotes the expression of TNF- $\beta$ and IFN- $\gamma$ from macrophages, promoting pathogen phagocytosis through CD32 and CD64 expression (Soehnlein et al., 2008). All these activities promote immune hemostasis. Curiously, AMP stored at a sufficient concentration in immune cells, such as NK-cells, mast cells, neutrophils, monocytes, and macrophages, are the leading molecules that firstly deal with the pathogens and their expression at the infected site regulated by the vitamin-D receptor. Vitamin-D receptor promotes the production of vitamins 1,25 D3, which not only induces the expression of AMP but also enables the host to acknowledge and react to microbes by CD14 and TLR2 expression (Schauber et al., 2007)(Liu et al., 2006). Even though the expression of AMP can kill microbes, continuous expression leads to autoimmune disorders, such as rosacea and psoriasis (Zhang and Gallo, 2016).

\subsection{Resistance to AMP}

Bacteria can develop various types of resistance mechanisms to AMP (Figure 7). Resistance can be expressed, for example, by surface remodeling (Hankins et al., 2012)(Malanovic and Lohner, 2016), modulation of gene expression of AMP (Sperandio et al., 2008) biofilm formation (Yeaman and Yount, 2003), proteolytic degradation (Kooi and Sokol, 2009) efflux pumps (Shafer et al., 1998)(Piddock, 2006)(Bengoechea and Skurnik, 2000), and by lipopolysaccharide (LPS) modification (Gunn, 2001). Recently, Cullen et al. (Cullen et al., 2015) reported a gene to induce dephosphorylation of LPS, which reduces the net negative charge on the bacterial membrane; as a result, the pathogen resists AMP by decreasing their electrostatic interaction with PM. It is worth mentioning that the anionic lipid bilayer structure of bacterial outer membranes interacts with the positive charge of AMP, resulting in rapid destruction of the bacterial membrane 
(Diehnelt, 2013). Additionally, reduced propensity to develop resistance against AMP compared to common antibiotics have been reported to date (Bahar and Ren, 2013). Figure 7 illustrates the overall resistance mechanisms to AMP.
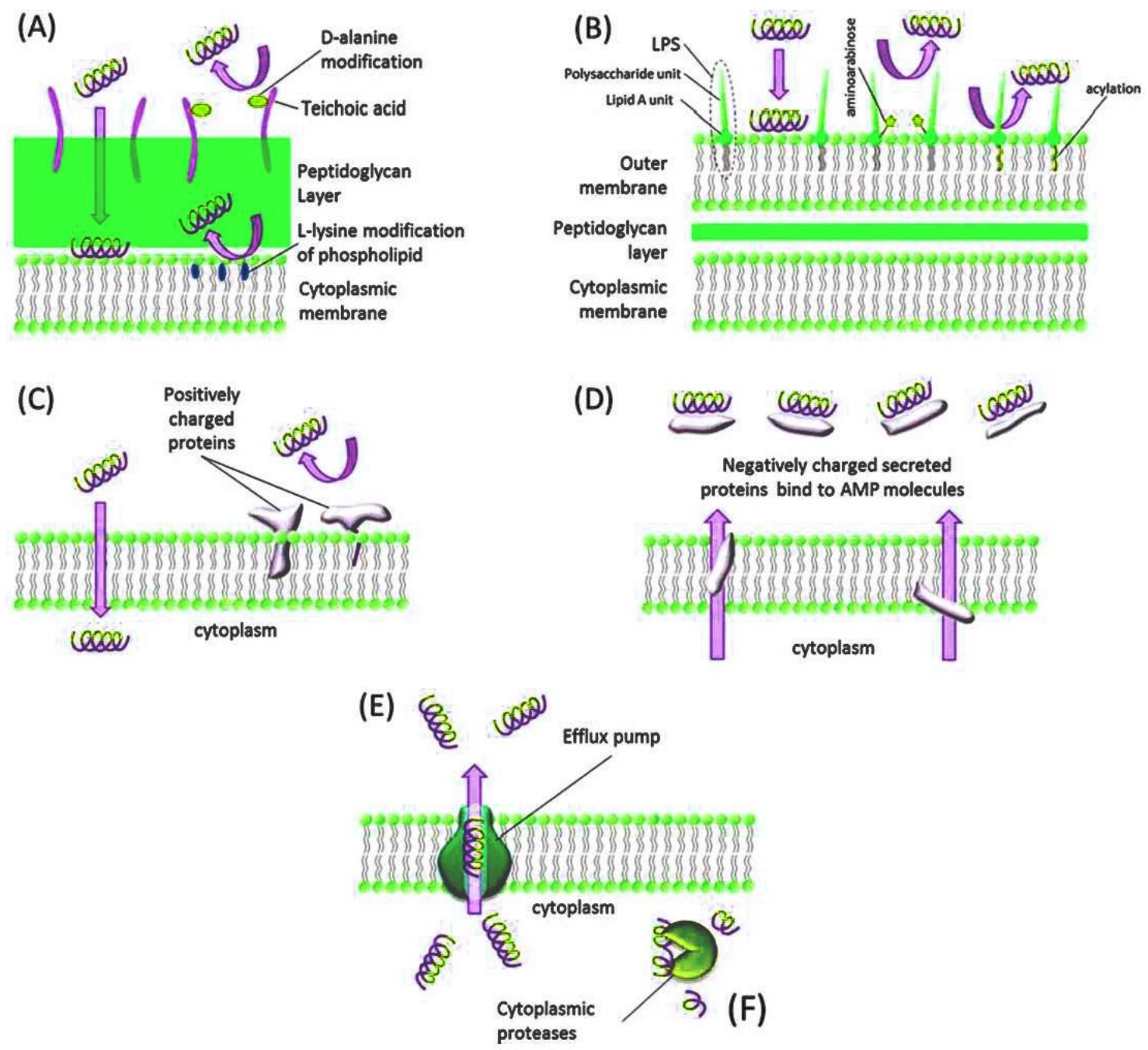

Fig. 7. Diagrammatic illustration of AMP resistance mechanisms: (A) Gram-positive bacteria, resistance to AMP occurs by D-alanine and L-lysine alteration of phospholipids by teichoic acids. (B) Gram-negative strains exhibits resistance towards AMP via altering lipopolysaccharide molecules with aminoarabinose or acylation of Lipid A unit of lipopolysaccharide molecules. (C) Bacteria release proteins (+ charged) that integrate with the membrane, and positively charged bacterial membrane can regulate cationic AMP. (D) Bacteria induce the formation of negatively charged proteins secreted to bind and block AMP in the 
extracellular environment. (E) The intracellular AMP are squeezed out by efflux pumps. (F) The AMP within the cell are susceptible to degradation by proteases.

\section{Inorganic NM as carriers for AMP}

Although AMP display broad-spectrum antimicrobial activity, they are rapidly degraded by proteases of bacteria and human defense cells, resulting in the loss of their antimicrobial efficacy. When administered intravenously, AMP are rapidly cleared from the circulatory system and deposition in the reticuloendothelial system (RES). AMP in the RES display loss in antimicrobial activity and increase in systemic toxicity (Singh et al., 2014)(VanderVen et al., 2015). Consequently, especially inorganic NM have gained significant interest lately as potential carriers of AMP, which confer protection against chemical and enzymatic degradation, controlled release possibilities, enhanced potency and reduced systemic toxicity of encapsulated or surface-immobilised AMP (Almaaytah et al., 2017).

\subsection{Inorganic NMfor the delivery of loaded AMP}

The well-defined nanometer pores of MSNs allow active packing of AMP and further control of their release at the target site. Loading and release kinetics of entrapped drug/biological moieties inside MSNs can be regulated by varying surface properties and pore size (Bharti et al., 2015). Adsorption of AMP to mesoporous silica was found to be regulated by the pore size and AMP concentration in solution. At low AMP concentration, AMP's dimer form strongly adsorbed into mesoporous silica with the same pore size as that of the AMP dimer through multivalent peptidesilica interactions (Braun et al., 2017). However, at higher AMP concentration, formation of trimer and tetramer forms of peptides showed higher affinity for the pore walls and outer surface of larger sized MSNs. 
The adsorption of AMP did not occur due to the low peptide-silica interaction that demands larger peptide aggregates to enhance adsorption. Peptides adsorbed onto small-sized MSN exhibited a faster release rate compared to that of peptides absorbed onto larger MSNs (Braun et al., 2017). Likewise, Lzquierdo-Barba et al (Izquierdo-Barba et al., 2009) compared the release behavior of high molecular weight LL-37 with low molecular weight chlorhexidine from silica monoliths and reported slow-release $(\sim 200 \mathrm{~h})$ of both antimicrobial compounds. The release rate of such antimicrobials can be altered through the conjugation of the thiol group to the pore wall of silica monoliths. Furthermore, both LL-37 and chlorhexidine containing mesoporous silica monoliths exhibited antimicrobial activity against both $S$. aureus and E.coli, and the monolith containing LL37 displayed low cytotoxicity against human keratinocytes and erythrocytes (Izquierdo-Barba et al., 2009). Linden et al. compared anionic MSN(-ve), cationic MSN(+ve), and anionic nonporous silica nanoparticles (NSP) for loading and discharge of the cationic LL37(LLGDFFRKSKEKIGKEFKRIVQRIKDFLRNLVPRTES) AMP, along with its impacts on the antimicrobial effect. MSN(-ve) were found to carry a higher amount of LL-37 compared to MSN(+ve) and NSP, and conferred protection to AMP against degradation by proteases. Interestingly, though less in quantity, cationic LL-37 non-electrostatically adsorbed onto MSN(+ve), which might happen due to the reduction of positive surface charge. When studied adsorption of these NM on anionic DOPE/DOPG (dioleoylphosphatidylethnolamine/ dioleylphosphatidylglycerol) bilayers, a bacteria-mimicking PM, it was found that MSN(-ve) neither adsorbed nor disturbed DOPE/DOPG bilayers unless it was loaded with LL-37 AMP. At the same time, NSP because of high -ve charge on their surface obtains a resilient LL-37 coating, 
exhibited low AMP release (Jacob, 2016). Like NSP, MSN(+ve) displayed particle mediated membrane disruption but also exhibited toxicity against erythrocytes (Braun et al., 2016).

Further addressing $\mathrm{SiO}_{2} \mathrm{NM}$ as sustained delivery vehicles of AMP, Johnson et al. studied the diffusion of AMP from bioinorganic Si-ANM. They were reported to release the entrapped cationic decapeptide, KSL (KKVVFKVKFK), in a sustained manner over 5 days. Interestingly, released KSL was found to be identical to its free form and retained antimicrobial activity. After 5 days of diffusion study, when Si-ANM had undergone antimicrobial assay against S.aureus and $S$. epidemidis, no antimicrobial effects were observed (MIC> $225 \mu \mathrm{g} / \mathrm{mL}$ ). Furthermore, the trypsin digestion assay revealed that free KSL was degraded entirely, whereas KSL recovered from SiANM after trypsin treatment was intact and active. These results show that $\mathrm{SiO}_{2} \mathrm{NM}$ not only confer protection to KSL against proteolytic degradation, but also facilitate sustained release of AMP. Sustained release of AMP over extended periods is an essential requirement for implantassociated infection, i.e. inhibition of bacterial growth or biofilm formation on the device surface (Eby, Farrington and Johnson, 2008).

\subsection{Inorganic NM for the delivery of the surface conjugated AMP}

The biomimetic mimicry, a novel approach for precise drug delivery, where biomolecules are conjugated on NM surfaces is one of the new frontiers in material research to solve the limitations associated with metal NM (Lee, Ashe and Laurencin, 2014). Surface conjugation of biomolecules to NM confers stability, prevent agglomeration, attenuate toxicity, prolong the circulation time, and increase biocompatibility (Baptista et al., 2013). For example, lysozyme incorporated with $\mathrm{TiO}_{2} \mathrm{NM}$ protect it from denaturation and confer functional properties to the bionanocomposite (Luckarift et al., 2006). Magnetic FeO NM were also used as carriers for delivery of significant biomolecules as depicted in Figure 8, such as peptides (Veiseh et al., 2009), 
antibodies (Tsourkas et al., 2005), aptamers, DNA (Josephson, Manuel Perez and Weissleder, 2001), and RNA (Reimhult, 2013) according to five different strategies:

A] Ligand binding through chemisorption of thiol groups onto the exterior surface

B] Electrostatic adsorption of opposite charges

C] Covalent binding by compatible functional groups

D] Non-covalent bonding, e.g. biotinylated oligonucleotides conjugated to streptavidin-Au NM E] Encapsulation, i.e., incorporation of the biomolecules inside within the NM matrix. 


\section{(i) Electrostatic:}
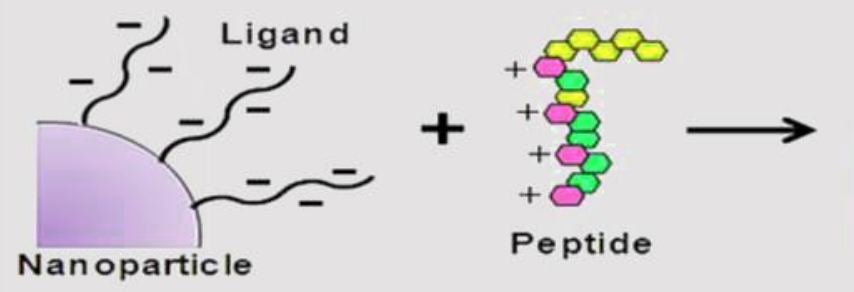

(ii) Direct:
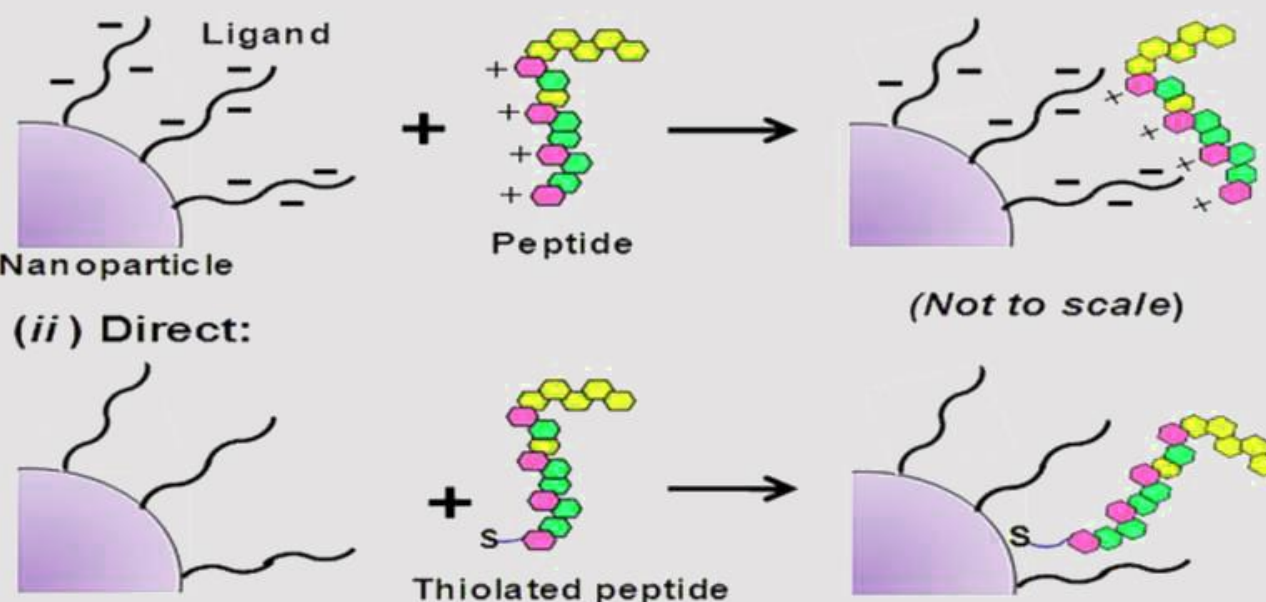

(Not to scale)

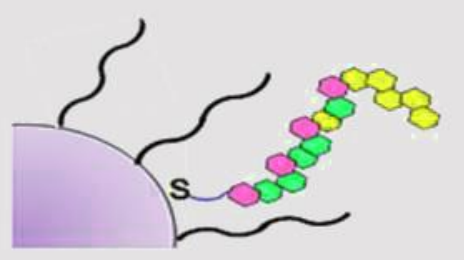

(iii) Secondary interactions:
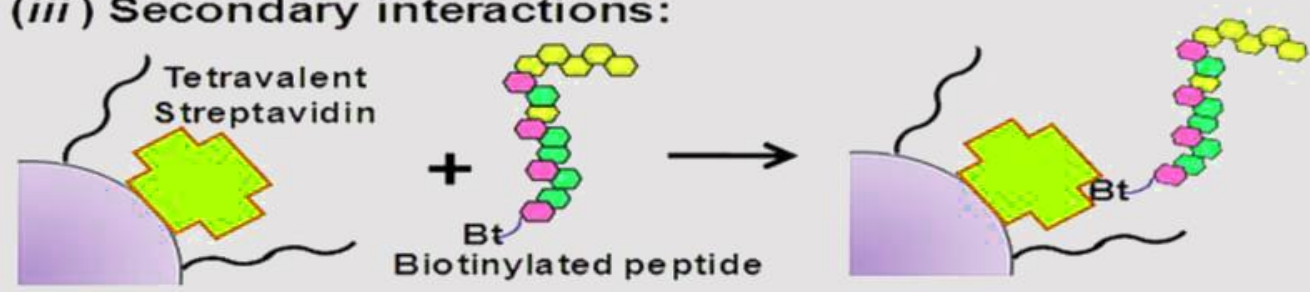

(iv) Covalent attachment to surface ligand:
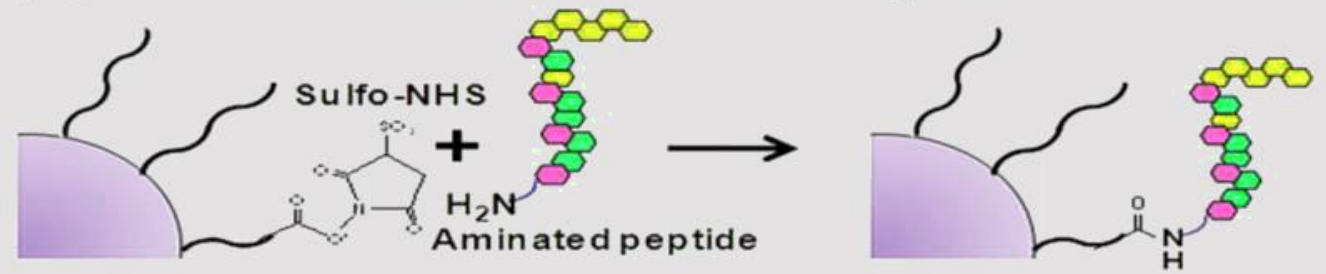

\section{(v) Encapsulation:}
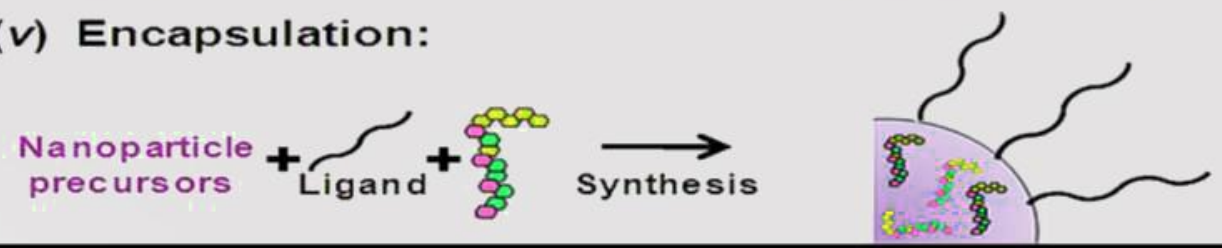

Fig.8. Five general strategies of peptides-NM generation: (i) Electrostatic interaction between the surface of the NM and the peptide to induce peptide assembly; (ii) Direct binding to NM surface; for example, direct binding of free thiols with the surface of Au NM. (iii) These strategies can modify the peptide surface so that it can specifically interact to form biotin-streptavidin complexes. (iv) Direct covalent attachment, by utilizing chemistry such as 1-ethyl-3-(3-dimethyl aminopropyl)-carbodiimide (EDC)-based coupling of amines to carboxyls; (v) Encapsulation of peptide inside the NM matrix.

Reproduced with the permission from (Sapsford et al., 2013) Copyright (C) 2013 American Chemical Society. 


\subsection{Antimicrobial applications of AMP-conjugated inorganic NM}

In this section, examples of recent research on AMP conjugated NM as antimicrobial agents are reviewed. In general, peptides exhibit a lower degree of toxicity and immune response than to highmolecular-weight polymers, such as polyethyleneimine (PEIs), which are easily degraded in the body by enzymes (Xue, Liu and Wong, 2014). Few of these peptides have been proven to have a specific binding affinity for cells. Conjugation of NM with these peptides not only elevate their cell uptake but also enhance their cellular localization (Liu et al., 2007)(Nativo, Prior and Brust, 2008). For example, chemical functionalization of the TAT-derived peptide (Chem, 1997) on other biomolecules such as proteins (Fawell et al., 1994), small interfering RNA (siRNA)(Turner et al., 2007), and liposomes (Pappalardo et al., 2009) facilitates their cellular uptake. Furthermore, Tatderived peptides act as carriers to facilitate delivery of proteins (Schwarze et al., 1999), QDs (Stroh et al., 2005) and polymeric micelles (Liu et al., 2008) to the central nervous system (CNS), because of their capability to cross the blood-brain barrier (BBB)(Alyautdin et al., 2014). Moreover, as described in section 3.1., peptide-NM are involved in cellular uptake in phagocytic immune cells and innate immune responses (Yang et al., 2016). Recent literature has also indicated that antimicrobial activity against gram-positive bacteria is exerted by cationic NM created by amphiphilic peptide self-assembly (Niño-Martínez et al., 2019). This amphiphilic peptide, C17H35GR7RGDS NM, contained seven arginine residues that facilitated membrane translocation and reduced bacterial adhesion to fibronectin. 


\section{AMP functionalized Au NM}

Ferreira et al. observed high antimicrobial activity by peptide-conjugated Au NM (CM-SH-Au NM) against E. coli (Ferreira et al., 2016). The in vivo antimicrobial potency of CM-SH-Au NM was tested in murine wounds, topically infected with gram-positive and gram-negative bacteria. Animals treated with CM-SH-Au NM were found to have a significant attenuation in bacterial count. Furthermore, in vivo biodistribution study revealed that less than 5\% of Au NM was deposited in the spleen, liver, lung, and kidney. The researchers concluded from the in vitro and in vivo results that CM-SH-Au NM has promising antibacterial potency. A disadvantage of AMP, when decorated onto Au NM, is induction of precipitation of the Au NM. Consequently, in this case, AMP on the Au NM surface is insufficient for antimicrobial activity. In contrast, AMP conjugation onto $\mathrm{Au}$ NM surfaces via the reduction of $\mathrm{Au}(\mathrm{III})$ in the presence of side-chain protected $\mathrm{N}$-terminus Cys containing peptide and $\mathrm{NaBH}_{4}$, confer secondary $\alpha$-helical structure upon AMP-conjugated Au NM interacting with the bacterial membrane. As a consequence, the desired antimicrobial effect is preserved, as shown in Figure 9.

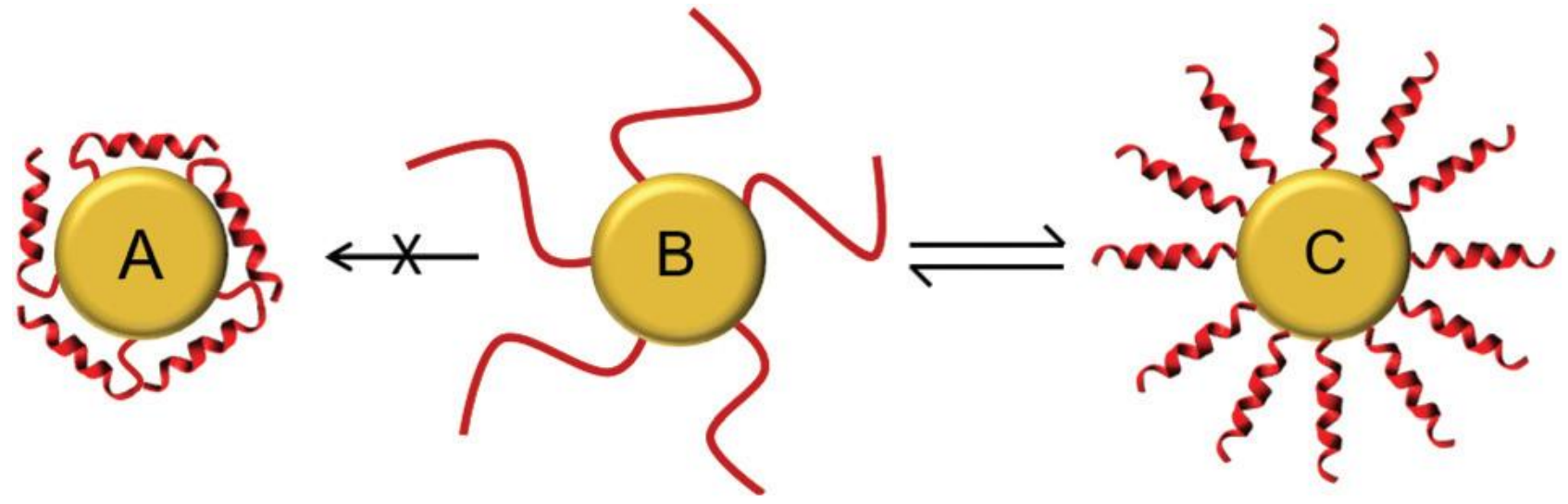

Fig. 9. Illustration of AMP conjugated onto the Au NM surface (B). Conjugates adopt secondary $\alpha$-helical structure upon contact with bacterial membranes to exhibit antimicrobial property (C). Any attachment of Lys with the Au NM leads to precipitation of Au NM (A). Reproduced with permission from(Wadhwani et al., 2017) Copyright (C) 2017 RSC Publishing 
AMP-Au NM conjugates confers AMP stability against protease degradation and enhances the AMP half-life for up to $24 \mathrm{~h}$. Interestingly, it was reported that AMP-Au NM retained similar activity as the free AMP in an aqueous buffer against both gram-positive and gram-negative bacteria (Wadhwani et al., 2017). Chang et al. evaluated the antimicrobial efficacy of 1dodecanethiol (DT) and Surfactin (SFT) immobilised gold nanodots (SFT-DT-AuNDs). They found >80-fold lower MIC compared to SFT and DT-AuNDs against MRSA stains. These effects were correlated to synergistic bacterial membrane damage by SFT and DT-AuNDs. Besides, hemolysis and cytotoxicity assays revealed higher biocompatibility of SFT-DT-AuNDs than free SFT. Lee $e t$ al. studied the efficacy of Au NM-Apt (Au NM conjugated with DNA aptamer) for efficient delivery of C-terminally hexahistidine tagged A3-APO ${ }^{\text {His }}$ peptide into $S$. typhimurium infected mammalian cells (Yeom et al., 2016). Changes in the morphology of S. typhimurium cells were observed when the cells were treated with A3-APO and A3-APO ${ }^{\text {His }}$ peptide. SEM analysis showed disruption of PM when incubated with $\mathrm{A} 3-\mathrm{APO}^{\mathrm{His}}$ whereas A3-APO did not affect the membrane. Besides, the SYTOX assay disclosed that A3APOH caused S. Typhimurium internal PM disturbance resulting in increased SYTOX green fluorescence intensity due to binding of the cationic dye to the nucleic acid. S. typhimurium-infected HeLa cells were used to test the antimicrobial potency of $\mathrm{Au}$ NM-AptHis-A3-APO ${ }^{\text {His }}$. The result showed that the number of intracellular S. typhimurium cells was found to be 30-50\% less when treated with Au NM-AptHisA3-APO ${ }^{\mathrm{His}}$ than those treated with $\mathrm{Au} \mathrm{NM}-\mathrm{Apt}^{\mathrm{His}}$, which exhibits negligible effects on $S$. typhimurium viability. Because all the S. typhimurium infected mice after intravenous administration of Au NM-AptHis-A3-APO ${ }^{\text {His }}$ survived, it was concluded that Au NM-Apt is more efficient in removing intracellular S. typhimurium cells both in vitro and in vivo without inducing toxicity to healthy mammalian cells. 


\section{AMP functionalized Ag NM}

Metal/metal oxide NM can impart new functionality and reactivity to the new compounds, which can lead to promising bactericidal effects against multidrug-resistant bacteria (Chaloupka, Malam and Seifalian, 2010)(Kalishwaralal et al., 2010). For example, bivalent Ag NM conjugated with histatin-1, an AMP that is involved in re-epithelialization processes (Oudhoff et al., 2008), has shown promising MIC values (around $1 \mathrm{mg} / \mathrm{L}$ ) against gram-positive and gram-negative bacteria with potent wound healing properties (Pal et al., 2014)(Pal et al., 2014). Ag NM at a certain concentration is known to be toxic to mammalian cell lines (Skalska and Strużyńska, 2015). Surface modification of Ag NM with AMP reduces the toxicity of Ag NM and enhances stability and antimicrobial activity. For instance, the strong interaction of positively charged non-cysteine containing AMP with Ag NM (Liu et al., 2013) can disturb the conformation of AMP, resulting in decreased antimicrobial efficacy. Therefore, the main parameter in the design of new conjugates is the balance of stability/strong interaction for achieving optimal antimicrobial activity. The $\mathrm{Ag}$ NM and resultant AMP-Ag NM conjugate have shown enhanced stability and antimicrobial efficacy in comparison to the Ag NM and AMP alone. When the antibacterial mechanism of AMP-Ag NM was studied, conjugates disturb bacterial PM more significantly compared to AMP alone.

Furthermore, fluorescence-activated cell sorting (FACS) assay has been used to measure bactericidal potency of AMP, AMP-Ag NM, and Ag NM. Results of bacterial cell death revealed synergistic antimicrobial activity AMP-Ag NM (60\% dead cell population) compared to Ag NM (31\%) and AMP (33\%), respectively. This study concluded that Ag NM, due to its negative charge, was unable to interact with PM and confirmed that AMP on the Ag NM surface is responsible for bacterial PM, damage followed by the arrest of transcription and translation (Pal et al., 2016). Similarly, Liu et. al. showed that conjugation of AMP with Ag NM elevate their bactericidal effect compared to 
unbound AMP, and enhanced the biocompatibility of Ag NM compared to using the Ag NM alone (Liu et al., 2013). Navani et. al. (Lambadi et al., 2015) found $\sim 3$ - fold antibiofilm activity increase of Polymyxin-B conjugated Au NM (PBAu NM) compared to citrate-capped Au NM. The result revealed that the antimicrobial activity of PBAu NM coated surgical blades was enhanced compared to citrate-capped Au NM and uncoated surgical blades. This was due to highly cationic Polymyxin-B on the Au NM surface. The result of in vitro antimicrobial assay, live/dead staining, and flow cytometry are also in agreement with the elevated antimicrobial activity of PBAu NM against $P$. aeruginosa.

Table 4: Examples of various AMP-conjugated metal NM. 


\begin{tabular}{|c|c|c|c|c|}
\hline AMP & Metal NM & Tested microorganism(s) & Effect(s) of nano-formulation & Ref. \\
\hline Bacteriocin & & & & (Thirumurugan, \\
\hline Bacteriocin produced by & & & & Ramachandran \\
\hline $\begin{array}{l}\text { Bacteriocin produced by } \\
\text { Lactobacillus } \\
\text { acidophilus } \mathrm{CH} 1\end{array}$ & $\mathrm{Au}$ & E bieneusi spores & $\begin{array}{l}\text { Increased the anti-microsporidial } \\
\text { effect without significant cell } \\
\text { toxicity }\end{array}$ & $\begin{array}{l}\text { (Mossallam, } \\
\text { Amer and Diab, } \\
\text { 2014) }\end{array}$ \\
\hline
\end{tabular}




\begin{tabular}{|c|c|c|c|c|}
\hline Nisin & $\begin{array}{l}\text { Nanofibers } \\
\text { with Ag }\end{array}$ & $\begin{array}{l}\text { S. aureus, } P . \quad \text { aeruginosa, } \quad K . \\
\text { pneumonia, E. coli, S. typhimurium }\end{array}$ & Provided a broad-spectrum AMA & $\begin{array}{l}\text { (Ahire, Neveling } \\
\text { and Dicks, 2015) }\end{array}$ \\
\hline PEP & $\mathrm{Au}$ & $\begin{array}{l}\text { S. aureus } \\
\text { E. coli }\end{array}$ & $\begin{array}{l}\text { Enhanced transfection efficiency } \\
\text { and synergetic AMA }\end{array}$ & $\begin{array}{l}\text { (L. H. Peng et } \\
\text { al., 2016) }\end{array}$ \\
\hline $\begin{array}{l}\text { EEEEAAAVVVK- } \\
\mathrm{C} 14 \mathrm{H} 26\end{array}$ & $\mathrm{Ag}$ & E. coli & $\begin{array}{l}\text { Exhibited low toxicity toward } \\
\text { eukaryotic cells }\end{array}$ & $\begin{array}{l}(\text { Pazos et al., } \\
\text { 2016)(Yu, Wang } \\
\text { and Wei, 2017) }\end{array}$ \\
\hline Esculentin-1a(1-21) $\mathrm{NH}_{2}$ & $\mathrm{Au}$ & P. aeruginosa & $\begin{array}{l}\text { A } 15 \text { fold increase in antimicrobial } \\
\text { potency compared to free peptide } \\
\text { alone without toxic to human } \\
\text { keratinocytes }\end{array}$ & $\begin{array}{l}\text { (Casciaro et al., } \\
\text { 2017) }\end{array}$ \\
\hline
\end{tabular}




\section{Conclusion and perspectives}

The bactericidal efficiency of various NM, antimicrobial peptides, and peptide conjugated NM against different bacterial strains have been provided in this review. In general, the antimicrobial activity of nanometals, AMP, and antimicrobial peptide conjugated NM depends on the bacterial cell surfaces and NM conjugation characteristics. The biomimetic properties of AMP assist the targeted delivery of peptide conjugated NM, whereas ions released from NM kill microbial pathogens. However, further studies should elucidate the precise mechanism of metal ions, whether membrane disturbance or cytoskeleton detachment from the plasma membrane is causing cell death. Most of the antimicrobial properties have to date been tested against $E$. coli and $S$. aureus. To demonstrate the wide variety of bactericidal/bacteriostatic characteristics of peptide conjugated NM, it will be essential to explore other pathogenic species and phenotypes. In comparison to bacteria, there are very few reports on the antifungal properties of antimicrobial peptides. Some studies have demonstrated that covalent surface modification with exposure to oxygen or the presence of UV can create rapid cytotoxicity. Therefore, toxicity should also be studied under circumstances of UV and air exposure. It has also been found that different physical and chemical parameters of NM, such as size, shape, surface-to-volume ratio, the surface charge of the particles, and their synthesis methods influence their antibacterial efficiency. For example, Ag NM with the same surface areas but with distinct shapes may have different bactericidal activity against pathogens. Thus, the antimicrobial effects of AMP conjugated to $\mathrm{NM}$ with different physicochemical characteristics against different bacterial strains should be the next line of research. One major limitation for advancements of peptide conjugated metal $\mathrm{NM}$ is that in vivo and in vitro antimicrobial activity do not discriminate 
whether peptide conjugated $\mathrm{NM}$ can kill pathogenic microorganisms selectively without influencing healthy mammalian cells. In this scenario, the study of the interaction of various shapes of NM on mammalian cells should be carried out. Moreover, non-metals such as Ag and $\mathrm{Cu}$ non-specifically kill pathogens and, therefore, toxicity against mammalian cells should also be investigated. 


\section{Acknowledgments}

The authors would like to acknowledge NordForsk Nordic University Hub project \#85352

(Nordic POP, Patient-Oriented Products) for the funding support enabling the collaboration leading to this review. Finally, the authors would like to express gratitude to Dr. Zhengwei Mao for guidance in writing the review.

\section{List of abbreviations}

\begin{tabular}{ll}
\hline NM & Nanomaterial \\
NO & Nitric oxide \\
PSi & Mesoporous silicon \\
THC & Thermal Hydrocarbonisation \\
AMP & Antimicrobial Peptides \\
SPION & Superparamagnetic iron oxide \\
APTES & 3-aminopropyltriethoxysilane \\
Ln-ZnO & Laurusnobilis-Zn oxide \\
CLSM & Confocal laser scanning microscopy \\
FE-SEM & Field emission scanning electron microscopy \\
$\mathrm{CNT}$ & Carbon Nanotube \\
$\mathrm{Ag}$ & Silver \\
$\mathrm{Cu}$ & Copper \\
$\mathrm{Au}$ & Gold \\
$\mathrm{Zn}$ & Zinc \\
$\mathrm{Ga}$ & Gallium \\
$\mathrm{Al}$ & Aluminum \\
$\mathrm{As}$ & Arsenic \\
$\mathrm{Pt}$ & Platinum \\
$\mathrm{Hg}$ & Mercury \\
\hline
\end{tabular}




\begin{tabular}{|c|c|}
\hline $\mathrm{TiO}_{2}$ & Titanium Dioxide \\
\hline $\mathrm{pG}$ & pristine graphene \\
\hline GO & graphene oxide \\
\hline $\mathrm{rGO}$ & reduced graphene oxide \\
\hline G-QDs & graphene quantum dots \\
\hline SWCNTs-Ag & Ag coated SWCNTs-Ag \\
\hline $\mathrm{Zn}$ & Zinc \\
\hline $\mathrm{ZnO}$ & Zinc Oxide \\
\hline $\mathrm{CuO}$ & Copper Oxide \\
\hline LDH & Layered double hydroxide \\
\hline CNFs & Carbon nanofibers \\
\hline ACFs & Activated carbon fiber \\
\hline SEM & Scanning Electron Microscopy \\
\hline TEM & Transmission Electron Microscopy \\
\hline $\mathrm{AA}$ & Amino Acid \\
\hline Ag-NM-L leaves & Ag NM synthesised from Caltropisprocera \\
\hline CM-SH & Cecropinmelittin with cysteine \\
\hline ICP-MS & Inductively coupled plasma mass spectrometry \\
\hline $\mathrm{A} 3-\mathrm{APO}^{\mathrm{His}}$ & C-terminally hexahistidine-tagged A3-APO \\
\hline i.v & intravenous \\
\hline Au NM-Apt & Au NM-DNA aptamer \\
\hline $\mathrm{Au}$ NM-Apt ${ }^{\mathrm{His}}$ & Au NM conjugated with His-tag DNA aptamer \\
\hline PEP & $\mathrm{AMP}(\mathrm{PEP})$ from lactoferrin \\
\hline NQR & NADH: ubiquinone oxidoreductase \\
\hline TBARS & Thiobarbituric acid-reactive substances \\
\hline ONMG & $o$-nitrophenol $\beta$-d-galactopyranosideside \\
\hline Ag NM-SiNW & Si nanowire composite with Ag NM \\
\hline CuNM-SiNW & Si nanowire composite with CuNM \\
\hline Ag-MESs & Ag encapsulated mesoporous silica nanocrystals \\
\hline DNA & Deoxyribonucleic acid, \\
\hline
\end{tabular}




\begin{tabular}{ll}
\hline RNA & Ribonucleic acid \\
MSSA & Methicillin-sensitive Staphylococcus aureus \\
MRSA & Methicillin-resistant Staphylococcus aureus \\
MRSE & Methicillin-resistant Staphylococcus epidermidis \\
$\mathrm{V}_{2} \mathrm{O}_{5}$ & Vanadium pentoxide $\mathrm{V}_{2} \mathrm{O}_{5}$ \\
OM & Outer membrane \\
PM & Plasma membrane \\
PGN & Peptidoglycan \\
LTA & Lipoteichoic acid \\
MLT & Maltose transporter \\
\hline
\end{tabular}




\section{References}

Aaron, S. D. et al. (2002) 'Single and combination antibiotic susceptibilities of planktonic adherent, and biofilm-grown Pseudomonas aeruginosa isolates cultured from sputa of adults with cystic fibrosis', Journal of Clinical Microbiology, 40(11), pp. 4172-4179. doi: 10.1128/JCM.40.11.4172-4179.2002.

Abdossamadi, Z., Seyed, N. and Rafati, S. (2016) 'Mammalian host defense peptides and their implication on combating Leishmania infection', Cellular Immunology, 309, pp. 23-31. doi: 10.1016/j.cellimm.2016.10.001.

Acker, H. Van and Coenye, T. (2016) 'The Role of Reactive Oxygen Species in AntibioticMediated Killing of Bacteria', Trends in Microbiology. Elsevier Ltd, xx, pp. 1-11. doi: 10.1016/j.tim.2016.12.008.

Agnihotri, S., Mukherji, Soumyo and Mukherji, Suparna (2014) 'Size-controlled silver nanoparticles synthesized over the range 5-100 nm using the same protocol and their antibacterial efficacy', RSC Advances, 4(8), pp. 3974-3983. doi: 10.1039/c3ra44507k.

Ahamed, M. et al. (2017) 'Ag-doping regulates the cytotoxicity of $\mathrm{TiO}<\mathrm{inf}>2</ \mathrm{inf}>$ nanoparticles via oxidative stress in human cancer cells', Scientific Reports, 7(1). doi: 10.1038/s41598-01717559-9.

Ahire, J. J., Neveling, D. P. and Dicks, L. M. T. (2015) 'Co-spinning of Silver Nanoparticles with Nisin Increases the Antimicrobial Spectrum of PDLLA: PEO Nanofibers', Current Microbiology. Springer US, pp. 24-30. doi: 10.1007/s00284-015-0813-y.

Ahmed, K. B. A., Raman, T. and Veerappan, A. (2016) 'Future prospects of antibacterial metal nanoparticles as enzyme inhibitor', Materials Science and Engineering: C. Elsevier B.V., 68, pp. 939-947. doi: 10.1016/j.msec.2016.06.034.

Alekshun, M. N. and Levy, S. B. (2007) 'Molecular Mechanisms of Antibacterial Multidrug Resistance', Cell, 128(6), pp. 1037-1050. doi: 10.1016/j.cell.2007.03.004.

Allahverdiyev, A. M. et al. (2011) 'Coping with antibiotic resistance: combining nanoparticles with antibiotics and other antimicrobial agents', Expert Review of Anti-infective Therapy, 9(11), pp. 1035-1052. doi: 10.1586/eri.11.121.

Almaaytah, A. et al. (2017) 'Development of novel ultrashort antimicrobial peptide nanoparticles with potent antimicrobial and antibiofilm activities against multidrug-resistant bacteria', Drug Design, Development and Therapy. doi: 10.2147/DDDT.S147450. 
Alyautdin, R. et al. (2014) 'Nanoscale drug delivery systems and the blood-brain barrier', International Journal of Nanomedicine, pp. 795-811. doi: 10.2147/IJN.S52236.

Anbanandam, A. et al. (2008) 'Molecular Basis for Proline- and Arginine-Rich Peptide Inhibition of Proteasome', Journal of Molecular Biology. Elsevier Ltd, 384(1), pp. 219-227. doi: 10.1016/j.jmb.2008.09.021.

Andersson, D. I., Hughes, D. and Kubicek-Sutherland, J. Z. (2016) 'Mechanisms and consequences of bacterial resistance to antimicrobial peptides', Drug Resistance Updates, pp. 43-57. doi: 10.1016/j.drup.2016.04.002.

Ann, L. C. et al. (2014) 'Effect of surface modification and UVA photoactivation on antibacterial bioactivity of zinc oxide powder', Applied Surface Science. Elsevier B.V., 292, pp. 405-412. doi: 10.1016/j.apsusc.2013.11.152.

Ansari, M. A. et al. (2013) 'Antibacterial potential of A12O3 nanoparticles against multidrug resistance strains of Staphylococcus aureus isolated from skin exudates', Journal of Nanoparticle Research, 15(10), p. 1970. doi: 10.1007/s11051-013-1970-1.

Ansari, M. A. et al. (2014) 'Interaction of A12O3 nanoparticles with Escherichia coli and their cell envelope biomolecules', Journal of Applied Microbiology, 116(4), pp. 772-783. doi: 10.1111/jam.12423.

Arakha, M. et al. (2015) 'Antimicrobial activity of iron oxide nanoparticle upon modulation of nanoparticle-bacteria interface.', Scientific reports, 5, p. 14813. doi: 10.1038/srep14813.

Bahar, A. A. and Ren, D. (2013) 'Antimicrobial peptides', Pharmaceuticals, 6(12), pp. 15431575. doi: 10.3390/ph6121543.

Bals, R. and Wilson, J. M. (2003) 'Cellular and Molecular Life Sciences Cathelicidins - a family of multifunctional antimicrobial peptides', 60, pp. 711-720. doi: 10.1007/s00018-003-2186-9.

Baltzer, S. a. and Brown, M. H. (2011) 'Antimicrobial Peptides - Promising Alternatives to Conventional Antibiotics', Journal of Molecular Microbiology and Biotechnology, 20(4), pp. 228-235. doi: 10.1159/000331009.

Baptista, A. et al. (2013) 'Nanofibers and Nanoparticles in Biomedical Applications', in Bioengineered Nanomaterials. CRC Press, pp. 93-124. doi: doi:10.1201/b15403-5.

Belguesmia, Y. et al. (2017) 'Chapter 1 - Resistance to Antibiotics and Antimicrobial Peptides: A Need of Novel Technology to Tackle This Phenomenon BT - Functionalized Nanomaterials for the Management of Microbial Infection', in Micro and Nano Technologies. Boston: Elsevier, 
pp. 1-22. doi: http://doi.org/10.1016/B978-0-323-41625-2.00001-6.

Bengoechea, J. A. and Skurnik, M. (2000) 'Temperature-regulated efflux pump/potassium antiporter system mediates resistance to cationic antimicrobial peptides in Yersinia', Molecular Microbiology, 37(1), pp. 67-80. doi: 10.1046/j.1365-2958.2000.01956.x.

Bharti, C. et al. (2015) 'Mesoporous silica nanoparticles in target drug delivery system: A review', International Journal of Pharmaceutical Investigation. doi: 10.4103/2230973X.160844.

Bhattacharya, R. and Mukherjee, P. (2008) 'Biological properties of " naked " metal nanoparticles 次', 60, pp. 1289-1306. doi: 10.1016/j.addr.2008.03.013.

Bierbaum, G. and Sahl, H. G. (1987) 'Autolytic system of Staphylococcus simulans 22: Influence of cationic peptides on activity of N-acetylmuramoyl-L-alanine amidase', Journal of Bacteriology, 169(12), pp. 5452-5458. doi: 10.1128/jb.169.12.5452-5458.1987.

Billings, N. et al. (2013) 'The Extracellular Matrix Component Psl Provides Fast-Acting Antibiotic Defense in Pseudomonas aeruginosa Biofilms', PLoS Pathogens, 9(8). doi: 10.1371/journal.ppat.1003526.

Blair, J. M. A. et al. (2015) 'Molecular mechanisms of antibiotic resistance', Nature Reviews Microbiology, 13, pp. 42-51. doi: 10.1039/c0cc05111j.

Blecher, K., Nasir, A. and Friedman, A. (2017) 'infectious disease in combating infectious disease a $\mathrm{n}$ d e s i o s c i e n c e o n o t d i s t r i b u t e', 5594(March). doi: 10.4161/viru.2.5.17035.

Booth, S. C., Weljie, A. M. and Turner, R. J. (2015) 'Metabolomics reveals differences of metal toxicity in cultures of Pseudomonas pseudoalcaligenes KF707 grown on different carbon', Frontiers in Microbiology, 6(JUL). doi: 10.3389/fmicb.2015.00827.

Braun, K. et al. (2016) 'Membrane interactions of mesoporous silica nanoparticles as carriers of antimicrobial peptides', Journal of Colloid and Interface Science, 475, pp. 161-170. doi: 10.1016/j.jcis.2016.05.002.

Braun, K. et al. (2017) 'Influence of mesopore size and peptide aggregation on the adsorption and release of a model antimicrobial peptide onto/from mesoporous silica nanoparticles: In vitro', Molecular Systems Design and Engineering. Royal Society of Chemistry, 2(4), pp. 393400. doi: 10.1039/c7me00059f.

Brogden, K. A. (2005) 'Antimicrobial peptides: pore formers or metabolic inhibitors in 
bacteria?', Nature reviews. Microbiology, 3(3), pp. 238-50. doi: 10.1038/nrmicro1098.

Brown, A. N. et al. (2012) 'Nanoparticles functionalized with ampicillin destroy multipleantibiotic-resistant isolates of Pseudomonas aeruginosa and Enterobacter aerogenes and methicillin-resistant Staphylococcus aureus', Applied and Environmental Microbiology, 78(8), pp. 2768-2774. doi: 10.1128/AEM.06513-11.

Burd, A. et al. (2007) 'A comparative study of the cytotoxicity of silver-based dressings in monolayer cell, tissue explant, and animal models', Wound Repair and Regeneration, 15(1), pp. 94-104. doi: 10.1111/j.1524-475X.2006.00190.x.

Cai, Y., Strømme, M. and Welch, K. (2013) 'Photocatalytic Antibacterial Effects Are Maintained on Resin-Based TiO2 Nanocomposites after Cessation of UV Irradiation', PLoS ONE, 8(10). doi: 10.1371/journal.pone.0075929.

Campoccia, D., Montanaro, L. and Arciola, C. R. (2013) 'A review of the biomaterials technologies for infection-resistant surfaces', Biomaterials, pp. 8533-8554. doi: 10.1016/j.biomaterials.2013.07.089.

Camporotondia, D. E. et al. (2013) 'Antimicrobial properties of silica modified nanoparticles', Microbial pathogens and strategies for combating them: science, technology and education.

Carré, G. et al. (2014) 'TiO 2 Photocatalysis Damages Lipids and Proteins in', 80(8), pp. 25732581. doi: 10.1128/AEM.03995-13.

Casals, E. et al. (2019) 'Biodistribution, Excretion, and Toxicity of Inorganic Nanoparticles', Theranostic Bionanomaterials. Elsevier, pp. 3-26. doi: 10.1016/B978-0-12-815341-3.00001-8.

Casciaro, B. et al. (2017) 'Acta Biomaterialia Gold-nanoparticles coated with the antimicrobial peptide esculentin-1a ( 1-21 ) NH 2 as a reliable strategy for antipseudomonal drugs'. Acta Materialia Inc., 47, pp. 170-181. doi: 10.1016/j.actbio.2016.09.041.

Cha, S. H. et al. (2015) 'Shape-Dependent Biomimetic Inhibition of Enzyme by Nanoparticles and Their Antibacterial Activity', ACS Nano, 9(9), pp. 9097-9105. doi: 10.1021/acsnano.5b03247.

Chaloupka, K., Malam, Y. and Seifalian, A. M. (2010) 'Nanosilver as a new generation of nanoproduct in biomedical applications', Trends in Biotechnology. Elsevier Ltd, 28(11), pp. 580-588. doi: 10.1016/j.tibtech.2010.07.006.

Chang, Y. et al. (2012) 'The Toxic Effects and Mechanisms of CuO and ZnO Nanoparticles', pp. 2850-2871. doi: 10.3390/ma5122850. 
Chaurasia, A. K. et al. (2016) 'Coupling of radiofrequency with magnetic nanoparticles treatment as an alternative physical antibacterial strategy against multiple drug resistant bacteria', Scientific Reports, 6. doi: 10.1038/srep33662.

Chem, J. B. (1997) 'CELL BIOLOGY AND METABOLISM : A Truncated HIV-1 Tat Protein Basic Domain Rapidly Translocates through the Plasma Membrane and Accumulates in the Cell Nucleus A Truncated HIV-1 Tat Protein Basic Domain Rapidly Translocates through the Plasma Membrane and A', 272(25), pp. 16010-16017.

Chen, C. W. et al. (2014) 'Metal nanobullets for multidrug resistant bacteria and biofilms', Advanced Drug Delivery Reviews, pp. 88-104. doi: 10.1016/j.addr.2014.08.004.

Chen, M., Yu, Q. and Sun, H. (2013) 'Novel strategies for the prevention and treatment of biofilm related infections', International Journal of Molecular Sciences, pp. 18488-18501. doi: 10.3390/ijms 140918488.

Chen, Y. et al. (2007) 'Role of peptide hydrophobicity in the mechanism of action of alphahelical antimicrobial peptides.', Antimicrobial agents and chemotherapy, 51(4), pp. 1398-406. doi: 10.1128/AAC.00925-06.

Chen, Y. et al. (2017) 'As-CATH1-6, novel cathelicidins with potent antimicrobial and immunomodulatory properties from Alligator sinensis, play pivotal roles in host antimicrobial immune responses', Biochemical Journal, 474(16), pp. 2861-2885. doi: 10.1042/BCJ20170334.

Cheng, J. T. J. et al. (2009) 'Effect of membrane composition on antimicrobial peptides aurein 2.2 and 2.3 from australian southern bell frogs', Biophysical Journal, 96(2), pp. 552-565. doi: 10.1016/j.bpj.2008.10.012.

Ciofu, O. et al. (2000) 'Chromosomal beta-lactamase is packaged into membrane vesicles and secreted from Pseudomonas aeruginosa.', The Journal of antimicrobial chemotherapy, 45(1), pp. 9-13. doi: 10.1093/jac/45.1.9.

Cornup, I. et al. (1994) 'The amphipathic a-helix concept Application to the de novo design of ideally amphipathic Leu, Lys peptides with hemolytic activity higher than that of melittin', 349, pp. 29-33.

Cullen, T. W. et al. (2015) 'Gut microbiota. Antimicrobial peptide resistance mediates resilience of prominent gut commensals during inflammation.', Science (New York, N.Y.), 347(6218), pp. 170-5. doi: 10.1126/science.1260580.

Dennison, S. R. et al. (2005) 'Amphiphilic alpha-helical antimicrobial peptides and their 
structure/function relationships.', Protein and peptide letters, 12, pp. 31-39. doi: $10.2174 / 0929866053406039$.

Diamond, G. et al. (2009) 'The Roles of Antimicrobial Peptides in Innate Host Defense', Current Pharmaceutical Design. doi: 10.2174/138161209788682325.

Diehnelt, C. W. (2013) 'Peptide array based discovery of synthetic antimicrobial peptides', Frontiers in Microbiology, 4(DEC), pp. 1-3. doi: 10.3389/fmicb.2013.00402.

El Din, S. N. et al. (2016) 'In vitro and in vivo antimicrobial activity of combined therapy of silver nanoparticles and visible blue light against Pseudomonas aeruginosa', International Journal of Nanomedicine, 11, pp. 1749-1758. doi: 10.2147/IJN.S102398.

Ding, F. et al. (2018) 'Size-Dependent Inhibitory Effects of Antibiotic Drug Nanocarriers against Pseudomonas aeruginosa', ACS Omega, 3(1), pp. 1231-1243. doi: 10.1021/acsomega.7b01956.

Dizaj, S. M. et al. (2014) 'Antimicrobial activity of the metals and metal oxide nanoparticles', Materials Science and Engineering C, pp. 278-284. doi: 10.1016/j.msec.2014.08.031.

Djafari, J. et al. (2016) 'New Synthesis of Gold- and Silver-Based Nano-Tetracycline Composites', ChemistryOpen, p. 169. doi: 10.1002/open.201600055.

Donlan, R. M. (2002) 'Biofilms: Microbial life on surfaces', Emerging Infectious Diseases, pp. 881-890. doi: 10.3201/eid0809.020063.

Dutta, R. K. et al. (2012) 'Studies on antibacterial activity of ZnO nanoparticles by ROS induced lipid peroxidation', Colloids and Surfaces B: Biointerfaces. Elsevier B.V., 94, pp. 143-150. doi: 10.1016/j.colsurfb.2012.01.046.

Ebbensgaard, A. et al. (2015) 'Comparative evaluation of the antimicrobial activity of different antimicrobial peptides against a range of pathogenic Bacteria', PLoS ONE, 10(12). doi: 10.1371/journal.pone.0144611.

Ebenhan, T. et al. (2014) 'Antimicrobial Peptides: Their Role as Infection-Selective Tracers for Molecular Imaging', BioMed Research International. doi: 10.1155/2014/867381.

Eby, D. M., Farrington, K. E. and Johnson, G. R. (2008) 'Synthesis of bioinorganic antimicrobial peptide nanoparticles with potential therapeutic properties', Biomacromolecules. doi: 10.1021/bm800512e.

Esmaeillou, M. et al. (2017) 'Vancomycin capped with silver nanoparticles as an antibacterial agent against multi-drug resistance bacteria', Advanced Pharmaceutical Bulletin, 7(3), pp. 479483. doi: 10.15171/apb.2017.058. 
Etayash, H. et al. (2013) 'Peptide-bacteria interactions using engineered surface-immobilized peptides from class IIa bacteriocins', Langmuir, 29(12), pp. 4048-4056. doi: 10.1021/la3041743. Ewald, A. et al. (2006) 'Antimicrobial titanium/silver PVD coatings on titanium', BioMedical Engineering OnLine, 5(1), p. 22. doi: 10.1186/1475-925X-5-22.

Fang, P. and Guo, M. (2015) 'Evolutionary Limitation and Opportunities for Developing tRNA Synthetase Inhibitors with 5-Binding-Mode Classification', pp. 1703-1725. doi: 10.3390/life5041703.

Fawell, S. et al. (1994) 'Tat-mediated delivery of heterologous proteins into cells.', Proceedings of the National Academy of Sciences of the United States of America, 91(2), pp. 664-668. doi: 10.1073/pnas.91.2.664.

Fernandez, D. I. et al. (2012) 'The antimicrobial peptide aurein 1.2 disrupts model membranes via the carpet mechanism', Physical Chemistry Chemical Physics, 14(45), pp. 15739-15751. doi: $10.1039 / \mathrm{c} 2 \mathrm{cp} 43099 \mathrm{a}$.

Ferreira, F. et al. (2016) 'Biomaterials One-step synthesis of high-density peptide-conjugated gold nanoparticles with antimicrobial ef fi cacy in a systemic infection model', 85. doi: 10.1016/j.biomaterials.2016.01.051.

Fidler, D. P. and Fidler, D. P. (2016) 'Relations The Globalization of Public Health : Emerging Infectious Diseases and International', 5(1), pp. 11-51.

Flemming, H. and Wingender, J. (2010) 'The biofilm matrix', Nature reviews. Microbiology, 8(9), pp. 623-33. doi: 10.1038/nrmicro2415.

Gable, J. E. et al. (2009) 'Fluorescence and UV resonance Raman study of peptide-vesicle interactions of human cathelicidin LL-37 and its F6W and F17W mutants', Biochemistry, 48(47), pp. 11264-11272. doi: 10.1021/bi900996q.

Gagnon, M. G. et al. (2016) 'Structures of proline-rich peptides bound to the ribosome reveal a common mechanism of protein synthesis inhibition', Nucleic Acids Research, 44(5), pp. 24392450. doi: 10.1093/nar/gkw018.

Gao, Y. et al. (2000) 'Inhibition of ubiquitin-proteasome pathway - mediated I $\kappa$ B $\alpha$ degradation by a naturally occurring antibacterial peptide', 106(3), pp. 439-448.

Ghosh, A. et al. (2014) 'Indolicidin Targets Duplex DNA : Structural and Mechanistic Insight through a Combination of Spectroscopy and Microscopy', pp. 2052-2058. doi: 10.1002/cmdc.201402215. 
Giacometti, A. et al. (2002) 'Potential therapeutic role of cationic peptides in three experimental models of septic shock', Antimicrobial Agents and Chemotherapy, 46(7), pp. 2132-2136. doi: 10.1128/AAC.46.7.2132-2136.2002.

Gordon, O. et al. (2010) 'Silver coordination polymers for prevention of implant infection: Thiol interaction, impact on respiratory chain enzymes, and hydroxyl radical induction', Antimicrobial Agents and Chemotherapy, 54(10), pp. 4208-4218. doi: 10.1128/AAC.01830-09.

Gounani, Z. et al. (2019) 'Mesoporous silica nanoparticles carrying multiple antibiotics provide enhanced synergistic effect and improved biocompatibility', Colloids and Surfaces B: Biointerfaces. doi: 10.1016/j.colsurfb.2018.12.035.

Gunn, J. S. (2001) 'Bacterial modification of LPS and resistance to antimicrobial peptides', in Journal of Endotoxin Research. doi: 10.1179/096805101101532558.

Gupta, A. et al. (1999) 'Molecular basis for resistance to silver cations in Salmonella', Nature Medicine, 5(2), pp. 183-188. doi: 10.1038/5545.

Gupta, A. et al. (2017) 'Synergistic antimicrobial therapy using nanoparticles and antibiotics for the treatment of multidrug-resistant bacterial infection', Nano Futures, 1(1), p. 015004. doi: 10.1088/2399-1984/aa69fb.

Hajipour, M. J. et al. (2012) 'Antibacterial properties of nanoparticles', Trends in Biotechnology, pp. 499-511. doi: 10.1016/j.tibtech.2012.06.004.

Han, G. et al. (2009) 'Nitric oxide releasing nanoparticles are therapeutic for Staphylococcus aureus abscesses in a murine model of infection', PLOS ONE, 4(11), pp. 1-7. doi: 10.1371/journal.pone.0007804.

Han, J. W. et al. (2014) 'Oxidative stress mediated cytotoxicity of biologically synthesized silver nanoparticles in human lung epithelial adenocarcinoma cell line.', Nanoscale research letters, 9(1), p. 459. doi: 10.1186/1556-276X-9-459.

Hancock, R. E. W. and Sahl, H. G. (2006) 'Antimicrobial and host-defense peptides as new antiinfective therapeutic strategies.', Nature biotechnology, 24(12), pp. 1551-7. doi: $10.1038 /$ nbt1267.

Haney, E. F. et al. (2013) 'Biochimica et Biophysica Acta Mechanism of action of puroindoline derived tryptophan-rich antimicrobial peptides', BBA - Biomembranes. Elsevier B.V., 1828(8), pp. 1802-1813. doi: 10.1016/j.bbamem.2013.03.023.

Hankins, J. V et al. (2012) 'Amino acid addition to Vibrio cholerae LPS establishes a link 
between surface remodeling in Gram-positive and Gram-negative bacteria'. doi: 10.1073/pnas.1201313109/-/DCSupplemental.www.pnas.org/cgi/doi/10.1073/pnas.1201313109.

Hao, N. et al. (2015) 'One-step synthesis of amine-functionalized hollow mesoporous silica nanoparticles as efficient antibacterial and anticancer materials', ACS Applied Materials and Interfaces. doi: 10.1021/am508219g.

Haque, M. et al. (2018) 'Health care-associated infections - An overview', Infection and Drug Resistance. doi: 10.2147/IDR.S177247.

Hassan, M. et al. (2014) 'Antimicrobial Peptides from Prokaryotes', in Novel Antimicrobial Agents and Strategies, pp. 71-90. doi: 10.1002/9783527676132.ch5.

He, Y. et al. (2016) 'Study on the mechanism of antibacterial action of magnesium oxide nanoparticles against foodborne pathogens', Journal of Nanobiotechnology. BioMed Central, 14(1), p. 54. doi: 10.1186/s12951-016-0202-0.

Heinlaan, M. et al. (2008) 'Toxicity of nanosized and bulk $\mathrm{ZnO}, \mathrm{CuO}$ and $\mathrm{TiO} 2$ to bacteria Vibrio fischeri and crustaceans Daphnia magna and Thamnocephalus platyurus', Chemosphere, 71(7), pp. 1308-1316. doi: 10.1016/j.chemosphere.2007.11.047.

Held, B. P. and Instruments, B. (2015) ' $\mathrm{h}$ i t e a p e $\mathrm{r}$ An Introduction to Reactive Oxygen Species Measurement of ROS in Cells', pp. 1-21.

Holban, A. M. and Andronescu, E. (2016) 'Chapter 10 - Inorganic nanoarchitectonics designed for drug delivery and anti-infective surfaces', in Surface Chemistry of Nanobiomaterials, pp. 301-327. doi: 10.1016/B978-0-323-42861-3.00010-8.

Hong, R. et al. (2012) 'Membrane Lipid Peroxidation in Copper Alloy-Mediated Contact Killing of Escherichia coli', pp. 1776-1784. doi: 10.1128/AEM.07068-11.

Hsueh, Y.-H., Tsai, P.-H. and Lin, K.-S. (2017) 'pH-Dependent Antimicrobial Properties of Copper Oxide Nanoparticles in Staphylococcus aureus', International Journal of Molecular Sciences, 18(4), p. 793. doi: 10.3390/ijms18040793.

Hu, Y. and Hong, X. (2017) 'Synthesis and Performance of Silver Photocatalytic Nanomaterials for Water Disinfection', in An, T., Zhao, H., and Wong, P. K. (eds) Advances in Photocatalytic Disinfection. Berlin, Heidelberg: Springer Berlin Heidelberg, pp. 85-127. doi: 10.1007/978-3662-53496-0_5.

Huang, H. et al. (2016) 'An Evaluation of Blood Compatibility of Silver Nanoparticles', Scientific Reports, 6(April), p. 25518. doi: 10.1038/srep25518. 
Huang, H. W. (2009) 'Free energies of molecular bound states in lipid bilayers: Lethal concentrations of antimicrobial peptides', Biophysical Journal, 96(8), pp. 3263-3272. doi: 10.1016/j.bpj.2009.01.030.

Huang, Q. et al. (2015) 'Atomic force microscopy measurements of bacterial adhesion and biofilm formation onto clay-sized particles.', Scientific reports. Nature Publishing Group, 5(October), p. 16857. doi: 10.1038/srep16857.

Huang, Y., Wu, C. and Aronstam, R. S. (2010) 'Toxicity of Transition Metal Oxide Nanoparticles: Recent Insights from in vitro Studies', pp. 4842-4859. doi: 10.3390/ma3104842.

Huang, Z. et al. (2008) 'Toxicological effect of $\mathrm{ZnO}$ nanoparticles based on bacteria', Langmuir, 24(8), pp. 4140-4144. doi: 10.1021/la7035949.

Husain, F. M. et al. (2016) 'Quorum sensing and biofilm inhibition by lactonase producing Bacillus amyloliquefaciens SBF1 strain isolated from date palm rhizosphere of Saudi Arabia', Journal of Pure and Applied Microbiology, 10(3), pp. 1745-1754.

Iannitelli, A. et al. (2011) 'Potential antibacterial activity of carvacrol-loaded poly(DL-lactideco-glycolide) (PLGA) nanoparticles against microbial biofilm', International Journal of Molecular Sciences, 12(8), pp. 5039-5051. doi: 10.3390/ijms12085039.

Islam, M. R. et al. (2012) 'Antimicrobial mechanism of lantibiotics', Biochemical Society Transactions, 40(6), pp. 1528-1533. doi: 10.1042/BST20120190.

Ivask, A. et al. (2010) 'Profiling of the reactive oxygen species-related ecotoxicity of $\mathrm{CuO}, \mathrm{ZnO}$, $\mathrm{TiO} 2$, silver and fullerene nanoparticles using a set of recombinant luminescent Escherichia coli strains: Differentiating the impact of particles and solubilised metals', Analytical and Bioanalytical Chemistry, 398(2), pp. 701-716. doi: 10.1007/s00216-010-3962-7.

Ivask, A. et al. (2012) 'Metal-Containing Nano-Antimicrobials: Differentiating the Impact of Solubilized Metals and Particles', in Cioffi, N. and Rai, M. (eds) Nano-Antimicrobials: Progress and Prospects. Berlin, Heidelberg: Springer Berlin Heidelberg, pp. 253-290. doi: 10.1007/9783-642-24428-5_9.

Izquierdo-Barba, I. et al. (2009) 'Incorporation of antimicrobial compounds in mesoporous silica film monolith', Biomaterials. doi: 10.1016/j.biomaterials.2009.07.003.

Jacob, R. (2016) 'Lipid bilayers and their interactions with the antimicrobial peptide LL37 : a TIR Raman study'.

Jenssen, H., Hamill, P. and Hancock, R. E. W. (2006) 'Peptide antimicrobial agents', Clinical 
Microbiology Reviews, pp. 491-511. doi: 10.1128/CMR.00056-05.

Jones, N. et al. (2008) 'Antibacterial activity of $\mathrm{ZnO}$ nanoparticle suspensions on a broad spectrum of microorganisms', FEMS Microbiology Letters, 279(1), pp. 71-76. doi: 10.1111/j.1574-6968.2007.01012.x.

Joo, H., Fu, C. and Otto, M. (2016) 'Bacterial Strategies of Resistance to Antimicrobial Peptides', Phil. Trans. R. Soc. B, 371, p. (this issue). doi: 10.1098/rstb.2015.0292.

Josephson, L., Manuel Perez, J. and Weissleder, R. (2001) 'Magnetic nanosensors for the detection of oligonucleotide sequences', Angewandte Chemie - International Edition, 40(17), pp. 3204-3206. doi: 10.1002/1521-3773(20010903)40:17<3204::AID-ANIE3204>3.0.CO;2-H.

Kalishwaralal, K. et al. (2010) 'Silver nanoparticles impede the biofilm formation by Pseudomonas aeruginosa and Staphylococcus epidermidis', Colloids and Surfaces B: Biointerfaces, 79(2), pp. 340-344. doi: 10.1016/j.colsurfb.2010.04.014.

Kanematsu, H. and Barry, D. M. (2015) 'Antibacterial Effect of Materials and Biofilm', in Kanematsu, H. and Barry, D. M. (eds) Biofilm and Materials Science. Cham: Springer International Publishing, pp. 169-174. doi: 10.1007/978-3-319-14565-5_21.

Karaman, D. Ş. et al. (2017) 'Current Approaches for Exploration of Nanoparticles as Antibacterial Agents', Antibacterial Agents. doi: 10.5772/68138.

Kasemets, K. et al. (2009) 'Toxicity of nanoparticles of $\mathrm{ZnO}, \mathrm{CuO}$ and $\mathrm{TiO} 2$ to yeast Saccharomyces cerevisiae', Toxicology in Vitro, 23(6), pp. 1116-1122. doi: 10.1016/j.tiv.2009.05.015.

Katva, S. et al. (2018) 'Antibacterial Synergy of Silver Nanoparticles with Gentamicin and Chloramphenicol against Enterococcus faecalis.', Pharmacognosy magazine, 13(Suppl 4), pp. S828-S833. doi: 10.4103/pm.pm_120_17.

Khan, S. et al. (2017) 'Photoinactivation of multidrug resistant bacteria by monomeric methylene blue conjugated gold nanoparticles', Journal of Photochemistry and Photobiology B: Biology, 174, pp. 150-161. doi: 10.1016/j.jphotobiol.2017.07.011.

Khan, S. A. et al. (2011) 'Bio-conjugated popcorn shaped gold nanoparticles for targeted photothermal killing of multiple drug resistant Salmonella DT104', Journal of Materials Chemistry, 21(Atcc 700408), p. 17705. doi: 10.1039/c1jm13320a.

Khan, S. N. and Khan, A. U. (2016) 'Breaking the spell: Combating multidrug resistant "superbugs", Frontiers in Microbiology. doi: 10.3389/fmicb.2016.00174. 
Khlebtsov, N. and Dykman, L. (2011) 'Biodistribution and toxicity of engineered gold nanoparticles: A review of in vitro and in vivo studies', Chemical Society Reviews, pp. 16471671. doi: 10.1039/c0cs00018c.

Khurana, C. and Chudasama, B. (2018) 'Nanoantibiotics: strategic assets in the fight against drug-resistant superbugs', International journal of nanomedicine, 13, pp. 3-6. doi: 10.2147/IJN.S124698.

Kirisits, M. J. (2015) 'Mechanistic lessons learned from studies of planktonic bacteria with metallic nanomaterials: implications for interactions between nanomaterials and biofilm bacteria', 6(July), pp. 1-8. doi: 10.3389/fmicb.2015.00677.

Kjos, M. et al. (2014) 'Sensitivity to the two-peptide bacteriocin lactococcin G is dependent on UppP, an enzyme involved in cell-wall synthesis', Molecular Microbiology, 92(6), pp. 11771187. doi: 10.1111/mmi.12632.

Kooi, C. and Sokol, P. A. (2009) 'Burkholderia cenocepacia zinc metalloproteases influence resistance to antimicrobial peptides', Microbiology, 155(9), pp. 2818-2825. doi: 10.1099/mic.0.028969-0.

Kruk, T. et al. (2015) 'Synthesis and antimicrobial activity of monodisperse copper nanoparticles', Colloids and Surfaces B: Biointerfaces, 128, pp. 17-22. doi: 10.1016/j.colsurfb.2015.02.009.

Kumar, A. et al. (2012) 'Microorganisms: A Versatile Model for Toxicity Assessment of Engineered Nanoparticles', in Cioffi, N. and Rai, M. (eds) Nano-Antimicrobials: Progress and Prospects. Berlin, Heidelberg: Springer Berlin Heidelberg, pp. 497-524. doi: 10.1007/978-3642-24428-5_17.

Kumar, M., Curtis, A. and Hoskins, C. (2018) 'Application of nanoparticle technologies in the combat against anti-microbial resistance', Pharmaceutics. doi: 10.3390/pharmaceutics10010011. Kuo, W. S. et al. (2009) 'Antimicrobial gold nanorods with dual-modality photodynamic inactivation and hyperthermia', Chemical Communications, (32), pp. 4853-4855. doi: 10.1039/b907274h.

Lai, H. Z. et al. (2015) 'Potent antibacterial nanoparticles for pathogenic bacteria', ACS Applied Materials and Interfaces, 7(3), pp. 2046-2054. doi: 10.1021/am507919m.

Lambadi, P. R. et al. (2015) 'Facile biofunctionalization of silver nanoparticles for enhanced antibacterial properties, endotoxin removal, and biofilm control', International Journal of 
Nanomedicine. doi: 10.2147/IJN.S72923.

Lara, H. H. et al. (2010) 'Bactericidal effect of silver nanoparticles against multidrug-resistant bacteria', World Journal of Microbiology \& Biotechnology, 26(4), pp. 615-621. doi: 10.1007/s11274-009-0211-3.

Lee, D., Ashe, K. and Laurencin, C. (2014) 'Surface Modification of Biomaterials at the Nanoscale: Biomimetic Scaffolds for Tissue Engineering Applications', in Nanotechnology and Regenerative Engineering. CRC Press, pp. 191-226. doi: doi:10.1201/b17444-9.

Lee, T.-H. and Aguilar, K. N. H. and M.-I. (2016) 'Antimicrobial Peptide Structure and Mechanism of Action: A Focus on the Role of Membrane Structure', Current Topics in Medicinal Chemistry, pp. 25-39. doi: http://dx.doi.org/10.2174/1568026615666150703121700.

Lellouche, J. et al. (2012) 'Antibiofilm surface functionalization of catheters by magnesium fluoride nanoparticles', International Journal of Nanomedicine, 7, pp. 1175-1188. doi: 10.2147/IJN.S26770.

Lemire, J. a, Harrison, J. J. and Turner, R. J. (2013) 'Antimicrobial activity of metals: mechanisms, molecular targets and applications.', Nature reviews. Microbiology. Nature Publishing Group, 11(6), pp. 371-84. doi: 10.1038/nrmicro3028.

Leung, Y. H. et al. (2016) 'Toxicity of $\mathrm{ZnO}$ and $\mathrm{TiO} 2$ to Escherichia coli cells', (October), pp. 1-13. doi: 10.1038/srep35243.

Li, L. li and Wang, H. (2013) 'Enzyme-coated mesoporous silica nanoparticles as efficient antibacterial agents in vivo', Advanced Healthcare Materials. doi: 10.1002/adhm.201300051.

Li, W.-R. et al. (2010) 'Antibacterial activity and mechanism of silver nanoparticles on Escherichia coli.', Applied microbiology and biotechnology, 85(4), pp. 1115-22. doi: 10.1007/s00253-009-2159-5.

Li, X. Z., Nikaido, H. and Williams, K. E. (1997) 'Silver-resistant mutants of Escherichia coli display active efflux of Ag+and are deficient in porins', Journal of Bacteriology, 179(19), pp. 6127-6132. doi: 10.1128/jb.179.19.6127-6132.1997.

Li, Y. et al. (2012) 'Mechanism of photogenerated reactive oxygen species and correlation with the antibacterial properties of engineered metal-oxide nanoparticles', ACS Nano, 6(6), pp. 51645173. doi: 10.1021/nn300934k.

Liu, L. et al. (2008) 'Biologically active core/shell nanoparticles self-assembled from 
cholesterol-terminated PEG-TAT for drug delivery across the blood-brain barrier', Biomaterials, 29(10), pp. 1509-1517. doi: 10.1016/j.biomaterials.2007.11.014.

Liu, L. et al. (2013) 'The potent antimicrobial properties of cell penetrating peptide-conjugated silver nanoparticles with excellent selectivity for Gram-positive bacteria over erythrocytes', Nanoscale doi: 10.1039/c3nr34254a.

Liu, P. T. et al. (2006) 'Toll-like receptor triggering of a vitamin D-mediated human antimicrobial response', Science, 311(5768), pp. 1770-1773. doi: 10.1126/science.1123933.

Liu, Y. et al. (2007) 'Synthesis, Stability, and Cellular Internalization of Gold Nanoparticles Containing Mixed Peptide - Poly ( ethylene glycol ) Monolayers Synthesis , Stability, and Cellular Internalization of Gold Nanoparticles Containing Mixed Peptide-Poly ( ethylene g', Analytical Chemistry, 79(6), pp. 2221-2229. doi: 10.1021/ac061578f.

Luckarift, H. R. et al. (2006) 'Rapid, room-temperature synthesis of antibacterial bionanocomposites of lysozyme with amorphous silica or titania', Small, 2(5), pp. 640-643. doi: 10.1002/smll.200500376.

Macomber, L., Elsey, S. P. and Hausinger, R. P. (2011) 'Fructose-1,6-bisphosphate aldolase (class II) is the primary site of nickel toxicity in Escherichia coli', Molecular Microbiology, 82(5), pp. 1291-1300. doi: 10.1111/j.1365-2958.2011.07891.x.

Macomber, L. and Imlay, J. A. (2009) 'The iron-sulfur clusters of dehydratases are primary intracellular targets of copper toxicity.', Proceedings of the National Academy of Sciences of the United States of America, 106(20), pp. 8344-9. doi: 10.1073/pnas.0812808106.

Mah, T. F. C. and O'Toole, G. A. (2001) 'Mechanisms of biofilm resistance to antimicrobial agents', Trends in Microbiology, pp. 34-39. doi: 10.1016/S0966-842X(00)01913-2.

Malanovic, N. and Lohner, K. (2016) 'Gram-positive bacterial cell envelopes: The impact on the activity of antimicrobial peptides', Biochimica et Biophysica Acta - Biomembranes, 1858(5), pp. 936-946. doi: 10.1016/j.bbamem.2015.11.004.

Malka, E. et al. (2013) 'Eradication of multi-drug resistant bacteria by a novel Zn-doped CuO nanocomposite', Small, 9(23), pp. 4069-4076. doi: 10.1002/smll.201301081.

Malmsten, M. (2014) 'Antimicrobial peptides.', Upsala journal of medical sciences, 119(2), pp. 199-204. doi: 10.3109/03009734.2014.899278.

Manke, A., Wang, L. and Rojanasakul, Y. (2013) 'Mechanisms of Nanoparticle-Induced Oxidative Stress and Toxicity', 2013. 
Marius, S. et al. (2011) 'Enhanced antibacterial effect of silver nanoparticles obtained by electrochemical synthesis in poly ( amide-hydroxyurethane ) media', pp. 789-796. doi: 10.1007/s10856-011-4281-z.

Markowska, K., Grudniak, A. M. and Wolska, K. I. (2013) 'Silver nanoparticles as an alternative strategy against bacterial biofilms', Acta Biochimica Polonica, pp. 523-530.

Marshall, S. H. and Arenas, G. (2003) 'Antimicrobial peptides: A natural alternative to chemical antibiotics andapotential for applied biotechnology', Electronic Journal of Biotechnology, pp. 96-109. doi: 10.2225/vol6-issue3-fulltext-1.

Martínez-Carmona, M., Gun'ko, Y. K. and Vallet-Regí, M. (2018) 'Mesoporous silica materials as drug delivery: "the nightmare" of bacterial infection', Pharmaceutics. doi: 10.3390/pharmaceutics 10040279 .

McShan, D. et al. (2015) 'Synergistic Antibacterial Effect of Silver Nanoparticles Combined with Ineffective Antibiotics on Drug Resistant Salmonella typhimurium DT104', Journal of Environmental Science and Health, Part C, 33(3), pp. 369-384. doi: 10.1080/10590501.2015.1055165.

Meghana, S. et al. (2015) 'Understanding the pathway of antibacterial activity of copper oxide nanoparticles', RSC Adv., 5(16), pp. 12293-12299. doi: 10.1039/C4RA12163E.

Miki, T., Holsts, O. and Hardt, W. D. (2012) 'The bactericidal activity of the C-type lectin regIII?? against gram-negative bacteria involves binding to lipid A', Journal of Biological Chemistry, 287(41), pp. 34844-34855. doi: 10.1074/jbc.M112.399998.

Millenbaugh, N. J. et al. (2015) 'Photothermal killing of Staphylococcus aureus using antibodytargeted gold nanoparticles', International Journal of Nanomedicine, 10, pp. 1953-1960. doi: 10.2147/IJN.S76150.

Mohamed, M. M. et al. (2017) 'Antibacterial effect of gold nanoparticles against Corynebacterium pseudotuberculosis', International Journal of Veterinary Science and Medicine, 5(1), pp. 23-29. doi: 10.1016/j.ijvsm.2017.02.003.

Mohankandhasamy et al. (2017) 'Development of gold nanoparticles coated with silica containing the antibiofilm drug cinnamaldehyde and their effects on pathogenic bacteria', International Journal of Nanomedicine, 12, pp. 2813-2828. doi: 10.2147/IJN.S132784.

Moongraksathum, B. and Chen, Y. W. (2018) 'Anatase TiO2co-doped with silver and ceria for antibacterial application', Catalysis Today, 310, pp. 68-74. doi: 10.1016/j.cattod.2017.05.087. 
Mossallam, S. F., Amer, E. I. and Diab, R. G. (2014) 'Potentiated anti-microsporidial activity of Lactobacillus acidophilus CH1 bacteriocin using gold nanoparticles', Experimental Parasitology, 144(1), pp. 14-21. doi: 10.1016/j.exppara.2014.06.002.

Mukherjee, S. et al. (2014) 'Antibacterial membrane attack by a pore-forming intestinal C-type lectin', Nature, 505(7481), pp. 103-107. doi: 10.1038/nature12729.

Mukhopadhyay, J. et al. (2004) 'Antibacterial peptide Microcin J25 inhibits transcription by binding within and obstructing the RNA polymerase secondary channel', Molecular Cell, 14(6), pp. 739-751. doi: 10.1016/j.molcel.2004.06.010.

Muthukrishnan, A. M. (2015) 'Green Synthesis of Copper-Chitosan Nanoparticles and Study of its Antibacterial Activity', Journal of Nanomedicine \& Nanotechnology, 06(01). doi: 10.4172/2157-7439.1000251.

Nair, M. G. et al. (2011) 'Structural, optical, photo catalytic and antibacterial activity of ZnO and Co doped ZnO nanoparticles', Materials Letters. Elsevier B.V., 65(12), pp. 1797-1800. doi: 10.1016/j.matlet.2011.03.079.

Nair, Shantikumar et al. (2009) 'Role of size scale of $\mathrm{ZnO}$ nanoparticles and microparticles on toxicity toward bacteria and osteoblast cancer cells', in Journal of Materials Science: Materials in Medicine doi: 10.1007/s10856-008-3548-5.

Nativo, P., Prior, I. A. and Brust, M. (2008) 'Uptake and intracellular fate of surface-modified gold nanoparticles', ACS Nano, 2(8), pp. 1639-1644. doi: 10.1021/nn800330a.

Nies, D. H. (2003) 'Efflux-mediated heavy metal resistance in prokaryotes', FEMS Microbiology Reviews, pp. 313-339. doi: 10.1016/S0168-6445(03)00048-2.

Niño-Martínez, N. et al. (2019) 'Molecular Mechanisms of Bacterial Resistance to Metal and Metal Oxide Nanoparticles', International journal of molecular sciences, 20(11). doi: 10.3390/ijms20112808.

Nocek, B. et al. (2012) 'Structural and Functional Characterization of Microcin C Resistance Peptidase MccF from Bacillus anthracis', Journal of Molecular Biology. Elsevier Ltd, 420(4-5), pp. 366-383. doi: 10.1016/j.jmb.2012.04.011.

Nowack, B. (2008) 'Exposure Modeling of Engineered Nanoparticles in the Environment', 41(0), pp. 4447-4453.

O’Neill, J. (2014) 'Antimicrobial Resistance: Tackling a crisis for the health and wealth of nations', Review on Antimicrobial Resistance, (December), pp. 1-16. 
Ogunseitan, O. A., Yang, S. and Ericson, J. (2000) 'Microbial ??-aminolevulinate dehydratase as a biosensor of lead bioavailability in contaminated environments', Soil Biology and Biochemistry, 32(13), pp. 1899-1906. doi: 10.1016/S0038-0717(00)00164-4.

Ojha, S., Sett, A. and Bora, U. (2017) 'Green synthesis of silver nanoparticles by Ricinus communis var. carmencita leaf extract and its antibacterial study', Advances in Natural Sciences: Nanoscience and Nanotechnology. IOP Publishing, 8(3). doi: 10.1088/2043-6254/aa724b.

Otari, S. V. et al. (2013) 'A novel microbial synthesis of catalytically active Ag-alginate biohydrogel and its antimicrobial activity', Dalton Transactions, 42(27), pp. 9966-9975. doi: $10.1039 / \mathrm{c} 3 \mathrm{dt} 51093 \mathrm{j}$.

Oudhoff, M. J. et al. (2008) 'Histatins are the major wound-closure stimulating factors in human saliva as identified in a cell culture assay.', The Federation of American Societies for Experimental Biology, 22(11), pp. 3805-3812. doi: 10.1096/fj.08-112003.

Padmavathy, N. and Vijayaraghavan, R. (2008) 'Enhanced bioactivity of ZnO nanoparticles - an antimicrobial study', Science and Technology of Advanced Materials, 9(3), p. 035004. doi: 10.1088/1468-6996/9/3/035004.

Pal, I. et al. (2016) 'Enhanced stability and activity of an antimicrobial peptide in conjugation with silver nanoparticle', Journal of Colloid and Interface Science. doi: 10.1016/j.jcis.2016.08.043.

Pal, S. et al. (2014) 'A multifunctional composite of an antibacterial higher-valent silver metallopharmaceutical and a potent wound healing polypeptide: a combined killing and healing approach to wound care', New J. Chem. New J. Chem, 38(38), pp. 3889-3898. doi: 10.1039/c4nj00160e.

Pal, S., Tak, Y. K. and Song, J. M. (2015) 'Does the antibacterial activity of silver nanoparticles depend on the shape of the nanoparticle? A study of the gram-negative bacterium Escherichia coli', Journal of Biological Chemistry, 290(42), pp. 1712-1720. doi: 10.1128/AEM.02218-06.

Palza, H. (2015) 'Antimicrobial polymers with metal nanoparticles', International Journal of Molecular Sciences, pp. 2099-2116. doi: 10.3390/ijms16012099.

Panácek, A. et al. (2016) 'Strong and nonspecific synergistic antibacterial efficiency of antibiotics combined with silver nanoparticles at very low concentrations showing no cytotoxic effect', Molecules, 21(1). doi: 10.3390/molecules21010026.

Panáček, A. et al. (2018) 'Bacterial resistance to silver nanoparticles and how to overcome it', 
Nature Nanotechnology, 13(1), pp. 65-71. doi: 10.1038/s41565-017-0013-y.

Papo, N. and Shai, Y. (2003) 'Can we predict biological activity of antimicrobial peptides from their interactions with model phospholipid membranes?', Peptides, pp. 1693-1703. doi: 10.1016/j.peptides.2003.09.013.

Pappalardo, J. S. et al. (2009) 'Improved transfection of spleen-derived antigen-presenting cells in culture using TATp-liposomes', Journal of Controlled Release, 134(1), pp. 41-46. doi: 10.1016/j.jconrel.2008.11.006.

Park, C. B., Kim, H. S. and Kim, S. C. (1998) 'Mechanism of action of the antimicrobial peptide buforin II: Buforin II kills microorganisms by penetrating the cell membrane and inhibiting cellular functions', Biochemical and Biophysical Research Communications, 244(1), pp. 253257. doi: 10.1006/bbrc. 1998.8159 .

Payne, J. N. et al. (2016) 'Novel synthesis of kanamycin conjugated gold nanoparticles with potent antibacterial activity', Frontiers in Microbiology, 7(MAY), pp. 1-10. doi: 10.3389/fmicb.2016.00607.

Pazos, E. et al. (2016) 'Nucleation and Growth of Ordered Arrays of Silver Nanoparticles on Peptide Nano fi bers: Hybrid Nanostructures with Antimicrobial Properties', pp. 4-7. doi: 10.1021/jacs.6b01570.

Peng, L. et al. (2016) 'Biomaterials Integration of antimicrobial peptides with gold nanoparticles as unique non-viral vectors for gene delivery to mesenchymal stem cells with antibacterial activity'. Elsevier Ltd, 103, pp. 137-149. doi: 10.1016/j.biomaterials.2016.06.057.

Peng, L. H. et al. (2016) 'Integration of antimicrobial peptides with gold nanoparticles as unique non-viral vectors for gene delivery to mesenchymal stem cells with antibacterial activity', Biomaterials. Elsevier Ltd, 103, pp. 137-149. doi: 10.1016/j.biomaterials.2016.06.057.

Percival, S. L., Bowler, P. G. and Dolman, J. (2007) 'Antimicrobial activity of silver-containing dressings on wound microorganisms using an in vitro biofilm model', International Wound Journal, 4(2). doi: 10.1111/j.1742-481X.2007.00296.x.

Peters, B. M., Shirtliff, M. E. and Jabra-Rizk, M. A. (2010) 'Antimicrobial peptides: Primeval molecules or future drugs?', PLoS Pathogens, 6(10). doi: 10.1371/journal.ppat.1001067.

Piddock, L. J. V (2006) 'Multidrug-resistance efflux pumps - not just for resistance.', Nature reviews. Microbiology, 4(8), pp. 629-636. doi: 10.1038/nrmicro1464.

Pokhrel, S. et al. (2009) 'Comparison of the mechanism of toxicity of binary and mixed binary 
metal oxide nanoparticles based on dissolution and oxidative stress properties', Chemie Ingenieur Technik, 81(8), pp. 1167-1167. doi: 10.1002/cite.200950629.

Prabhu, S. and Poulose, E. K. (2012) 'Silver nanoparticles: mechanism of antimicrobial action, synthesis, medical applications, and toxicity effects', International Nano Letters, 2(1), p. 32. doi: $10.1186 / 2228-5326-2-32$.

Pradeepa et al. (2016) 'Preparation of gold nanoparticles by novel bacterial exopolysaccharide for antibiotic delivery', Life Sciences, 153, pp. 171-179. doi: 10.1016/j.1fs.2016.04.022.

Premanathan, M. et al. (2011) 'Selective toxicity of $\mathrm{ZnO}$ nanoparticles toward Gram-positive bacteria and cancer cells by apoptosis through lipid peroxidation', Nanomedicine: Nanotechnology, Biology, and Medicine, 7(2), pp. 184-192. doi: 10.1016/j.nano.2010.10.001.

Qayyum, S. et al. (2016) 'Nanoparticles vs. biofilms: a battle against another paradigm of antibiotic resistance', Med. Chem. Commun., 7(8), pp. 1479-1498. doi: 10.1039/C6MD00124F.

Rahim, K. A. A. and Mohamed, A. M. A. (2015) 'Bactericidal and antibiotic synergistic effect of nanosilver against methicillin-resistant staphylococcus aureus', Jundishapur Journal of Microbiology, 8(11), pp. 1-6. doi: 10.5812/jjm.25867.

Rai, M., Yadav, A. and Gade, A. (2009) 'Silver nanoparticles as a new generation of antimicrobials', Biotechnology Advances. Elsevier Inc., 27(1), pp. 76-83. doi: 10.1016/j.biotechadv.2008.09.002.

Rainnie, D. J. and Bragg, P. (1974) 'The effect of silver ions on the respiratory chain of Escherichia coli', Can. J. Microbiol., 20, pp. 883-889. doi: 10.1139/m74-135.

Rajakumar, G. et al. (2017) 'Evaluation of anti-cholinesterase, antibacterial and cytotoxic activities of green synthesized silver nanoparticles using from Millettia pinnata flower extract', Microbial Pathogenesis, 103, pp. 123-128. doi: 10.1016/j.micpath.2016.12.019.

Rajchakit, U. and Sarojini, V. (2017a) 'Recent Developments in Antimicrobial-PeptideConjugated Gold Nanoparticles', Bioconjugate Chemistry, pp. 2673-2686. doi: 10.1021/acs.bioconjchem.7b00368.

Rajchakit, U. and Sarojini, V. (2017b) 'Recent Developments in Antimicrobial Peptide Conjugated Gold Nanoparticles', Bioconjugate Chemistry. American Chemical Society. doi: 10.1021/acs.bioconjchem.7b00368.

Ramasamy, M., Lee, J. H. and Lee, J. (2017) 'Direct one-pot synthesis of cinnamaldehyde immobilized on gold nanoparticles and their antibiofilm properties', Colloids and Surfaces B: 
Biointerfaces, 160, pp. 639-648. doi: 10.1016/j.colsurfb.2017.10.018.

Rebuffat, S. (2012) 'Microcins in action: amazing defence strategies of Enterobacteria', 40, pp. 1456-1462. doi: 10.1042/BST20120183.

Reddy, K. M. et al. (2007) 'Selective toxicity of zinc oxide nanoparticles to prokaryotic and eukaryotic systems', Applied Physics Letters, 90(21). doi: 10.1063/1.2742324.

Reimhult, E. (2013) 'Imaging and Triggered Release through Design of Ultrastable Core?Shell Iron

Oxide Nanoparticles', in Bioengineered Nanomaterials.

CRC Press, pp. 177-198. doi: doi:10.1201/b15403-9.

Ren, G. et al. (2009) 'Characterisation of copper oxide nanoparticles for antimicrobial applications', International Journal of Antimicrobial Agents, 33(6), pp. 587-590. doi: 10.1016/j.ijantimicag.2008.12.004.

Richards, R. et al. (2000) 'Consolidation of Metal Oxide Nanocrystals . Reactive Pellets with Controllable Pore Structure That Represent a New Family of Porous, Inorganic Materials', (11), pp. 4921-4925. doi: 10.1021/ja994383g.

Rizzo, L. et al. (2013) 'Urban wastewater treatment plants as hotspots for antibiotic resistant bacteria and genes spread into the environment: A review', Science of the Total Environment. Elsevier B.V., 447, pp. 345-360. doi: 10.1016/j.scitotenv.2013.01.032.

Rozek, A., Friedrich, C. L. and Hancock, R. E. W. (2000) 'Structure of the bovine antimicrobial peptide indolicidin bound to dodecylphosphocholine and sodium dodecyl sulfate micelles', Biochemistry, 39(51), pp. 15765-15774. doi: 10.1021/bi000714m.

Ruparelia, J. P. et al. (2008) 'Strain specificity in antimicrobial activity of silver and copper nanoparticles', Acta Biomaterialia, 4(3), pp. 707-716. doi: 10.1016/j.actbio.2007.11.006.

S. Roy, A. et al. (2010) 'Effect of Nano - Titanium Dioxide with Different Antibiotics against Methicillin-Resistant Staphylococcus Aureus', Journal of Biomaterials and Nanobiotechnology, 01(01), pp. 37-41. doi: 10.4236/jbnb.2010.11005.

Saeb, A. T. M. et al. (2014) 'Production of Silver Nanoparticles with Strong and Stable Antimicrobial Activity against Highly Pathogenic and Multidrug Resistant Bacteria', 2014.

Saito, T. et al. (1992) 'Mode of photocatalytic bactericidal action of powdered semiconductor TiO2 on mutans streptococci', Journal of Photochemistry and Photobiology, B: Biology, 14(4), pp. 369-379. doi: 10.1016/1011-1344(92)85115-B.

Salouti, M. and Ahangari, A. (2014) 'Nanoparticle based Drug Delivery Systems for Treatment 
of Infectious Diseases, Application of Nanotechnology in Drug Delivery', Application of Nanotechnology in Drug Delivery, pp. 1-20. doi: 10.5772/58423.

Dos Santos Ramos, M. A. et al. (2018) 'Nanotechnology-based drug delivery systems for control of microbial biofilms: A review', International Journal of Nanomedicine, 13, pp. 1179-1213. doi: 10.2147/IJN.S146195.

Sapsford, K. E. et al. (2013) 'Functionalizing nanoparticles with biological molecules: Developing chemistries that facilitate nanotechnology', Chemical Reviews, pp. 1904-2074. doi: $10.1021 / \mathrm{cr} 300143 \mathrm{v}$.

Schauber, J. et al. (2007) 'Injury enhances TLR2 function and antimicrobial peptide expression through a vitamin D-dependent mechanism', Journal of Clinical Investigation, 117(3), pp. 803811. doi: $10.1172 / \mathrm{JCI} 30142$.

Schembri, M. A., Kjaergaard, K. and Klemm, P. (2003) 'Global gene expression in Escherichia coli biofilms', Molecular Microbiology, 48, pp. 253-267.

Schooling, S. R. and Beveridge, T. J. (2006) 'Membrane vesicles: An overlooked component of the matrices of biofilms', Journal of Bacteriology, 188(16), pp. 5945-5957. doi: 10.1128/JB.00257-06.

Schwarze, S. R. et al. (1999) 'In vivo protein transduction: delivery of a biologically active protein into the mouse.', Science, 285(5433), pp. 1569-1572. doi: 10.1126/science.285.5433.1569.

Scinicariello, F. et al. (2007) 'Lead and ??-aminolevulinic acid dehydratase polymorphism: Where does it lead? A meta-analysis', Environmental Health Perspectives, 115(1), pp. 35-41. doi: 10.1289/ehp.9448.

Secinti, K. D. et al. (2011) 'Nanoparticle silver ion coatings inhibit biofilm formation on titanium implants', Journal of Clinical Neuroscience, 18(3), pp. 391-395. doi: 10.1016/j.jocn.2010.06.022.

Seil, J. T. and Webster, T. J. (2012) 'Antimicrobial applications of nanotechnology: Methods and literature', International Journal of Nanomedicine, 7, pp. 2767-2781. doi: 10.2147/IJN.S24805.

Şen Karaman, D. et al. (2016) 'Shape engineering boosts antibacterial activity of chitosan coated mesoporous silica nanoparticle doped with silver: A mechanistic investigation', Journal of Materials Chemistry B. doi: 10.1039/c5tb02526e.

Şen Karaman, D., Manner, S. and Rosenholm, J. M. (2018) 'Mesoporous silica nanoparticles as 
diagnostic and therapeutic tools: how can they combat bacterial infection?', Therapeutic Delivery. doi: 10.4155/tde-2017-0111.

Shafer, W. M. et al. (1998) 'Modulation of Neisseria gonorrhoeae susceptibility to vertebrate antibacterial peptides due to a member of the resistance/nodulation/division efflux pump family.', Proceedings of the National Academy of Sciences of the United States of America, 95(4), pp. 1829-1833. doi: 10.1073/pnas.95.4.1829.

Shah, R. R. et al. (2008) 'The antibacterial effects of biphasic brookite-anatase titanium dioxide nanoparticles on multiple-drug-resistant Staphylococcus aureus', in Journal of Biomedical Nanotechnology, pp. 339-348. doi: 10.1166/jbn.2008.324.

Shah, S. N. A. et al. (2017) 'Hazardous Effects of Titanium Dioxide Nanoparticles in Ecosystem', Bioinorganic Chemistry and Applications. doi: 10.1155/2017/4101735.

Shai, Y. (2002) 'Mode of action of membrane active antimicrobial peptides', Biopolymers Peptide Science Section, pp. 236-248. doi: 10.1002/bip.10260.

Shaikh, S. et al. (2017) 'Synthesis and Characterization of Cefotaxime Conjugated Gold Nanoparticles and Their Use to Target Drug-Resistant CTX-M-Producing Bacterial Pathogens', Journal of Cellular Biochemistry, 118(9), pp. 2802-2808. doi: 10.1002/jcb.25929.

Shaker, M. A. and Shaaban, M. I. (2017) 'Formulation of carbapenems loaded gold nanoparticles to combat multi-antibiotic bacterial resistance: In vitro antibacterial study', International Journal of Pharmaceutics, 525(1), pp. 71-84. doi: 10.1016/j.ijpharm.2017.04.019.

Shanmugam, S. and Gopal, B. (2014) 'Copper substituted hydroxyapatite and fluorapatite: Synthesis, characterization and antimicrobial properties', Ceramics International, 40(10), pp. 15655-15662. doi: 10.1016/j.ceramint.2014.07.086.

Sharma, R., Kwon, S. and Chen, C. J. (2013) 'Silver Nanoparticles', in Bioengineered Nanomaterials. CRC Press, pp. 241-268. doi: doi:10.1201/b15403-12.

Sharma, T. K. et al. (2012) 'Interaction of Bacteriocin-Capped Silver Nanoparticles with Food Pathogens and Their Antibacterial Effect', International Journal of Green Nanotechnology, 4(2), pp. 93-110. doi: 10.1080/19430892.2012.678757.

Shimanovich, U. and Gedanken, A. (2016) 'Nanotechnology solutions to restore antibiotic activity', J. Mater. Chem. B. Royal Society of Chemistry, 4, pp. 824-833. doi: 10.1039/C5TB01527H.

Siddiqi, K. S., Husen, A. and Rao, R. A. K. (2018) 'A review on biosynthesis of silver 
nanoparticles and their biocidal properties', Journal of Nanobiotechnology. doi: 10.1186/s12951018-0334-5.

Singh, S. et al. (2014) 'Effects of PEGylation on membrane and lipopolysaccharide interactions of host defense peptides', Biomacromolecules, 15(4), pp. 1337-1345. doi: 10.1021/bm401884e. Sitaram, N. and Nagaraj, R. (1999) 'Interaction of antimicrobial peptides with biological and model membranes: Structural and charge requirements for activity', Biochimica et Biophysica Acta - Biomembranes, pp. 29-54. doi: 10.1016/S0005-2736(99)00199-6.

Skalska, J. and Strużyńska, L. (2015) 'Toxic effects of silver nanoparticles in mammals - does a risk of neurotoxicity exist?', Folia Neuropathologica. doi: 10.5114/fn.2015.56543.

Skerlavaj, B., Romeo, D. and Gennaro, R. (1990) 'Rapid membrane permeabilization and inhibition of vital functions of gram-negative bacteria by bactenecins', Infection and Immunity, 58(11), pp. 3724-3730.

Slavin, Y. N. et al. (2017) 'Metal nanoparticles: Understanding the mechanisms behind antibacterial activity', Journal of Nanobiotechnology. doi: 10.1186/s12951-017-0308-z.

Soehnlein, O. et al. (2008) 'Neutrophil primary granule proteins HBP and HNP1-3 boost bacterial phagocytosis by human and murine macrophages', Journal of Clinical Investigation, 118(10), pp. 3491-3502. doi: 10.1172/JCI35740.

Sondi, I. and Salopek-Sondi, B. (2004) 'Silver nanoparticles as antimicrobial agent: a case study on E. coli as a model for Gram-negative bacteria', J Colloid Interface Sci, 275(1), pp. 177-182. doi: 10.1016/j.jcis.2004.02.012.

Sperandio, B. et al. (2008) 'Virulent Shigella flexneri subverts the host innate immune response through manipulation of antimicrobial peptide gene expression.', The Journal of experimental medicine, 205(5), pp. 1121-32. doi: 10.1084/jem.20071698.

Stevens, K. N. J. et al. (2009) 'The relationship between the antimicrobial effect of catheter coatings containing silver nanoparticles and the coagulation of contacting blood', Biomaterials, 30(22), pp. 3682-3690. doi: 10.1016/j.biomaterials.2009.03.054.

Stroh, M. et al. (2005) 'Quantum dots spectrally distinguish multiple species within the tumor milieu in vivo.', Nature medicine, 11(6), pp. 678-82. doi: 10.1038/nm1247.

$\mathrm{Su}, \mathrm{H}$. L. et al. (2011) 'Novel nanohybrids of silver particles on clay platelets for inhibiting silver-resistant bacteria', PLoS ONE, 6(6). doi: 10.1371/journal.pone.0021125.

Sutariya, V. et al. (2014) 'Introduction?Biointeractions of Nanomaterials: Challenges and 
Solutions', in Biointeractions of Nanomaterials. CRC Press, pp. 148. doi: doi:10.1201/b17191-2.

Tee, J. K. et al. (2016) 'Oxidative stress by inorganic nanoparticles', Wiley Interdisciplinary Reviews: Nanomedicine and Nanobiotechnology, pp. 414-438. doi: 10.1002/wnan.1374.

Thannickal, V. J. and Fanburg, B. L. (2000) 'Reactive oxygen species in cell signaling.', American journal of physiology. Lung cellular and molecular physiology, 279(6), pp. L1005-28. doi: $10.1164 / \mathrm{rccm} .2206007$.

Thapa, R. et al. (2017) 'Enzyme-mediated formulation of stable elliptical silver nanoparticles tested against clinical pathogens and MDR bacteria and development of antimicrobial surgical thread', Annals of Clinical Microbiology and Antimicrobials, 16(1). doi: 10.1186/s12941-0170216-y.

Thirumurugan, A., Ramachandran, S. and Shiamala Gowri, A. (2013) 'Combined effect of bacteriocin with gold nanoparticles against food spoiling bacteria - an approach for food packaging material preparation', International Food Research Journal.

Thiwawong, T., Onlaor, K. and Tunhoo, B. (2013) 'A Humidity Sensor Based on Silver Nanoparticles Thin Film Prepared by Electrostatic Spray Deposition Process', 2013.

Tian, Y. et al. (2014) 'Facile, one-pot synthesis, and antibacterial activity of mesoporous silica nanoparticles decorated with well-dispersed silver nanoparticles', ACS Applied Materials and Interfaces. doi: 10.1021/am5026424.

Tillotson, G. S. and Theriault, N. (2013) 'New and alternative approaches to tackling antibiotic resistance.', F1000prime reports, 5(December), p. 51. doi: 10.12703/P5-51.

Travan, A. et al. (2007) 'Silver Nanocomposites and Their Biomedical Applications', in Nanotechnologies for the Life Sciences. Wiley-VCH Verlag GmbH \& Co. KGaA. doi: 10.1002/9783527610419.ntls0219.

Tseng, B. S. et al. (2013) 'The extracellular matrix protects Pseudomonas aeruginosa biofilms by limiting the penetration of tobramycin', Environmental Microbiology, 15(10), pp. 2865-2878. doi: 10.1111/1462-2920.12155.

Tsourkas, A. et al. (2005) 'In vivo imaging of activated endothelium using an anti-VCAM-1 magnetooptical probe', Bioconjugate Chemistry, 16(3), pp. 576-581. doi: 10.1021/bc050002e. Turner, J. J. et al. (2007) 'RNA targeting with peptide conjugates of oligonucleotides, siRNA and PNA', Blood Cells, Molecules, and Diseases, 38(1), pp. 1-7. doi: 
10.1016/j.bcmd.2006.10.003.

Ubini, B. I. C. E. F. (2003) 'Serial Review : Role of Reactive Oxygen and Nitrogen Species ( ROS / RNS ) in Lung Injury and Diseases Guest Editor: Brook T . Mossman ( RNS ) GENERATION BY SILICA IN INFLAMMATION AND FIBROSIS', 34(12), pp. 1507-1516. doi: 10.1016/S0891-5849(03)00149-7.

VanderVen, B. C. et al. (2015) 'Novel Inhibitors of Cholesterol Degradation in Mycobacterium tuberculosis Reveal How the Bacterium's Metabolism Is Constrained by the Intracellular Environment', PLoS Pathogens. doi: 10.1371/journal.ppat.1004679.

Vedovato, N. and Rispoli, G. (2007) 'A novel technique to study pore-forming peptides in a natural membrane', European Biophysics Journal, 36(7), pp. 771-778. doi: 10.1007/s00249007-0152-4.

Veiseh, O. et al. (2009) 'Inhibition of tumor-cell invasion with chlorotoxin-bound superparamagnetic nanoparticles', Small, 5(2), pp. 256-264. doi: 10.1002/smll.200800646.

Veldhuizen, E. J. A. et al. (2014) 'Antimicrobial and immunomodulatory activities of PR-39 derived peptides', PLOS ONE, 9(4). doi: 10.1371/journal.pone.0095939.

Wadhwani, P. et al. (2017) 'Antibiotic gold: Tethering of antimicrobial peptides to gold nanoparticles maintains conformational flexibility of peptides and improves trypsin susceptibility', Biomaterials Science. doi: 10.1039/c7bm00069c.

Wang, G., Li, X. and Wang, Z. (2009) 'APD2: The updated antimicrobial peptide database and its application in peptide design', Nucleic Acids Research, 37(SUPPL. 1). doi: 10.1093/nar/gkn823.

Wang, L., Hu, C. and Shao, L. (2017) 'The antimicrobial activity of nanoparticles: Present situation and prospects for the future', International Journal of Nanomedicine, pp. 1227-1249. doi: 10.2147/IJN.S121956.

Wang, S. et al. (2010) 'Rapid colorimetric identification and targeted photothermal lysis of Salmonella bacteria by using bioconjugated oval-shaped gold nanoparticles', Chemistry - A European Journal, 16(19), pp. 5600-5606. doi: 10.1002/chem.201000176.

Wang, S. et al. (2016) 'Antimicrobial peptides as potential alternatives to antibiotics in food animal industry', International Journal of Molecular Sciences. doi: 10.3390/ijms17050603.

Wang, Z., Shen, Y. and Haapasalo, M. (2014) 'Dental materials with antibiofilm properties', Dental Materials. doi: 10.1016/j.dental.2013.12.001. 
Wang, Z. and Wang, G. (2004) 'APD: the Antimicrobial Peptide Database.', Nucleic acids research, 32(Database issue), pp. D590-2. doi: 10.1093/nar/gkh025.

Wijesiri, N. et al. (2017) 'Photodynamic Inactivation of Multidrug-Resistant Staphylococcus aureus Using Hybrid Photosensitizers Based on Amphiphilic Block Copolymer-Functionalized Gold Nanoparticles', pp. 2-7. doi: 10.1021/acsomega.7b00738.

Wilmes, M. et al. (2014) 'Killing of staphylococci by $\theta$-defensins involves membrane impairment and activation of autolytic enzymes', Antibiotics, pp. 617-631. doi: 10.3390/antibiotics3040617.

Wingender, J., Neu, T. R. and Flemming, H.-C. (1999) 'What are bacterial extracellular polymeric substances?', in Microbial Extracellular Polymeric Substances, pp. 1-19. doi: 10.1007/978-3-642-60147-7_1.

Wu, P., Imlay, J. A. and Shang, J. K. (2010) 'Mechanism of Escherichia coli inactivation on palladium-modified nitrogen-doped titanium dioxide', Biomaterials, 31(29), pp. 7526-7533. doi: 10.1016/j.biomaterials.2010.06.032.

Xie, Y. et al. (2011) 'Antibacterial activity and mechanism of action of zinc oxide nanoparticles against Campylobacter jejuni', Applied and Environmental Microbiology, 77(7), pp. 2325-2331. doi: 10.1128/AEM.02149-10.

Xu, F. F. and Imlay, J. A. (2012) 'Silver(I), mercury(II), cadmium(II), and zinc(II) target exposed enzymic iron-sulfur clusters when they toxify Escherichia coli', Applied and Environmental Microbiology, 78(10), pp. 3614-3621. doi: 10.1128/AEM.07368-11.

Xue, H. Y., Liu, S. and Wong, H. L. (2014) 'Nanotoxicity: a key obstacle to clinical translation of siRNA-based nanomedicine.', Nanomedicine (London, England), 9(2), pp. 295-312. doi: 10.2217/nnm.13.204.

Yadav, H. M. et al. (2016) 'Enhanced photocatalytic inactivation of bacteria on Fe-containing $\mathrm{TiO} 2$ nanoparticles under fluorescent light', Journal of Materials Science: Materials in Medicine, 27(3), pp. 1-9. doi: 10.1007/s10856-016-5675-8.

Yaganza, E. S. et al. (2004) 'Ultrastructural alterations of Erwinia carotovora subsp. atroseptica caused by treatment with aluminum chloride and sodium metabisulfite', Applied and Environmental Microbiology, 70(11), pp. 6800-6808. doi: 10.1128/AEM.70.11.6800-6808.2004. Yamanaka, M., Hara, K. and Kudo, J. (2005) 'Bactericidal actions of a silver ion solution on Escherichia coli, studied by energy-filtering transmission electron microscopy and proteomic 
analysis', Applied and Environmental Microbiology, 71(11), pp. 7589-7593. doi: 10.1128/AEM.71.11.7589-7593.2005.

Yang, H. et al. (2016) 'Endosomal pH modulation by peptide-gold nanoparticle hybrids enables potent anti-inflammatory activity in phagocytic immune cells', Biomaterials, 111, pp. 90-102. doi: 10.1016/j.biomaterials.2016.09.032.

Yang, L. et al. (2001) 'Barrel-Stave Model or Toroidal Model? A Case Study on Melittin Pores', Biophysical Journal, 81(3), pp. 1475-1485. doi: 10.1016/S0006-3495(01)75802-X.

Yeaman, M. R. and Yount, N. Y. (2003) 'Mechanisms of antimicrobial peptide action and resistance.', Pharmacological reviews, 55(1), pp. 27-55. doi: 10.1124/pr.55.1.2.

Yemmireddy, V. K. and Hung, Y. C. (2017) 'Using Photocatalyst Metal Oxides as Antimicrobial

Surface Coatings to Ensure Food Safety-Opportunities and Challenges', Comprehensive Reviews in Food Science and Food Safety. doi: 10.1111/1541-4337.12267.

Yen, H.-J., Hsu, S.-H. and Tsai, C.-L. (2009) 'Cytotoxicity and immunological response of gold and silver nanoparticles of different sizes.', Small, 5(13), pp. 1553-1561. doi: 10.1002/smll.200900126.

Yeom, J. H. et al. (2016) 'Gold nanoparticle-DNA aptamer conjugate-assisted delivery of antimicrobial peptide effectively eliminates intracellular Salmonella enterica serovar Typhimurium', Biomaterials, 104, pp. 43-51. doi: 10.1016/j.biomaterials.2016.07.009.

Yount, N. Y. et al. (2006) 'Advances in antimicrobial peptide immunobiology', Biopolymers Peptide Science Section, pp. 435-458. doi: 10.1002/bip.20543.

Yount, N. Y. and Yeaman, M. R. (2013) 'Peptide antimicrobials: Cell wall as a bacterial target', Annals of the New York Academy of Sciences, 1277(1), pp. 127-138. doi: 10.1111/nyas.12005.

Yu, X., Wang, Z. and Wei, G. (2017) 'nanomaterial hybrids', Journal of Materials Chemistry B. Royal Society of Chemistry, 5, pp. 1130-1142. doi: 10.1039/C6TB02659A.

Yuan, P. et al. (2018) 'Metal Nanoparticles for Diagnosis and Therapy of Bacterial Infection', Advanced Healthcare Materials, 1701392, p. 1701392. doi: 10.1002/adhm.201701392.

Zasloff, M. (2002) 'Antimicrobial peptides of multicellular organisms', Nature, 415(0028-0836 (Print)), pp. 389-395. doi: 10.1038/415389a.

Zhang, L. and Gallo, R. L. (2016) 'Antimicrobial peptides', Current Biology, 26(1), pp. R14R19. doi: 10.1016/j.cub.2015.11.017.

Zhang, P. (2016) 'Ecotoxicity Analyses of Nanomaterials', in Toxicology of Nanomaterials. 
Wiley-VCH Verlag GmbH \& Co. KGaA, pp. 367-392. doi: 10.1002/9783527689125.ch15.

Zhao, Z. et al. (2017) 'Bacteria-Activated Theranostic Nanoprobes against Methicillin-Resistant Staphylococcus aureus Infection', ACS Nano, 11(5), pp. 4428-4438. doi: 10.1021/acsnano.7b00041.

Zharov, V. P. et al. (2006) 'Photothermal Nanotherapeutics and Nanodiagnostics for Selective Killing of Bacteria Targeted with Gold Nanoparticles', Biophysical Journal. Elsevier, 90(2), pp. 619-627. doi: 10.1529/biophysj.105.061895.

Zhou, G. et al. (2008) 'Synthesis, characterization, and antibacterial activities of a novel nanohydroxyapatite/zinc oxide complex', Journal of Biomedical Materials Research - Part A, 85(4), pp. 929-937. doi: 10.1002/jbm.a.31527. 


\section{${ }^{*}$ Conflict of Interest}

\section{Declaration of interests}

$\bigotimes$ The authors declare that they have no known competing financial interests or personal relationships that could have appeared to influence the work reported in this paper.

$\square$ The authors declare the following financial interests/personal relationships which may be considered as potential competing interests:

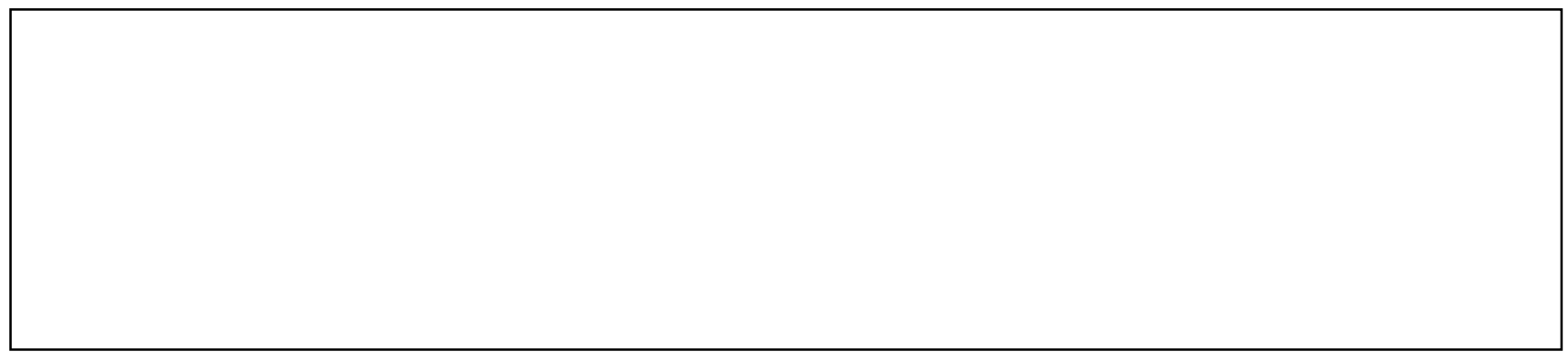




\section{Credit author statement}

All authors have made substantial contributions to the design of the review paper at some stage during the manuscript preparation process; AND

Drafting the work / revising it critically for important intellectual content; AND

Final approval of the version to be published; AND

Agreement to be accountable for all aspects of the work in ensuring that questions related to the accuracy or integrity of any part of the work are appropriately presented.

On behalf of the authors,

in Turku, Finland 23.03.2020

Prof. Jessica Rosenholm

(Submitting author) 